\title{
Everyday Storytelling: supporting the mediated expression of online personal testimony
}

by

Aisling Geraldine Mary Kelliher

B.A. Communication Studies, Dublin City University, 1996

M.Sc. Multimedia Systems, University of Dublin, Trinity College, 1998

M.S. Media Arts and Sciences, Massachusetts Institute of Technology, 2001

\author{
SUbMITTED TO THE PROGRAM IN MEDIA ARTS AND SCIENCES \\ SCHOOL OF ARCHITECTURE AND PLANNING \\ IN PARTIAL FULFILLMENT OF THE REQUIREMENTS FOR THE DEGREE OF \\ DOCTOR OF PHILOSOPHY IN MEDIA ARTS AND SCIENCES \\ AT THE
}

MASSACHUSETTS INSTITUTE OF TECHNOLOGY

FEBRUARY, 2007

(C) MASSACHUSETTS INSTITUTE OF TECHNOLOGY, 2007. ALL RIGHTS RESERVED.

1

\section{Sighature of Aythor}

Program in Media Arts and Sciences

January 12, 2007

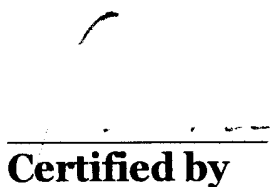

Glorianna Davenport

Principal Research Associate

Program in Media Arts and Sciences

Thesis Supervisor

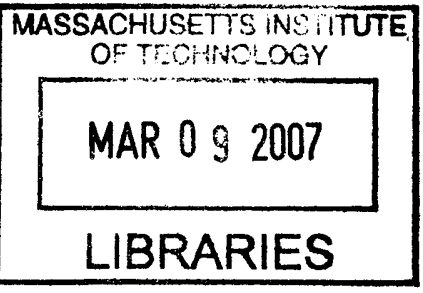

ROTCH

\footnotetext{
Accepted by

Andrew Lippman

Chair, Departmental Committee on Graduate Studies

Program in Media Arts and Sciences
} 


\title{
Everyday Storytelling: supporting the mediated expression of online personal testimony
}

by

\author{
Aisling Geraldine Mary Kelliher
}

Submitted to the Program in Media Arts and Sciences, School of Architecture and Planning, on January 12, 2007, in partial fulfillment of the requirements for the degree of Doctor of Philosophy in Media Arts and Sciences

\section{Abstract}

Personal stories make our experiences memorable over time. Transforming our fragmentary memories into shareable narratives helps us to understand and communicate who we are as individual and social beings. This thesis presents 'Everyday Mediated Storytelling', a model of the casual storyteller's process of capturing, creating and sharing personal mediated narratives. The purpose of this model is to better support rich-media storytelling through systems that enable storytellers to engage with personal media in a reflective, meaningful and shareable process.

Based on the Everyday Mediated Storytelling model, an online authoring and publishing application for creating everyday rich-media narratives named 'Confectionary' was developed. Confectionary provides the storyteller with a spatial storytelling environment that encourages creativity and experimentation, supports a wide variety of storymaking styles, provides novel wayfinding strategies for story discovery and enables the audience to actively and broadly interpret personal rich-media stories. As a spatial storytelling environment, Confectionary reduces cognitive overload on the storyteller by making it easy to begin authoring, supports a wide variety of storymaking strategies and styles and enables the audience to engage in reflective dialogs through multiple active feedback modes.

Results from a comparative evaluation with other current best practice within the context of online media and story sharing applications indicate that a spatial authoring and publishing application is more enjoyable to use, better facilitates the process of beginning to tell stories and is easier to navigate and explore. Quantitative and qualitative results from a lengthy study with a group of committed users signify the success of the system as an engaging everyday tool for personal storytelling that stimulated self-reflection and broadened the scope of media capture techniques and storytelling strategies demonstrated by its users.

Critical lessons were learned about methodology and system design for rich-media personal storytelling. The model, methodology, and system presented in this thesis provide a basis for understanding how we move fluidly between our direct experiences, our cognitive and emotional reflections and our storied representations and interpretations. This thesis also demonstrates how a spatial everyday authoring and publishing application advances the digital storytelling process from one of collective anthology to one of storied reflection.

Thesis Advisor: Glorianna Davenport

Title: Principal Research Associate, Program in Media Arts and Science, MIT 


\section{Everyday Storytelling: \\ supporting the mediated expression of online personal testimony \\ by \\ Aisling Geraldine Mary Kelliher}

The following people served as advisors and readers for this thesis:

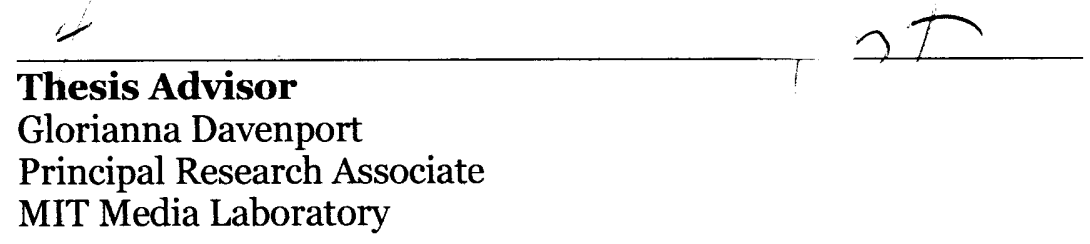

Thesis Keader

Walter Bender

Senior Research Scientist

MIT Media Laboratory

President, One Laptop Per Child

Thesis Reader

Bakhtiar Mikhak

Visiting Scientist

MIT Media Laboratory

Co-founder and Principal, Media Modifications LLC 


\section{Acknowledgements}

I am grateful and indebted to many people who have supported, challenged and guided me during this research journey.

My advisor Glorianna Davenport for her provocative thinking, amazing creativity and steadfast support. My readers Walter Bender and Bakhtiar Mikhak for their thoughtful input and great conversations over the years. Richard Kearney for his tremendous assistance in framing this research.

The Interactive Cinema/Media Fabrics group who have been the greatest team to work and think with: Barbara Barry, Hyun Yeul-Lee, Ali Mazalek, Paul Nemirovsky, Pengkai Pan, James Seo and Arnan Sipitakiat.

Friends and colleagues at the Media Lab who have provided much intellectual stimulation and hilarity: Brian, Cameron, Jason, Dan, Nikita, Peter, Erik, Conor, Dean, Stefan, Natalia, Diana, Cory, Joannie, Nathan, Lily, Noah, Ben, Kelly, Tara, Carson, Nyssim, Tad, Win, Yael, Saul, Dave, Mike, Bill, Casey, Jim.

Push Singh for sharing your towering intellect and warm heart. You are missed my friend.

Media Lab administrative and support staff: Linda Peterson, Pat Solakof, Stacey Slotnik, Kevin Davis, Cornell King, Paula Aguilera. The amazing sys admins: Will Glesnes, Elizabeth Harvey-Forsythe, Jeannie Finks and all in NECSYS.

Inspiring people around the Lab and elsewhere: John Maeda, Chris Csikzentmihalyi, David Cavallo, Hiroshi Ishii, Diane Willow, Marie Redmond and Jack Driscoll.

The denizens of the Mauve: Christine 'DMX' Gaspar, Jimmy Carl Forren, Jamie Rollins, Rebecca Bureau, Liz Burrow. The network of buddies: Dave, Courtney, Meg, Shannon, Mike, Heemin, Min-Suh, Fred, Marianna, Alicia, Muireann, Johanna, Eleanor.

Ruth Thomasian and all at ProjectSAVE archives.

Special thanks to Jacqueline Karaaslanian for her tremendous assistance, good humor and generosity of spirit. It is been a pleasure and delight to work and play alongside you.

Barbara Barry has been an intellectual ally, conversational firestarter and wonderful friend. I thank you.

Galen Harris is the greatest fake cousin in the world. Ever.

Mom, Dad and Gráinne: your support, love and encouragement have sustained me on this long journey. I couldn't have done it without you.

Thanassis: for everything, but especially for being the best thing available. 


\section{Contents}

\section{LIST OF FIGURES $\quad 12$ \\ LIST OF TABLES 14}

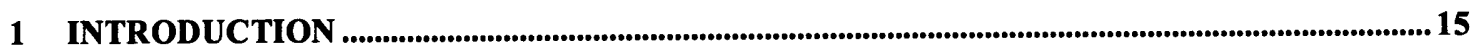

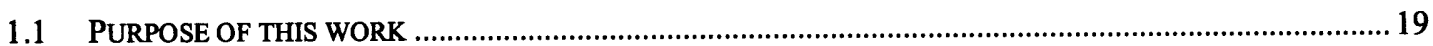

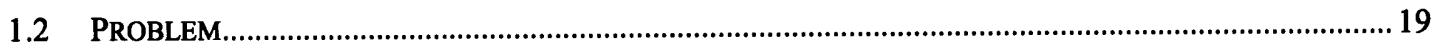

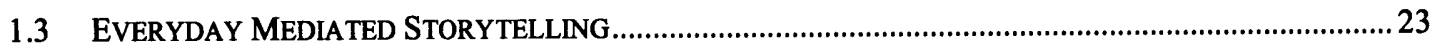

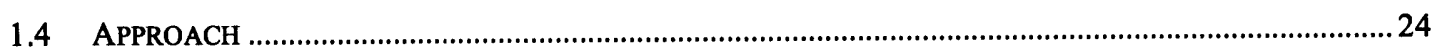

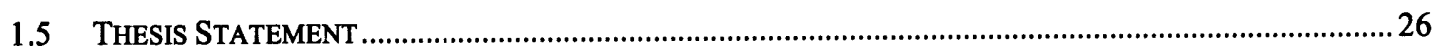

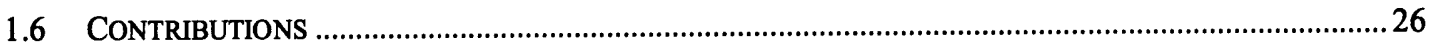

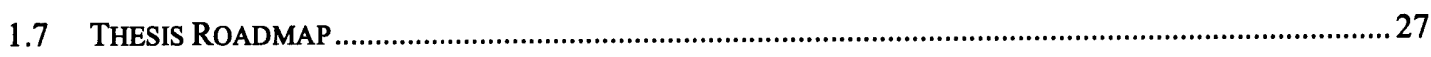

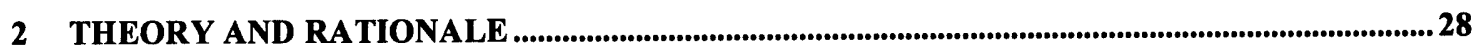

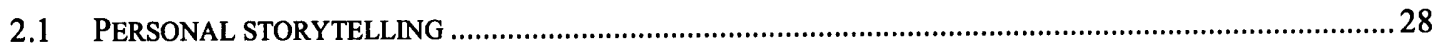

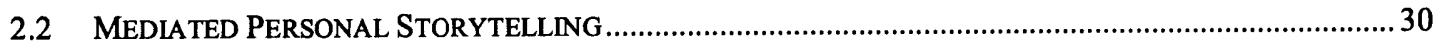

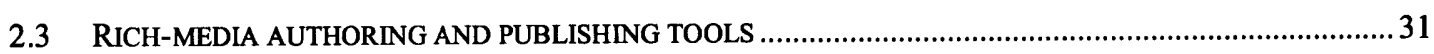

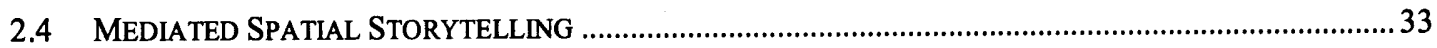

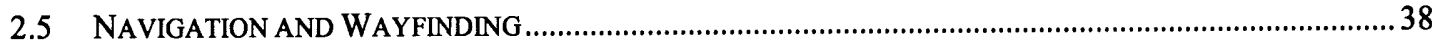

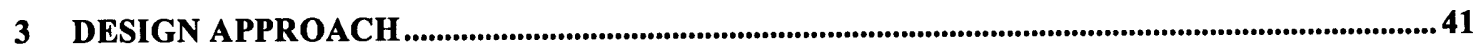

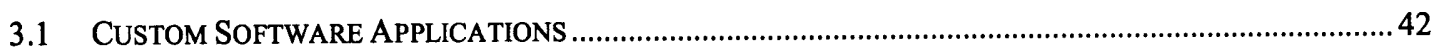

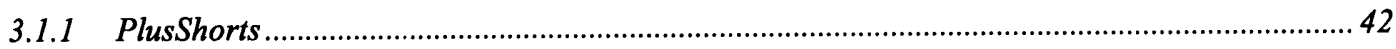

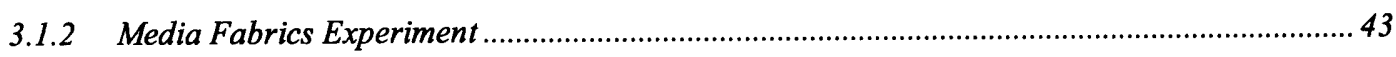

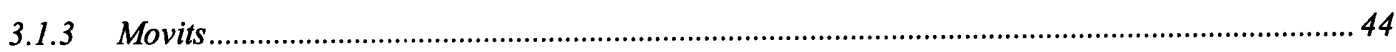

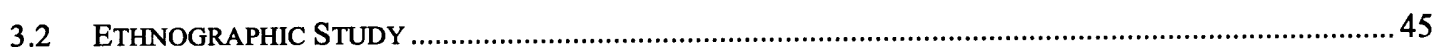

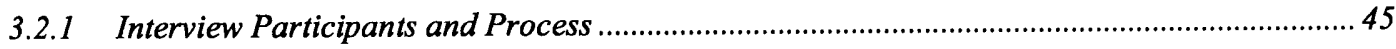

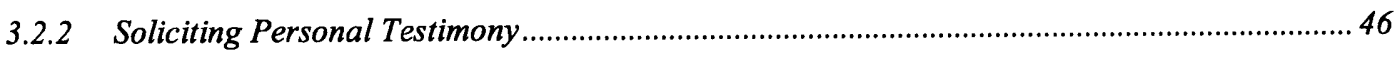

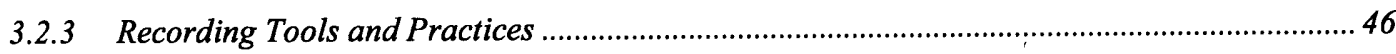

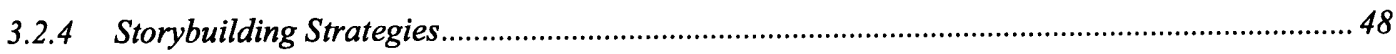

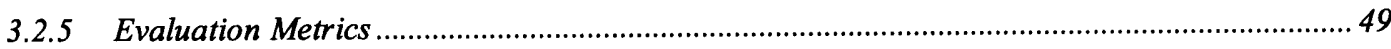

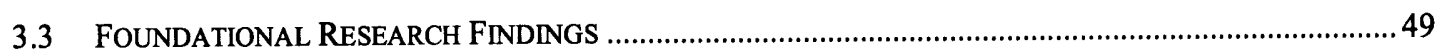

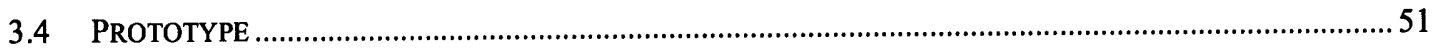

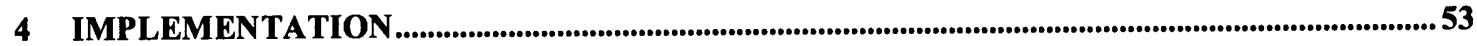

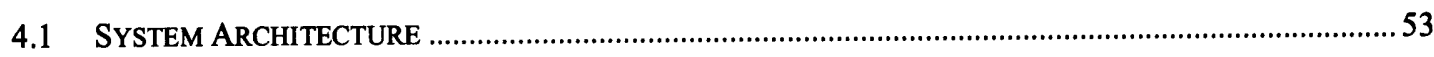

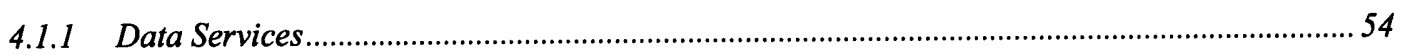




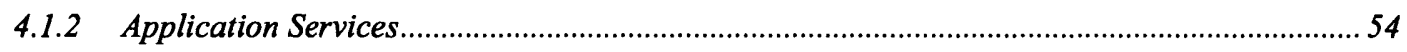

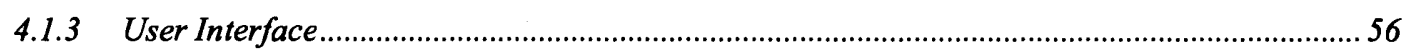

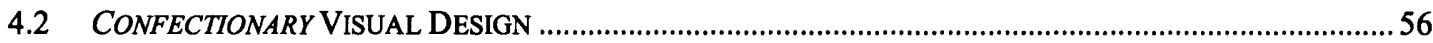

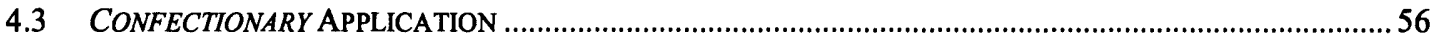

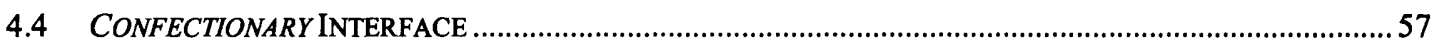

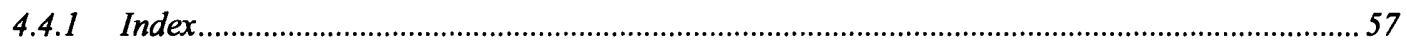

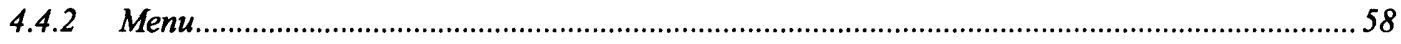

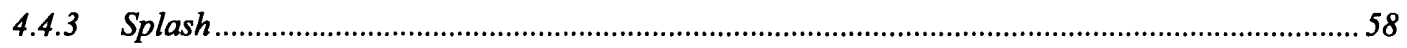

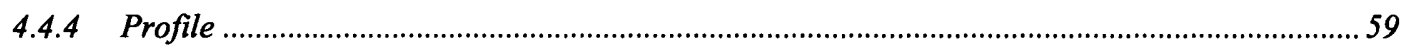

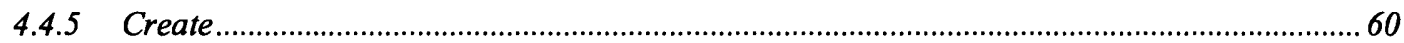

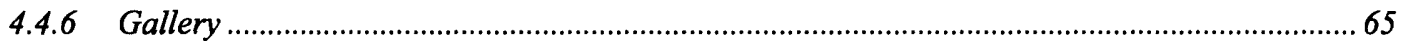

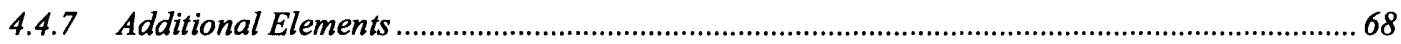

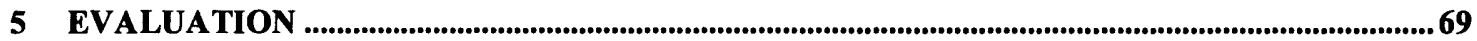

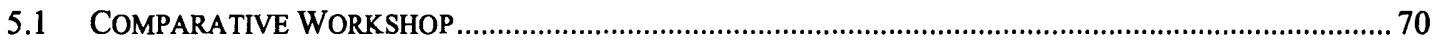

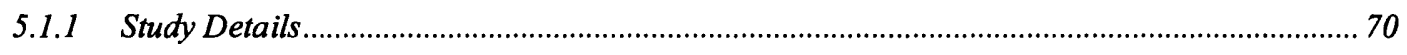

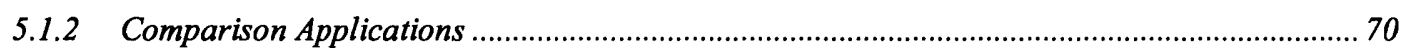

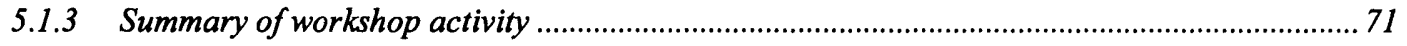

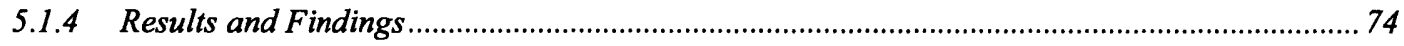

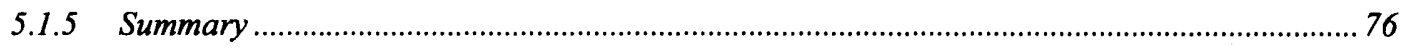

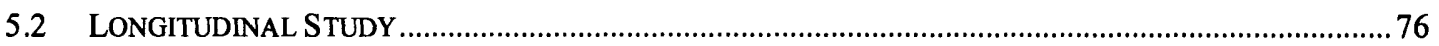

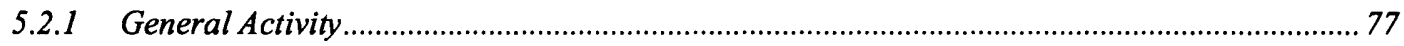

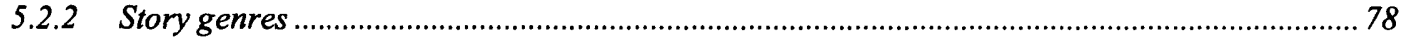

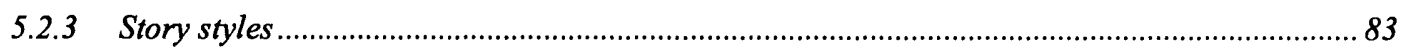

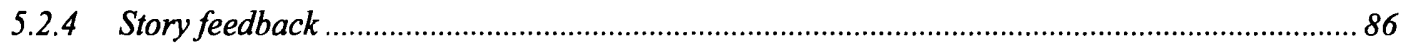

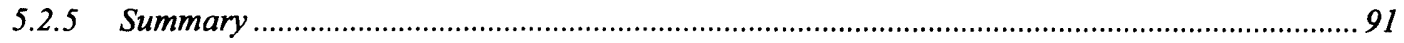

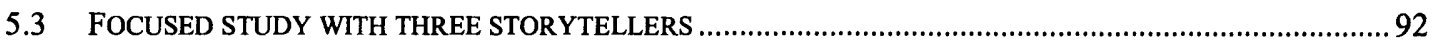

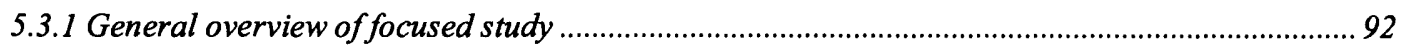

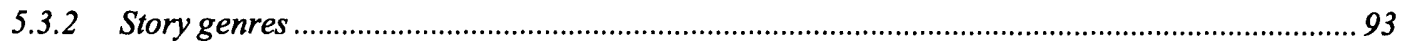

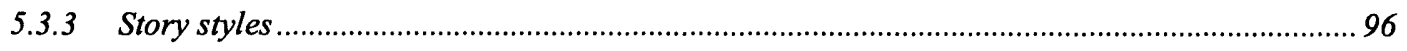

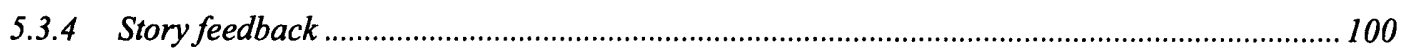

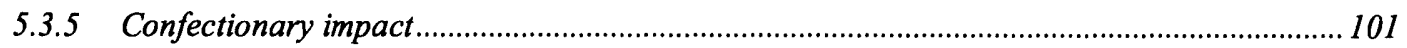

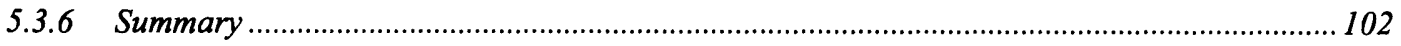

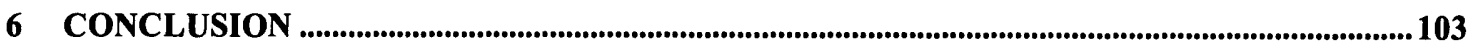

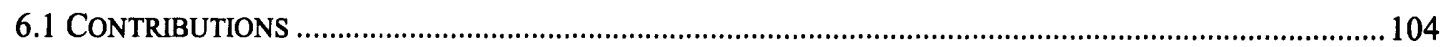

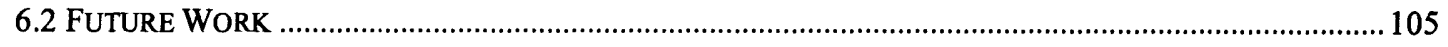

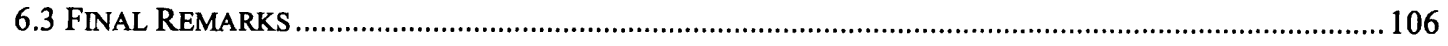


BIBLIOGRAPHY

APPENDIX A

APPENDIX B

APPENDIX C
108

111

114

118 


\section{List of Figures}

Figure 1: Personal story exchange process.....................................................................15

Figure 2: Mediated analog story exchange process ........................................................17

Figure 3: Mediated networked story exchange process ................................................... 18

Figure 4: Everyday Mediated Storytelling Model ..........................................................23

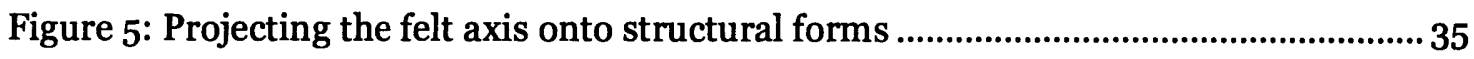

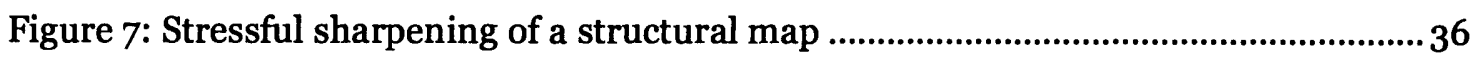

Figure 8: Illustrations of visual techniques from 'A Primer of Visual Literacy' ............... 37

Figure 9: Confectionary Stories from the Hi:Nomadic workshop.....................................52

Figure 10: Confectionary three-layer system architecture ..................................................53

Figure 11: Confectionary database schema ....................................................................... 55

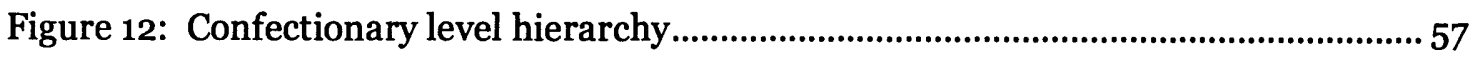

Figure 13: Confectionary splash interface ......................................................................5 59

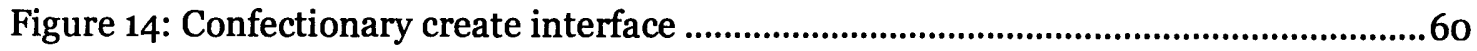

Figure 15: Image, movie and audio media archive display ...........................................62

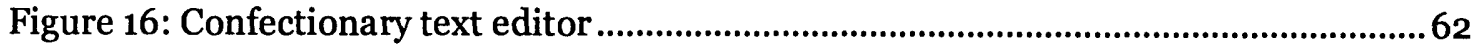

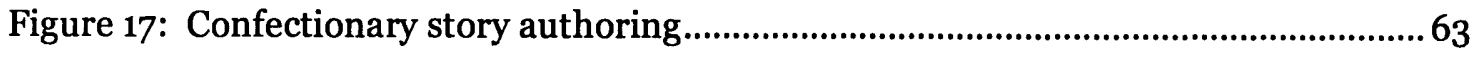

Figure 18: Confectionary story privacy settings ................................................................ 63

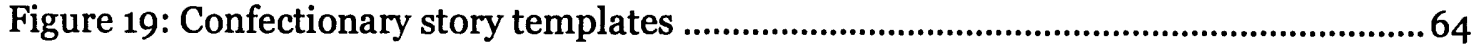

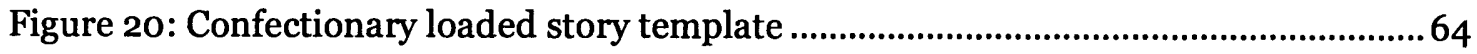

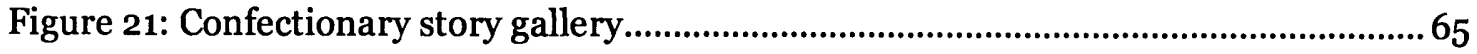

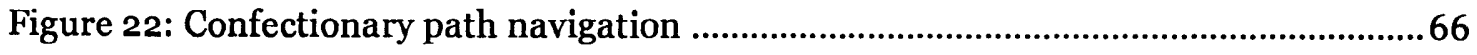

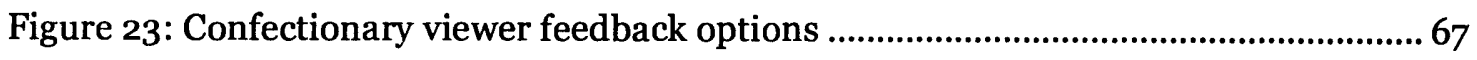

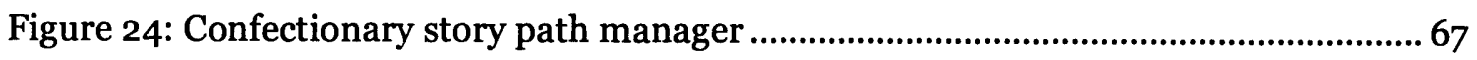

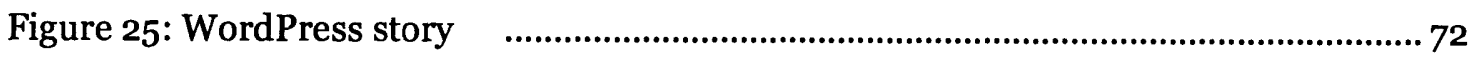

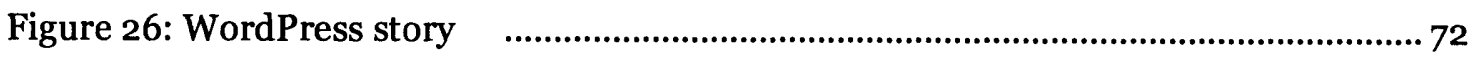

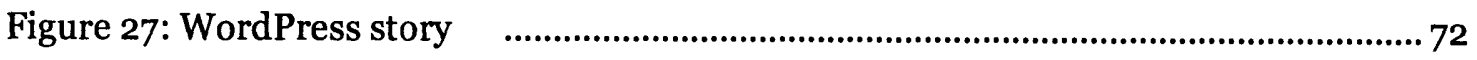

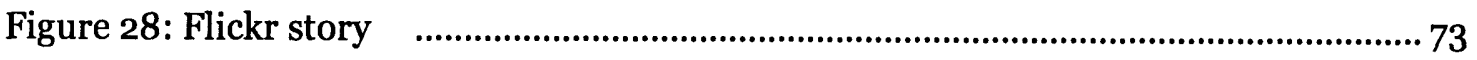

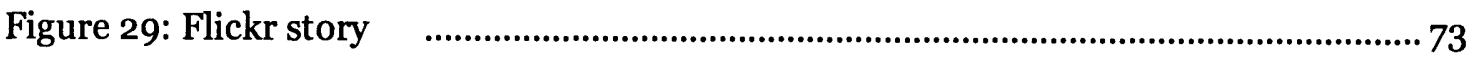

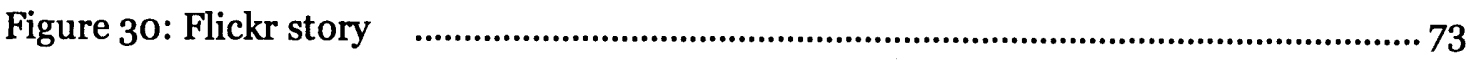

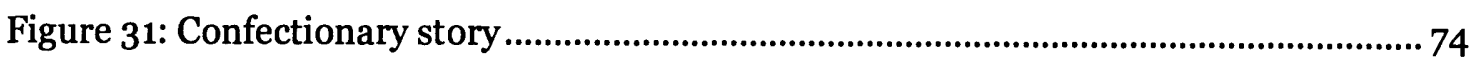

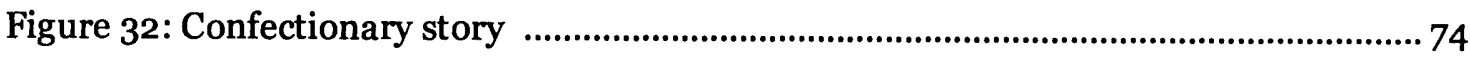

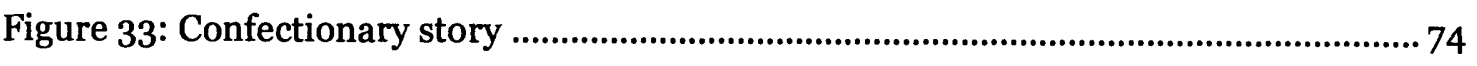


Figure 34: Timed relationship between media upload and story creation ......................... 77

Figure 35: Examples of personal documentary Confectionary stories ............................... 79

Figure 36: Examples of informative Confectionary stories ............................................... 79

Figure 37: Examples of poetic Confectionary stories ..........................................................80

Figure 38: Examples of media postcard Confectionary stories ..........................................80

Figure 39: Examples of comedic Confectionary stories ..................................................... 81

Figure 40: Examples of abstract Confectionary stories ................................................... 81

Figure 41: Examples of fictional Confectionary stories......................................................82

Figure 42: Examples of portrait Confectionary stories ................................................82

Figure 43: Examples of left-right, top-down spatial story layouts .....................................83

Figure 44: Examples of symmetrical spatial story layouts .................................................84

Figure 45: Examples of grouped spatial story layouts ..........................................................84

Figure 46: Examples of predictable spatial story layouts ...................................................85

Figure 47: Examples of complex spatial story layouts by one participant......................... 85

Figure 48: Examples of simple spatial story layouts by one participant ...........................86

Figure 49: Number of comments assigned to Confectionary stories .................................89

Figure 50: Range of number of stories used in wayfinding story paths ............................90

Figure 51: Subject A template based story layouts .............................................................. 96

Figure 52: Subject A personal template

Figure 53: Subject A personal template

Figure 54: Subject A compositional style .................................................................... 97

Figure 55: Subject B's evolving compositional style.........................................................98

Figure 56: Subject C simple style

Figure 57: Subject C media postcard style …...............................................................99 


\section{List of Tables}

Table 1: Summary of foundational research directives .......................................................50

Table 2: Comparative workshop activity data ......................................................................... 72

Table 3: Summary of focused study Confectionary activity.............................................93 


\section{Introduction}

Telling stories is a fundamental part of what makes us human, arising from the desire to transform the fragmented chaos of our daily lives into a patterned, coherent and shareable narrative. This process of testifying to our life experiences in a reflective manner helps us understand and convey who we are as individuals and as members of a larger, cultural society [Kearney 2002]. When we exchange stories, our narrative imagination supports us in empathizing with the memories of those whose experiences are foreign to us. Stories possess a cathartic power that creates a safe distance for the listener from the raw experiences themselves while simultaneously soliciting a powerful form of sympathy that enables us to see the world through the eyes of another [Kearney 2002]. Figure 1 depicts a typical personal story exchange between two people in the physical world. I tell you the story of how I broke my leg, leaving out some of the more gory details, as I know you are particularly sensitive. In this way, the abbreviated version of the story helps to create a safe distance for you from the more disturbing elements of my experience. Upon hearing my story, you immediately offer your sympathies, ask how long I'll be on crutches and then proceed to tell me a cheerful anecdote about overcoming adversity.

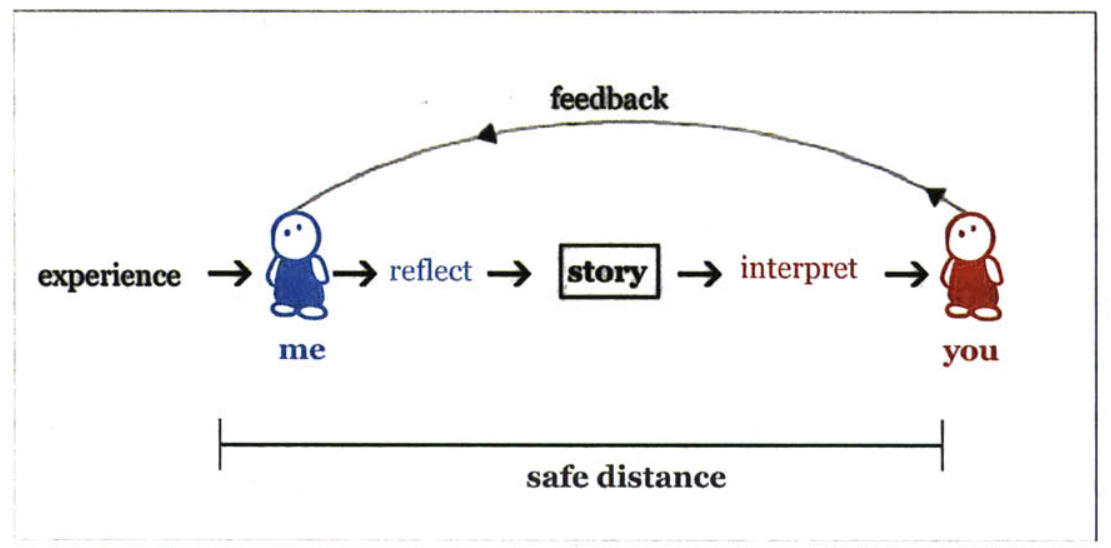

Figure 1: Personal story exchange process

It is through this communicative act of storytelling that we are given, as Aristotle says, a shareable world. In today's somewhat fractured society, the need for exchanging our narrative memories has never been more acute as we struggle to rationalize our increasingly polarizing global world. 
In its most primitive form, personal storytelling can be described as the simple exchange of experience where we aspire to communicate that which is memorable and valuable [Ricoeur 1992]. In bearing witness to our experiences we reveal not only what we have experienced but also how we remember experiencing it. Personal memory can be defined as a self-reflexive, individual historical consciousness that can be expressed through the artifacts that we collect, the stories we tell and the photos we frame as significant [Crane 1996]. Through documenting and recording our lives we make them in a sense visible. From the earliest cave drawings to oil portraits, photographs and home movies, we have used a variety of media and technologies to support our endeavors in representing ourselves and our life experiences.

The basic properties of a particular medium determine what type of narratives can be told, how they are presented, why they are communicated and how the audience experiences them [Ryan 2004]. For example, Henry David Thoreau ${ }^{1}$ kept a hand-written journal for 24 years detailing his observations of nature and as a testament to his resolve to live a pure and simple life. The immediacy of the journal was its greatest attraction for Thoreau who observed 'the writer who postpones the recording of his thoughts uses an iron which has cooled to burn a hole with' [Torrey \& Allen p293 1949]. Thoreau's journal didn't reach a public audience until thirty years after his death. Over a century later, his previously unseen journal transcripts are finding a new audience as they are being published online by the Thoreau estate. Working with a different medium, the filmmaker Jonas Mekas² tells stories of his childhood in Lithuania using footage he captured on the streets of New York. He uses lighting, pacing and movement to represent his presence in the movie. He considered his movies as personal documents and found an audience for his work in galleries, archives and collectives. Figure 2 depicts the process by which Mekas made and distributed his diary movies. He captures his experiences with his camera, reflects upon his footage and constructs a final movie artifact. People then gather at a screening location to watch the movie together. This audience is generally interested in independent personal moviemaking, which influences their understanding and appreciation for the movie's perceived value and meaning.

\footnotetext{
${ }^{1}$ Henry David Thoreau (1817-1862) was a noted American essayist, poet and philosopher of nature. He is known most famously for his masterwork 'Walden'(1854) and his essay advocating civil liberties, 'Civil Disobedience' (1849).

2 Jonas Mekas is a curator, writer and filmmaker, who heavily influenced American avant-garde filmmaking in the 1950's. Founder of Anthology Film Archives and the Filmmaker's Cooperative, Mekas is also renowned for his classic diary films such as Walden (1969), Lost, Lost, Lost (1975) and Reminiscences of a Voyage to Lithuania (1972).
} 
They share their opinions about the film with Mekas, but their feedback will not alter this particular movie in any way.

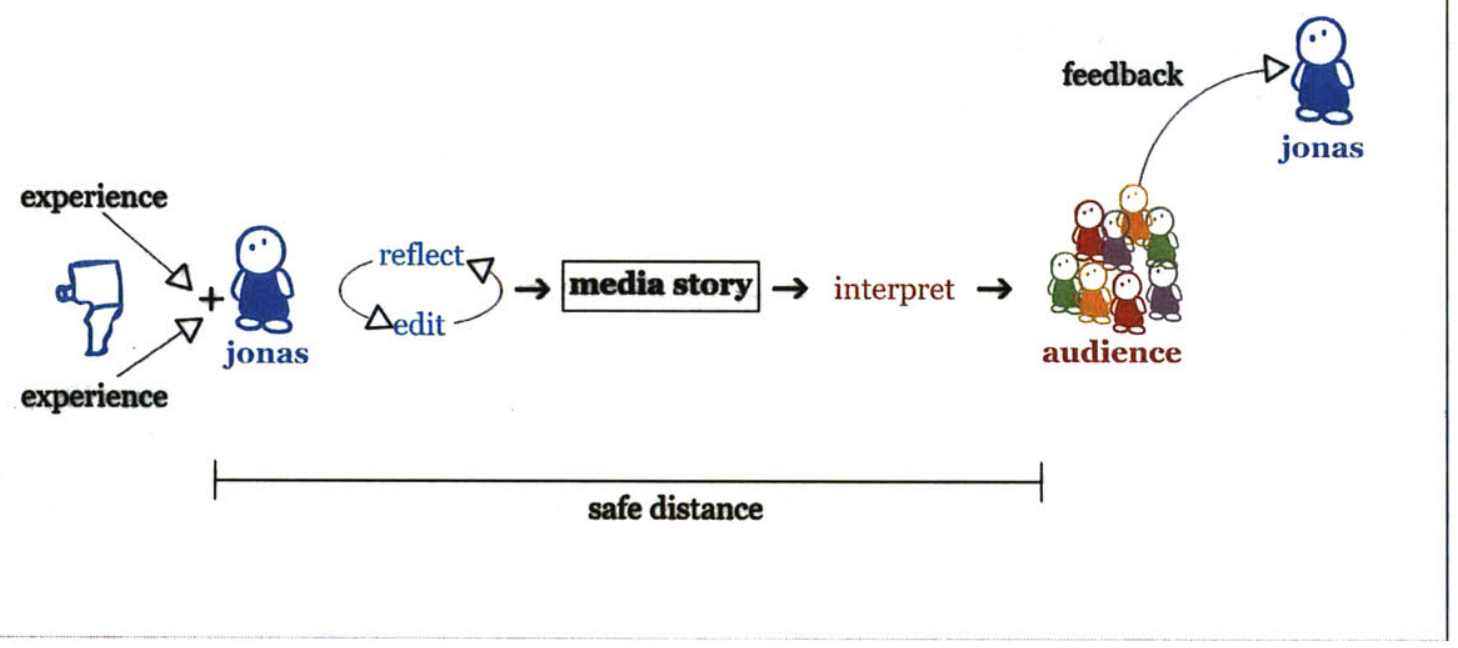

Figure 2: Mediated analog story exchange process

Both Mekas and Thoreau embraced the media tools available to them at the time to record and represent their everyday experiences. Through the act of intervening and deliberately constructing narratives from their lives lived, these two storytellers afford their audience sufficient distance for reflection and interpretation. In today's world, the proliferation of personal media recording devices, home editing systems and advances in network communications provide opportunities for exploring alternative forms of digital mediated storytelling. The media explosion of the digital age has introduced new forms of expression (VR, hypertext, multimedia websites) and communication (email, IM, textmessaging). At the same time, digital technology has 'reimagined' the production, distribution and appropriation of older media forms. Digital media is 'collection-based and computationally ready', instantly available to be browsed, sequenced and exchanged in individual or collaborative real-time endeavors [Davenport 2004].

We organize our digital media collections using software such as Picasa or iTunes, and then perhaps share them online via weblogs or on Flickr. Figure 3 depicts the exchange of personal media stories in today's networked and distributed world. I use my camera cellphone, my digital camera and my digital camcorder to capture moments in my everyday life. I organize and categorize my media in an editorial process that makes it 
more manageable, more findable and prepared for sharing. I upload my media to my MySpace account adding to my personal profile story, or I write a post on my weblog interspersed with photographs letting my network of friends know what I have been doing lately. I share my media story with the general public or perhaps restrict access to selected individuals or groups whom I feel are the appropriate audience. In defining what types of narratives different participants receive, I can create varying levels of audience distance to protect my more private or salacious stories.

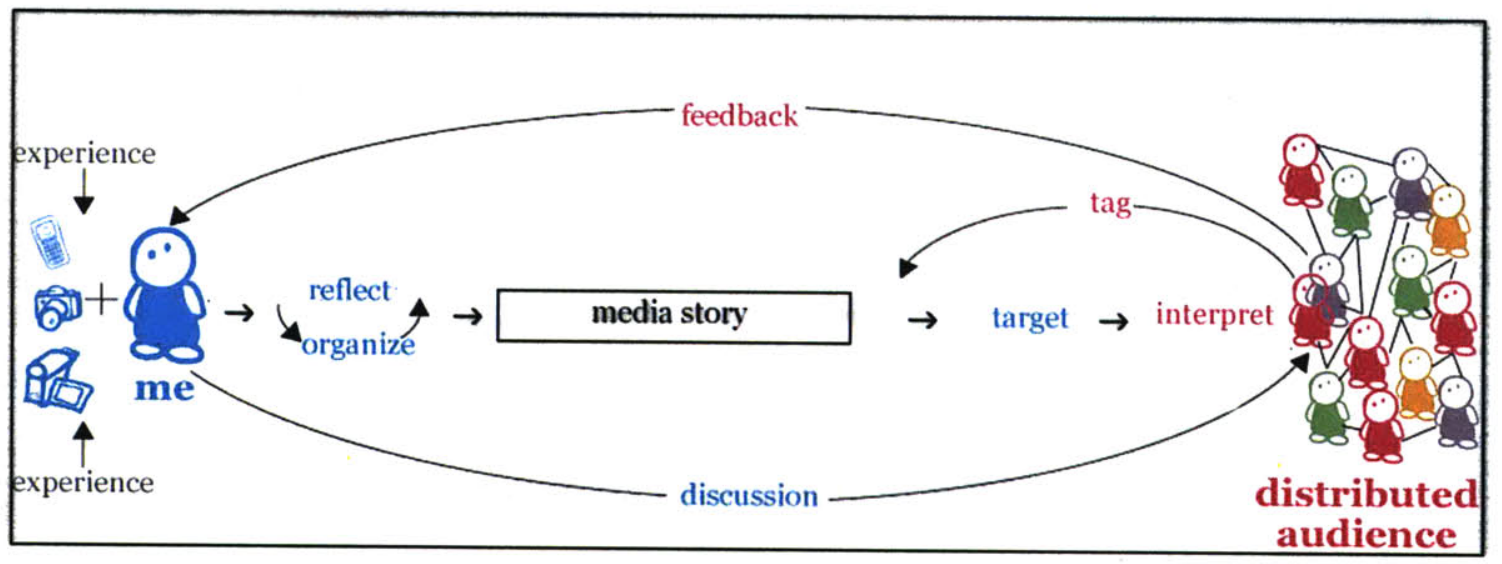

Figure 3: Mediated networked story exchange process

An audience can send me feedback directly through email or online comments and they can categorize and tag my story with descriptive keywords that increase its findability. Their published input becomes part of my story, extending its meaning for future audiences.

In creating and sharing our personal mediated stories, our choice of media recording device, editing software and publishing platform greatly impacts the types of stories told, how they are displayed, how they are responded to and how they are understood. Our level of technical expertise, storytelling flair and the availability of time within our daily schedule also impact our capacity to positively engage in a process of mediated personal story exchange. 


\subsection{Purpose of this work}

The purpose of this work is to better understand the process of creating and sharing mediated personal testimony and to develop technologies and a representative form that supports the everyday casual storyteller in expressing, communicating and understanding personal rich-media narratives. This thesis presents both a model of the casual storyteller's process of capturing, creating and sharing personal stories and an online authoring and publishing application for creating everyday mediated stories called 'Confectionary'. Confectionary provides the storyteller with a spatial storytelling environment that encourages creativity and experimentation, supports a wide variety of storymaking styles, provides novel wayfinding strategies for story discovery and enables the audience to actively and broadly interpret personal rich-media stories. The application was evaluated by novice and experienced media storytellers and important lessons were learned about modeling the personal mediated storytelling process and the use of everyday spatial storytelling tools for creating, sharing and reflecting upon personal narratives.

\subsection{Problem}

Casual everyday media storytellers are the disparate amateur photographers, homemoviemakers and scrapbook enthusiasts who document their life experiences for their future grandchildren, an imagined posterity, or simply to keep a record of their life lived. In recent years, these everyday storytellers have in increasing numbers, transitioned from analog to digital cameras, from the world of videotape to the world of networked digital messaging, from media as artifact to media communication as process. However, the available toolset for media communication and exchange remains largely tied to the idea of unique artifact as represented by single pictures or single edited movies. For everyday storytellers, the process of capturing, composing and sharing media memories of their daily experiences can be time-consuming, complicated and frustrating. The difficulty rests in part with the storied characteristics of today's media forms, how this relates to available publication environments and how these publication environments provide active support and critical feedback.

Let us examine each of these briefly. The storied characteristic or 'narrativity' of a still photograph may rest in the visual alone (a portrait of a nervous bride). The storied 
aspect is generally enhanced when accompanied by a short narrative description contributed by the photo subject or by the portrait taker ("I held my breath for so long I fainted at the altar" or "it was a picture perfect day and the roses were all in bloom"). Often, the storied characteristic resides in the assembly and juxtaposition of several photographs accompanied by a narration. Movies require more editing and assembly. The presence of visuals with synchronous sound helps carry storied meaning. However to access this meaning, the movie first must be made and then watched. Everyday movies tend to be made up of a series of scenes (decorating the tent, guests arriving at the church, bridal procession, the vows, the cake is cut, the father dances with the bride etc.). Movie meaning does not easily translate to text-based descriptions as the nuance that allows us to relate to the characters and their situation is complex and subtle.

There are few readily available everyday tools for ordinary people to engage with their media in meaningful and storied ways. Everyday tools are those that are enmeshed in our routine daily activities. Pencils, typewriters and cellphones are examples of tools that are deeply embedded in our common cultural practices. In "Reinventing Comics", Scott McCloud describes how the tools of everyday life "harbor one of a few simple, powerful ideas: that the world can be shaped to our will; that thoughts can be sent through time and distance; that we can extend our physical abilities; that we can extend out lives" [McCloud p136 200o]. Today's multifunctional cameras, audio recorders and video enabled cellphones come outfitted with dense arrays of buttons, dials and displays and are generally accompanied by thick user manuals describing the hundreds of functions offered. Once the amateur storymaker gains familiarity with these functions, her proclivity for taking photographs or shooting videos becomes partly based on her willingness to invest time and effort in learning to manipulate media editing and composing software such as Photoshop or Final Cut Pro. The complexity of these software packages require considerable time investment on the part of the average everyday user to even get up to speed with understanding the potentiality of the software. While products such as iMovie offer a more consumer friendly approach, it still requires users to come up with ideas for their overall movie framework or segment structure. Furthermore, because the story artifacts generated by these tools bear little trace of the creative selection and decision-making process that went into their construction, there are few opportunities for novice users to use these artifacts as exemplars for learning. 
More daunting still is the question of how and where to share one's media creations. In the past, an amateur moviemaker was generally restricted to showing their personal narratives in the home environment. While the everyday publishing and sharing of personal media online is becoming more prevalent, as evidenced by sites such as YouTube and Flickr, it is still a non-trivial exercise to create works for these sites that fulfill our narrative imagination. Moreover these media sharing websites remain focused largely on growing as big a collection of media as possible, while providing minimal tools for the sharing of points of view or creating connections between individual media entities. For instance, media entities on these websites are all displayed uniformly with every contribution, regardless of it's content or the intent of the contributor, sized and composed identically. After a while our individual contributions can appear dwarfed by the enormity of the collection, where all the contributions of others seem just about the same, and more likely than not we feel that we have missed some potential for meaningmaking. One fairly obvious limitation of these sites, along with that offered by other popular publishing platforms such as MySpace, is that each caters only to one particular style of storytelling. MySpace focuses on personal profiling; weblogs support chronological storytelling; while Flickr and YouTube provide platforms that can result in a diverse collection of artifacts that suggest the future of event-driven narratives (Hurricane Katrina, New Years Eve etc). Neither MySpace nor today's leading weblog publishing software focus on the integration of user's text-based narratives with their actual media collections. Mp3's, photos and videos are largely segregated into separate subsections apart from the primary text. This seriously constrains the potential for creating compelling and expressive mixed-media narratives.

When we look at the relationship between feedback and story discoverability, the websites described above all provide features for commenting, tagging, linking and designating favorites. This functionality allows participants to explore groupings based on tags (which indicate semantic or contextual relationships), social features such as community groups and interest pools, and automated system pointers such as 'most viewed' and 'most recent'. Here again the focus is on the collection and categorization of individual entities with few opportunities for audiences to contribute in a more thoughtful, connected, storied and 'curatorial' fashion. 
The nature of the problem is subtle. Consider the difference between all poems and a poetry anthology. When we are in the space of all poems we are awash with examples but we have only crude organizational modes with which to steer: title, author, length, or perhaps subject. When we pick up an anthology, we are able to immerse ourselves in a thoughtfully 'curated' set of poems that someone decided held meaning as a group. When we sample a poem, the meaning of the individual artifact is augmented by its inclusion in the set. In a more narrative mode, the same can be said for a scene in a movie. In this case, the meaning of the scene is augmented by its inclusion in the larger entity and by the position it holds in the overall arrangement of scenes. In "The Laws of Simplicity", John Maeda proposes a possible definition of simplicity as "subtracting the obvious, and adding the meaningful" [Maeda p9o 2006]. Given the difficulties described above, simplifying the process of creating and sharing personal media stories involves rethinking the relationship between narrative purpose and the design and functionality of supporting technologies in ways that augment and integrate engagement and critical reflection.

Tools for everyday mediated story expression and communication must prove appealing and useful to users with a wide variety of technical abilities, disparate motivations for telling stories and multiple storytelling styles and approaches. Everyday media storytellers need environments that move beyond the simple cataloguing of discrete media entities, and instead support the integrated composition of multiple forms of media in thought-provoking reflective narratives. The page based metaphor of the Internet provides some clues to the potential for a new form of narrative, one that is composed, where a balance exists between the instant identification of meaning and the more subtle development of meaning over time. We see a need to address this balance at the level of the individual entity and at the level of a "curatorial" function. Real-world museums and galleries often provide visitors with carefully scripted navigation paths designed to direct the visitor on a particular 'received' journey through the displayed collection. The Art Institute of Chicago produces themed self-guides for discovering works involving dance ("Dance Fever Guide"), bodily perfection ("You Look Marvelous") and inspired by the movie Ferris Bueller's Day Off, a guide that riffs on titles of movies set or filmed in Chicago ("On Location"). In this vein, supporting participants in creating and sharing anthological story pathways elevates the role of the audience from that of entity specific commentator to one of considered interpreter of story collections. 


\subsection{Everyday Mediated Storytelling}

Everyday Mediated Storytelling is a model of how ordinary people can express, share and experience story-centered personal reflections. The media capture, story authoring and publishing, and audience feedback components of the Everyday Mediated Storytelling model is depicted in Figure 4 below.

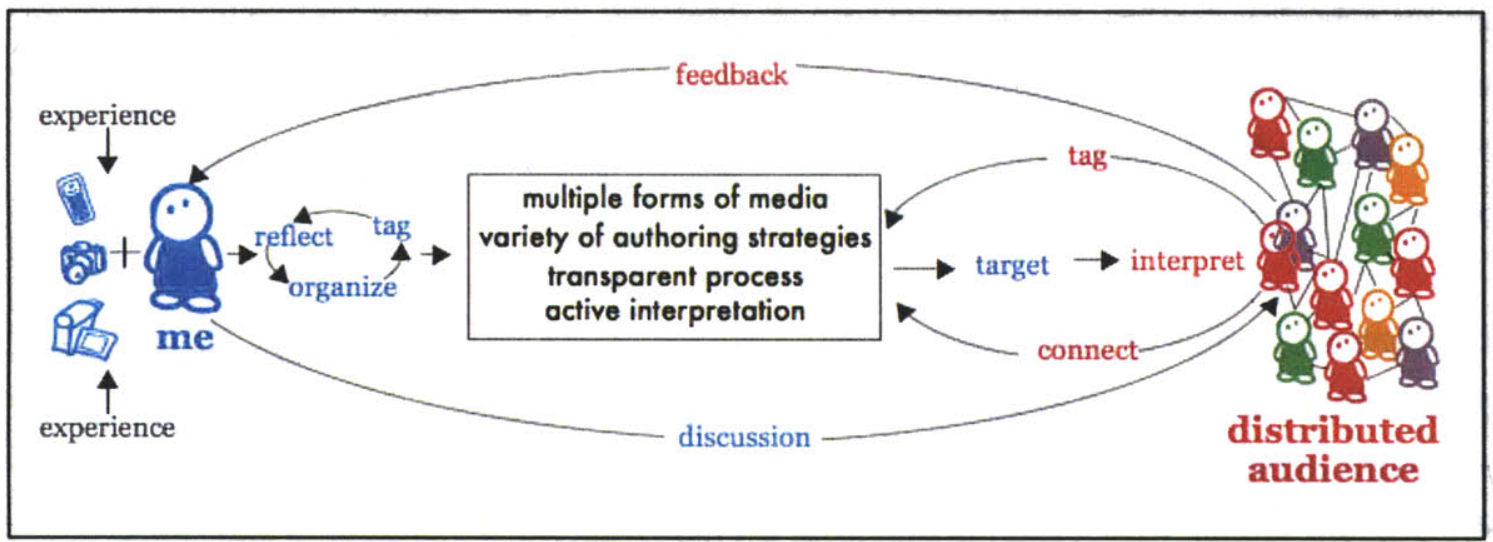

Figure 4: Everyday Mediated Storytelling Model

The everyday mediated storyteller captures her experiences using a variety of digital recording devices such as a camera-enabled cellphone, digital camera, audio recorder and digital video camera. She organizes her captured media by renaming files and grouping them into thematic directories. She edits, crops and manipulates her original media files in preparation for inclusion in her mediated stories. She selects the media files from her collection that will enable her to best tell her story, uploading them to a central on-line server. She authors and publishes her personal rich-media stories in a spatial environment that allows her to reflect and create in an easy, risk-free and playful manner. Within this spatial environment she explores a variety of integrated rich-media storymaking styles, ranging from poetic and ambiguous to direct reportage. She juxtaposes, layers and styles her media entities into rich-media story collages arranged on a 2D spatial canvas. She browses through other stories on the server examining the story strategies of others and learning from their approach. She completes her story and targets her desired audience by limiting or allowing access to her story. Once contributed, she may participate in defining the context for her story by creating her own paths or connections between her story and other stories on the server. Whether they promote chronological interpretation of a series of story sequences or an anthology 
based approach, these pathways provide the audience with some directed, meaningful navigation strategies. The audience (who may themselves participate as storytellers and pathmakers) can thereby discover a story in one of several ways: browsing (randomly) by title, checking the most commented story contributions, or exploring recently added paths. While some of these paths may be automatically 'curated' by the system (such as assembling collections by author, date or community grouping), others distinguished by an imaginative title or description ("Forests and Trees", "Celebrated Entrances", "follow me on a frightening journey through the nighttime desert") will provide a more narrative tour through the material. The audience can provide feedback by adding comments and metadata, or by creating a new pathway, thereby adding their own perspective on a meaningful journey.

The combined effect of those relationships articulated and contained within the $2 \mathrm{D}$ space of an individual story and relationships made explicit through the designation of persistent pathways provides the envisioned system to support the 'Everyday Mediated Storytelling Model' with a unique potential for narrative construction and reflection. While the $2 \mathrm{D}$ collage-like story can convey relationships between narrative elements, the conscious construction of the pathway provides the participants with the ability to create and witness a trail of narrative intentionality. As a captive audience, this temporal progression of storied frames bids us engage our imagination and respond not exclusively to what has been specified but to a world we intuit from a progression of personal testimonies.

\subsection{Approach}

The model discussed above, and expanded by way of the scenario, draws on: theoretical discussions of narrative and personal testimony; personal experience creating richmedia artifacts; the construction of several experimental environments for media sharing; and on a handful of studies I have conducted with media storymakers, as well as professionals, tasked with soliciting difficult stories from others.

In order to explore hypotheses that are embedded in the model, I designed and implemented an online rich-media story authoring and publishing application called Confectionary, and studied several groups of story-makers and story-receivers as they used this environment. Designed to support the exchange of personal mediated 
testimony, Confectionary provides storytellers with a simple tool for uploading media (movies, still pictures, audio files) and authoring story compositions by arranging multiple media elements on a 2D spatial canvas. The spatial nature of the application instigates activity and encourages experimentation by the simple addition or deletion of media entities, drag-and-drop functionality and sizing and transparency settings. Through the use of community and individual profiles, Confectionary storytellers can assign varying levels of disclosure to their stories, allowing stories to remain private, fully public, or viewable only by designated individuals or communities. In this way, the application provides storytellers with a 'safe' and trusted environment for reflecting on their experiences and creating and sharing personal narratives of a sensitive or difficult nature. The publishing interface encourages audience feedback through a novel pathmaking feature that allows participants to construct preferred methods of wayfinding through the entire collection of stories. Additional feedback features support the commenting of individual stories and/or paths, the designation of favorite stories and the display of viewing and commenting statistics.

Confectionary extends the idea of composition beyond the framework of a single image or movie. It suggests instead that it is the relationship between artifacts that can help people elevate their everyday media to transform memories into powerful personal testimony that is engaging and transformative to the maker and to the audience. Grounded in our model of everyday mediated storytelling, the Confectionary application is used as a foundation for studying how we can use our personal media to reflect on and communicate that which is meaningful and connected in our everyday lived experience. 


\subsection{Thesis Statement}

\section{A spatial metaphor for authoring and publishing, and a path metaphor for connecting and experiencing, mediated personal testimony, enable ordinary people to express, share and experience story-centered personal reflections.}

The Confectionary software application has been developed in order to explore and verify five key claims of this thesis statement:

- Story-centered personal reflection by casual storytellers can be supported by a spatial rich-media authoring and publishing environment

- A spatial rich-media authoring metaphor allows storytellers to easily create narrative relationships between media entities making the process of constructing storied meaning direct and transparent

- A spatial rich-media authoring metaphor supports a wide variety of storymaking strategies, motivations and styles

- A path metaphor significantly increases the meaning making capability for all participants in a rich-media authoring and publishing environment

- Story-centered reflective dialogs can be supported by a rich-media authoring and publishing environment with multiple active feedback modes

\subsection{Contributions}

This thesis presents a number of contributions to the field of mediated storytelling:

- Creation of a model of the casual storyteller's process of creating and sharing personal everyday mediated narratives

- Introduction of a spatial metaphor for the construction of relational meanings and increased narrativity of everyday media.

- Introduction of a path framework to create sequential "narrative" or relational meaning between spatial frames of everyday media. 
- Implementation of a spatial story authoring and publishing application for the everyday expression and publication of personal media narratives

- Demonstration that this environment enables story-centered personal reflection and supports a wide variety of storymaking strategies, motivations and styles

- Demonstration that this environment supports story-centered reflective dialogs through multiple active feedback modes.

\subsection{Thesis Roadmap}

In this chapter we have examined the process of testifying to our life experiences by creating and sharing mediated personal stories. We have detailed the problems that the everyday storyteller faces in capturing, composing and publishing their mediated stories and developed a model and systematic approach that enables ordinary people to express their personal experiences as an everyday mediated experience. Chapter Two examines the theory and rationale guiding this research situated within the fields of personal storytelling, mediated personal storytelling, rich-media authoring and publishing tools, mediated spatial storytelling, and navigation and wayfinding. Chapter Three details my research journey in developing a design approach based on personal media-making experiences, the development of several computational environments for personal media sharing and on studies I conducted with media storymakers, as well as professionals, tasked with soliciting difficult stories from others. Chapter Four describes the implementation of the Confectionary application. Chapter Five reports on the use of the Confectionary system by groups of novice and expert users, drawing comparisons with current best practice, evaluating the application affordances and characterizing identified story styles and approaches. Chapter Six concludes with a summary of the work presented and suggestions for refinements and future research. This is followed by a Bibliography and Appendices. The Appendices depict screengrabs of the stories created in Confectionary during the course of this thesis work, data from workshop surveys, and questionnaires and consent forms used during the system evaluation. In addition, the Confectionary application can be accessed and explored online at http://mf.media.mit.edu/confectionary 


\section{Theory and Rationale}

This chapter surveys related work in the theory of personal storytelling, mediated personal storytelling, rich-media authoring and publishing tools, mediated spatial storytelling, and navigation and wayfinding. I examine our fundamental motivations for creating and sharing personal stories and explore the broad variety of representational forms we have employed over the centuries to construct and relate the stories of our lives. Existing channels for mediated storytelling are compared with the spatial paradigm proposed by Confectionary and particular attention is paid to evaluating the impact of

spatial composition techniques on narrative meaning. This chapter also considers modes of navigation and wayfinding as found across contemporary web-based storytelling systems. The comparison of contemporary applications will allow the reader to better distinguish the novel pathmaking and spatial authoring features of Confectionary that may impact the quality of personal reflection that this application makes available to casual storytellers.

\subsection{Personal storytelling}

We understand and interpret our life experiences by constructing stories that transform and reimagine our worldly existence. The act of storytelling is essentially a communicative one: every story involves "somebody telling something to someone about something" [Kearney p5 2002]. In recounting our personal stories we organize and clarify fragments of experienced time into narrative configurations that are related back to the life world of the audience. This process involves a dynamic and circular movement from action to text and back again [Ricoeur 1984]. It is this interplay of agency between the author, actor and the audience that provides us with our sense of selfhood and indeed our narrative identity, both as individuals and as social, cultural beings [Kearney 2002]. Ultimately, when we share a personal story we are offering the listener "an invitation to intimacy" [Stahl p37 1989]. This intimacy is strengthened as we respond to one another and exchange stories in a conversational process by which we come to know one another better. Selya Benhabib stresses the significance of dialogue and conversation as cooperative models for communicative exchange stating that "in conversation, I must know how to listen, I must know how to understand your point of view...If I cannot listen, if I cannot understand, and if I cannot represent, the conversation stops, 
develops into an argument, or maybe never gets started" [Benhabib p359 1992]. This process of reflective storied dialog serves to enrich our personal narratives by making connections to other contrasting or supporting stories and creating an expanded multivoiced record that speaks of the individual and social mind.

Paul Ricoeur, working within the philosophical tradition of critical hermeneutics, championed the idea of interpreting and evaluating our experiences not only in relation to our own personal understanding, but also in comparison with the experiences of those in our surrounding culture. Ricoeur favored moving "from a pure phenomenology of reflective consciousness to a hermeneutic phenomenology which recognizes that the subject's retrieval of itself and of meaning requires a detour through the objective structures of culture, religion, society and language" [Kearney p217 1996]. This consideration of the concept of singularity engaged in a tacit relationship with the external other, leads us to an understanding of interpretive practice that is both referential and encompassing. Within this framework, narrative meaning is derived from the mediation between man and himself (self-understanding), the mediation between men (communicability) and the mediation between man and the world (referentiality) [Ricoeur 1991].

The Everyday Mediated Storytelling model as presented in Chapter 1 encapsulates the dynamic interplay between the storyteller, the story and the audience in an interactive process that oscillates between the lived and the narrated world. Within the Confectionary application, the cyclical interplay between participants is explicitly supported by feedback mechanisms such as generated viewer statistics, comments and favorites. Invitations to intimacy are also under the control of the storyteller through the designation of disclosure attributes that label the story as public, private or accessible to particular communities or individuals. The Confectionary wayfinding paths not only allow the storyteller to experience their own stories in a broad variety of alternative contexts, they also supply the audience with a level of interpretive agency that is both communicable and referential. 


\subsection{Mediated Personal Storytelling}

By documenting and recording our lives, we make them in a sense visible. Through the creation of external artifacts, we are able to share our experiences with others while also providing some memorable evidence to return to again and again. We not only recount, but also justify our actions at the originally experienced time and in the later moment of recollection. With this autobiographical process we construct and relate the story of our lives. It is a process that challenges history's claim to be the science of the human past or the only set of procedures by which a valid representation of events can be generated [Popkin 2003].

Described by Aram Saroyan as "a kind of willed immortality", the desire to leave a trace and have our existence matter compels us to create and share representations of our lived experiences, in a process whereby "we write [our] names over and over and over again" [Saroyan p51 1982]. For centuries, people have used diaries, journals, scrapbooks and commonbooks to record the events of the day, interesting anecdotes, their thoughts and their hopes for the future. The diary exists as a form of literature for the everyman, presenting an intriguing insight into the daily activities, social mores and cultural climate of the journal's author. In A Book of One's Own, Thomas Mallon, having read many diaries, concludes three things: "writing books is too good an idea to be left to authors; no one has had an easy life; no one has ever kept a diary for just himself" [Mallon xvi 1984]. Fundamentally, there is a desire to have what is being documented understood by some form of audience, whether descendants, a potential publisher or a future self.

The $19^{\text {th }}$ century invention of photography provided an exciting new medium for individuals to record and document their family lives, but it was not until the emergence of the Brownie camera by Eastman Kodak in 1900 that photography became affordable for the masses. Kodak can also claim some responsibility for the popular proliferation of the photo album with its cultivation of the cultural concept of the family matriarch carefully capturing, composing and arranging photographs into books of memories [Snyder \& Levine 2006]. Similarly, the emergence of cheap, portable movie cameras in the 1960's provided another expressive medium for investigating and capturing the human condition. Home-movies embrace the informal and the disorganized, where 
confusing breaks in continuity and gaps in footage can be explained by the memories of the viewing audience who are themselves, the stars of the show.

With the advent and growth of the World Wide Web, mediated personal storytelling has developed a distributed global audience thanks to personal publishing technologies like weblogs, podcasts and wikis, and media hosting services such as Flickr, YouTube and MySpace. Mother's treasured photo album on the bookshelf has now become a dynamic, communal and annotated entity that is accessible to potentially millions of viewers. These technologies embrace a style of personal storytelling that is fragmented, serialized and highly connected. Like the clipped and abbreviated dialog of instant messaging, micro-narratives in the form of multimedia story snippets are the main form of communication and expression in these online sites.

The Confectionary application supports users in documenting their lives using multiple forms of media in an environment that allows for the expression of a wide variety of authoring strategies and styles. In comparison, the collection focused Flickr and YouTube support users in sharing only one particular type of media in an environment where each submitted entity is displayed identically, leaving little room for experimentation or personalization. Confectionary provides storytellers with agency and control over accessibility to their stories, allowing for the creation of a body of work that has a gradient of disclosure ranging from completely private, to limited access to fully available. In this way, storytellers can create a more nuanced form of multi-media diary, which is at times expressive to the general human condition and at other times speaks only to the individual mind.

\subsection{Rich-media authoring and publishing tools}

The convergence of media technologies and digital computing afforded the emergence of rich-media storytelling. Rich-media story authoring involves the assembling of a variety of entities to create a mixed media presentation that can express and communicate an experience. Advances in database design and distributed networks have greatly expanded opportunities for the publishing and sharing of rich-media stories.

Commercially successful multimedia authoring tools such as Flash, Director, Authorware and Mediaforge are targeted towards multimedia professionals and technically-savvy users with the necessary time and energy to invest in gaining proficiency with the 
technology. Based on timeline or graph-based authoring paradigms, these software tools rely on scripting mechanisms of varying complexity for coordinating interactivity, nonlinear playback or asynchronous events. The linear nature of timeline-based tools, while ideal for authors with clear storytelling goals, is less appropriate for those who wish to casually experiment and play with a variety of possible storytelling strategies and approaches. While these tools are perfectly suitable for an expert or professional multimedia designer, they do not easily lend themselves to everyday use by the casual, amateur user.

Within the research community, scripting strategies for rich-media story authoring are demonstrated by the M-Views [Pan 2004] and Dexter [Murtaugh 1996] systems, while graphical approaches to authoring multimedia in comic-style environments have been successful in encouraging children's storytelling [Antle 2003, 2004], stimulating dialog between child storytellers [Steiner \& Moher, 2002], and for acquiring stories from adult Internet users for use in a common-sense reasoning system [Williams et al., 2005]. These tools are undoubtedly powerful technologies for storytellers and designers with clearly defined multimedia story goals, but again, are not suitable for casual, everyday use.

With each of the technologies mentioned above, the act of authoring is segregated from that of publishing, and so the final story presentation bears little trace of the creative selection and decision-making process that went into its construction. It is therefore difficult for the audience viewing the displayed story to intuit how it was made or use the viewing experience as an opportunity for learning and developing their own storymaking skill-set. The invention in the late 1970's of WYSIWYG (What You See Is What You Get) style word processing applications helped document creators visualize in real time what they were doing. Previously, inline markup code was required to designate layout and style features that were not observable until the document was compiled and the code interpreted. The WYSIWYG paradigm encouraged a type of risk-free experimentation and playful exploration that would earlier have been difficult to achieve. While this approach can have its limitations within the field of text processing, its potential as a framework for multimedia storytelling has not been widely explored. 
There has been considerable work in recent years in the area of online collaborative story construction. Community-centric story construction initiatives such as the Silver Stringers, Community Memory and The Palaver Tree projects focus on creating straightforward publishing tools and learning environments for groups of users already familiar with one another in the physical world [Smith et al., 2000][Endter 2000][Ellis \& Bruckman, 2001]. In the case of the Silver Stringers project, which has been operating for over 10 years, senior citizens participate as reporters, photographers, illustrators and editors of a localized web-based publication. The Palaver Tree initiative supports intergenerational storytelling, where school children interview and chat online with elders in the community about their diverse experiences. Commercial online rich-media storytelling endeavors such as Tellingstories.com facilitate clients in creating multimedia slideshows using personal media that can then be shared with family and friends in CD or email attachment format.

The Everyday Mediated Storytelling model situates the acts of story authoring and story publishing together as a wholly integrated process. Within the Confectionary application, the authoring and publishing interfaces are the same, meaning that the system can be considered to support the WYSIWYG framework. The entire application has been designed specifically for the casual storyteller and is therefore suitable for those with limited technical abilities. Rich-media stories can be simply authored in minutes and require no scripting or programming activities. Media is dragged and dropped around a 2-dimensional story canvas inviting exploration through expressive experimentation with layout, sizing and transparency settings. The viewing audience can actively participate in extending this act of story exchange by adding comments or creating preferred navigational paths through collections of selected stories.

\subsection{Mediated Spatial Storytelling}

From cave drawings to Egyptian paintings, stained glass windows to comics, telling stories in 2-dimensional space has been a popular and instinctual human pursuit. Within the realm of traditional personal storytelling, we have created stories using a variety of spatial strategies in diaries, photo albums, collages and scrapbooks. These organizational spatial constructs support varying levels of narrativity, depending on their sequential and their configurational qualities [Steiner 2004]. Narrativity in this case refers to the potential for a text (verbal or non-verbal) to evoke a 'narrative script'; a mental cognitive 
construct built by the interpreter in response to a text [Ryan 2004]. The observer decodes the text through a sensory, perceptual and cognitive analysis of its composition, content and form. While there are many prominent design theorists who discuss composition within the spatial plane, the theorists and practitioners who have most influenced this thesis research have focused on the role of narrative design and comprehension in relation to $2 \mathrm{D}$ space. In particular, they have examined the power of the spatial plane in quickly relaying complex narrative constructs through informed use of compositional strategy, layout techniques and prudent media combinations.

Scott McCloud is a cartoonist and comic theorist who studies the art of spatial storytelling in graphic form. According to McCloud, words, pictures and icons "are the vocabulary of the language called comics" [McCloud p 47 1994]. The process of creating a comic involves a series of strategic choices on behalf of the author, that include choosing the moment to represent, the angle to frame the moment, the imagery to depict the moment and the words that will enhance the image and add value to the story [McCloud 2006]. The comic author invokes structural (panel sizing, page composition) and stylistic (line type, color) strategies to create additional narrative context surrounding the chosen moment in an imaginative rendering of sequential moment panels. Meaning is created both within the composition of the specific moment panel itself and in the movement of the narrative from panel to successive panel. In “Understanding Comics”, McCloud uses the term 'closure' to describe how we can perceive something as whole even while observing incomplete and fragmentary information [McCloud 1994]. Successive panels within comics, separated only by a small gap or 'gutter', can transport the active reader "across significant distances of time and space" [McCloud p71 1994]. This interpretative process is as much a product of what is actually depicted by the author and what is simultaneously inferred and imagined by the reader. Sequences of gutter-separated images provide a narrative richness far greater than that of an image alone, and with a level of immediate transparency far greater than that of a single time-dependent movie.

Donis A. Dondis defines composition as "the interpretive means for controlling the reinterpretation of a visual message by those who experience it" [Dondis p104 1973]. Just as there is a dynamic and integrated connection between form and content within a work, there is also an equally intertwined relationship between the creator and the 
audience in interpreting the meaning and message of a work. In his seminal text on design strategies "Visual Explanations", Edward Tufte analyzes how the design and arrangement of images can function as a form of narrative. He uses the term 'confection' to identify a form of visual collage executed within the domain of information. He defines a confection as "an assembly of many visual events, selected...from various Streams of Story, then brought together and juxtaposed on the still flatland of paper. By means of a multiplicity of image-events, confections illustrate an argument, present and enforce visual comparisons, combine the real and the imaginary, and tell us yet another story" [Tufte p121 1997]. Using strategies of multiplicity, overlapping, transparency and compartmentalizing, the confection maker creates a visual artifact that is logically consistent and "by virtue of the architecture of (its) arguments, (it) makes reading and seeing and thinking identical" [Tufte p151 1997]. The WYSIWYG nature of a confection provokes an intuitive viewer perception of the general gist of the story that in its intricacy and thoughtful composition invites us to delve deeper and contemplate coming to 'know' the confection story further.

In 'A Primer of Visual Literacy', Dondis ascribes three central considerations for constructing and interpreting a visual work: the significance of the individual elements (color, texture, proportion etc.); the expressive power of the individual techniques (symmetry, regularity, repetition, contrast); and the media context (painting, photography, architecture) [Dondis xi 1973]. Gestalt psychology has been successfully employed to examine how humans physically and psychologically articulate visual output and respond to visual stimuli in a holistic way. One of the primary influences on human perception of visual works is our need for balance, to simply be able to remain upright [Dondis 22 1973]. This response manifests itself in our imposition on visual stimuli, no matter how regular or irregular, of a vertical and horizontal 'felt axis' as depicted by Dondis in Figure 5. Our eyes are naturally drawn to these area axes, thus increasing their compositional importance.

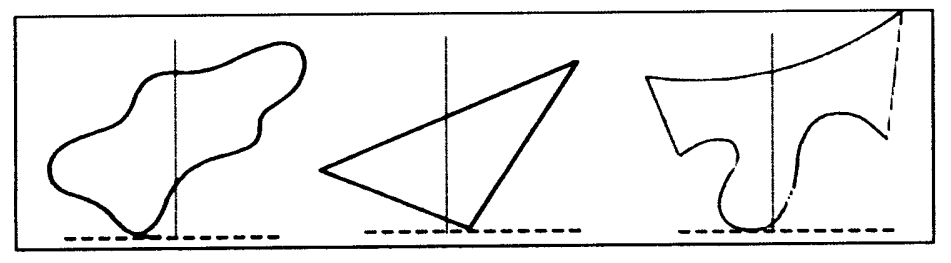

Figure 5: Projecting the felt axis onto structural forms 
We also classify visual compositions as being relatively stable or stressful depending on how the author has 'leveled' or 'sharpened' the potential for harmonious interpretation. For example, in Figure 6, the central placement of the dot in the rectangular field is an example of leveling, as it is harmonious and creates stability.

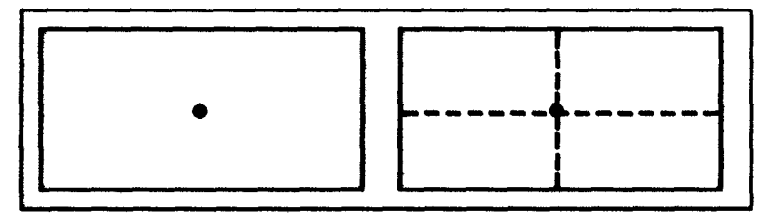

Figure 6: Harmonious leveling of a structural map

However, the placement of the dot in Figure 7 is visually surprising and invokes a more stressful reading. The sharpening effect is caused by the dot's off-center placement from the horizontal, vertical and diagonal cross-sections.

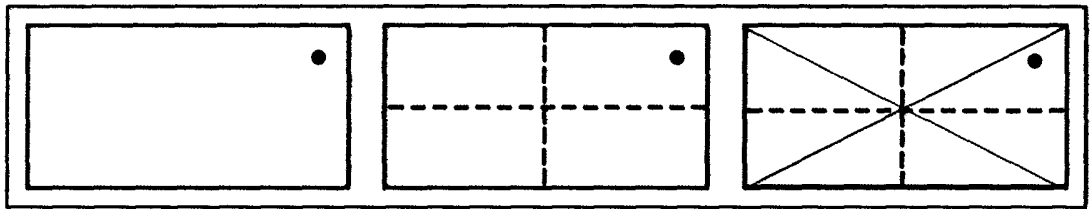

Figure 7: Stressful sharpening of a structural map

Within the Western world and strongly influenced by print formation, we are also conditioned to approach a visual piece in a left-to-right, top-down way, meaning that works that are leveled or sharpened according to this condition are considered more harmonious and balanced.

The Gestalt principle called the 'law of grouping' also applies in determining how we create associations and relations between elements in a visual representation. Depending on placement and similarity (size, texture, tone), we interpret different elements as being attracted or repulsed from one another. Other psychophysical ways of seeing explored by Gestalt psychologists include balancing positive-negative images such as the Chinese symbol of yin-yang, the perception that larger items appear to be closer and overlapping items denoting relative distance. In Figure 8, Dondis illustrates some visual techniques alongside their opposite polarities [Dondis 1973]. Between these binary positions lies a 
rich continuum of approaches for visual expression and communication that can be used to support, augment or contradict the message content.

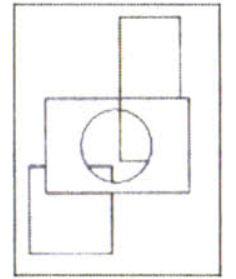

balance

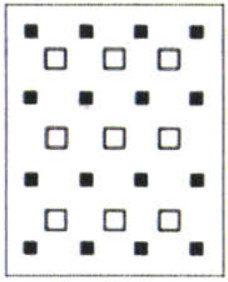

simplicity

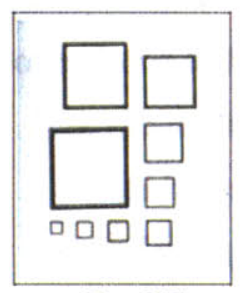

predictability

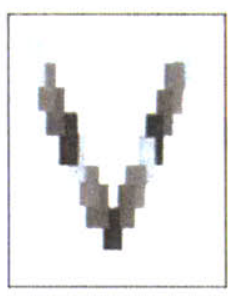

sequentiality

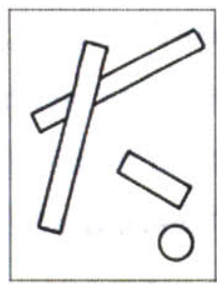

instability
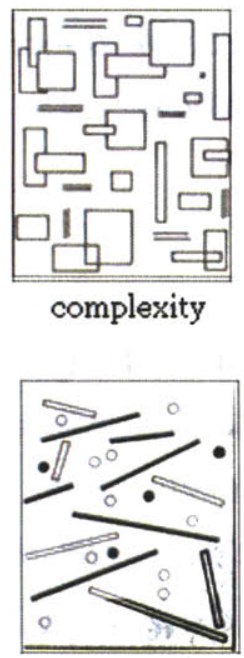

spontaneity

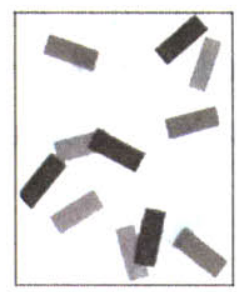

randomness

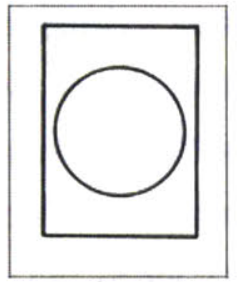

symmetry

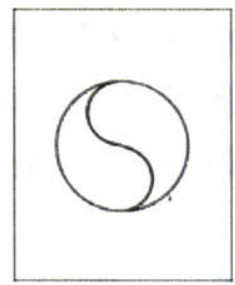

unity

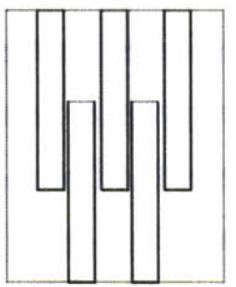

consistency

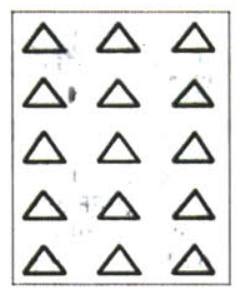

repetition

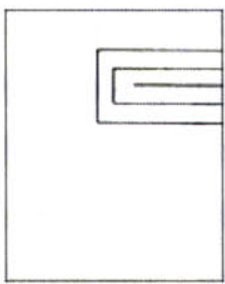

asymmetry

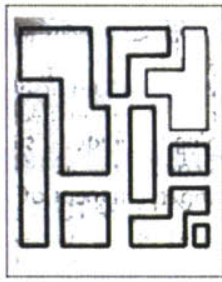

fragmentation

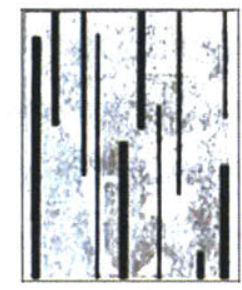

variation

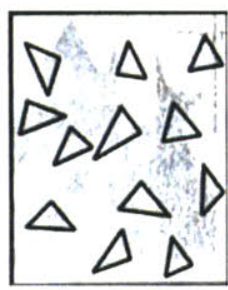

episodicity

Figure 8: Illustrations of visual techniques from 'A Primer of Visual Literacy'

McCloud identifies six key steps involved in the creation of a work in any medium: idea/purpose, form, idiom/genre, structure, craft and surface [McCloud p182 1994]. The Everyday Mediated Storytelling model identifies the purpose of creating personal stories as the fundamental desire to make our experiences memorable over time and to come to better understand ourselves as individual and social beings. These stories are manifest in the Confectionary application in the form of online rich-media stories 
created on a 2-dimensional spatial canvas. The subject matter and style of the stories are informed by a variety of genres, from Dadaist poetry to documentary filmmaking, collage and portraiture. The Confectionary application provides the storyteller with structured authoring features and functions that support a broad range of communicative and expressive techniques. To paraphrase McCloud, the vocabulary of the language of Confectionary includes words, images, movies and audio that can be arranged in a spatial canvas. This canvas displays all the elements of the story at once in a process that strives to emulate Tufte's claim to make "reading and seeing and thinking identical". The application supports the manipulation of compositional techniques such as layering, repetition, transparency and size while the color, size and orientation of textual elements can also be controlled. Furthermore, Confectionary offers the author a sequencing component in the form of pathmaking, which serves to extend the story process beyond that of the individual canvas.

Storytellers hone their craft over time as they probe the boundaries of the applications, experimenting with generic story templates, learning from the approaches of others and determining their own preferred storymaking style. At the surface level, the production value of the created stories is both determined by the quality of the original media and the presentation interface of the Confectionary application itself. More importantly however, is the addition to this 6-stage process of one other crucial step-feedback. Audience interpretation, manifested as commentary, 'curating' and connecting is a vital component in the growth and expansion of a work. For example, the story author receives direct evidence of how their story is understood by others, while the story interpreter gets to compose their own story sequence using the creations of others.

\subsection{Navigation and Wayfinding}

Being able to make our way through space in a coherent, safe and pleasant manner is fundamental whether we are hiking in the mountains or surfing the web. In "The Image of the City", Kevin Lynch defines the concept of environmental legibility whereby we navigate through physical space using recognizable patterns [Lynch 1960]. Lynch provides a vocabulary for describing the fundamental elements of a city: paths, edges, districts, nodes and landmarks. From these elements, humans read the city by constructing an environmental wayfinding map. This map not only helps us to move 
through the city, it also deeply informs our impression of the beauty and power of the city. Peter Morville describes findability as 'the quality of being locatable or navigable' as measured at both the object and the system level [Morville p4 2005]. At the object level we can observe the attributes that make an object more likely to be discovered - the title of a book, the color of a warning sign, the presence of a GPS locator. At the system level we can examine the success or failure of the system in supporting users in finding their way - can the emergency exit be found during a fire, can the spreadsheet be found in the database. In today's information saturated world, Morville uses the term ambient findability to describe a "fast emerging world where we can find anyone or anything from anywhere at anytime" [Morville p62 2005]. Although we are obviously not yet at this highly desirable state, there are numerous techniques we can employ to enhance findability particularly in the online digital realm. Web usability experts remind us that users scan websites rather than read them, therefore information should be broken down into small chunks, navigation schemes should include redundancy, and provenance in the form of user interactive history used to promote items of relevance.

In the physical world, navigating through story-space can mean simply turning over the pages in a book, whereby we have a clear understanding of where we are in the story based on the felt amount of pages left to be turned. In the realm of digital story-space, we require other forms of recognizable patterns to help us navigate and locate ourselves in a veritable 'sea of stories'. The "Elastic Charles" journal is one of the earliest examples of a hypermedia story environment that supported the story author in creating discoverable navigation pathways or 'guided tours' through a collection of media entities [Davenport \& Brondmo 1989]. Viewing audiences selected author assigned 'link indicators' to move from one piece of media to the next while their entire interaction history was recorded and stored for later playback to further facilitate navigation and to help create a visual mapping of the storied information space. Automatist storytelling systems such as the ConTour application provided machine driven suggestions for 'steerable paths' based on author keyword input and a spreading activation network playback approach. Users of the ConTour system experienced it as a form of digital editing assistant that proposed preferred navigation paths through a database of storied media entities [Davenport \& Murtaugh 1999]. A web variant of the ConTour system, mentioned earlier named Dexter, was used to create an 'evolving documentary' portrait of Jerome B. Wiesner, former President of MIT. In this system, story suggestions to the audience were indicated by way 
of a conceptual mapping. Here the context of a selected clip was revealed by the highlighting of additional surrounding media that was related by time period, theme or story character [Davenport 1997]. Each of these computational storytelling applications provided strategies for helping the storyteller and the audience successfully navigate a digital story-space by virtue of suggested pathways forward and visualizations of 'territory' previously experienced.

Within the Confectionary application, the wayfinding elements that enhance discoverability can be understood as paths, privacy boundaries, communities, favorites and most viewed/comments. Features such as favorites, communities, and most viewed/comments while useful, are fairly standard in contemporary media and story sharing applications such as YouTube, Flickr and MySpace. However, it is with the application of privacy settings to story compositions as opposed to discrete media entities, and the introduction of wayfinding paths that Confectionary offers the storyteller and the audience something new. Within Confectionary, the same media entity may exist in private, public and semi-private story compositions. Depending on how it is juxtaposed with other media entities or text input, a particular image or photograph may evoke a breezy carefree interpretation or create a sacred and intimate private reading. In comparison with other online story sharing applications, where media entities are assigned to one particular privacy setting, Confectionary allows story authors to test the boundaries of their privacy comfort levels with their own personal media reflections in an experimental, yet safe story sharing environment. With wayfinding paths, the internally referential realm of the $2 \mathrm{D}$ story composition expands to encompass a collection of story canvases in a connected and purposeful trail. Authors and audiences alike can participate as anthology makers, growing multiple story pathways organized sequentially, thematically, aesthetically or perhaps emotionally. Navigating through a Confectionary wayfinding path and discovering one of your own stories amidst a trail of new and unfamiliar compositions, in Lynch's geographical world might be like coming across the Eiffel Tower in rural Ohio. In this startlingly new context, the familiar is redefined and reimagined, giving us pause to think about how our represented experiences are being seen through the eyes of another. 


\section{Design Approach}

This thesis proposes a novel approach to personal story exchange in which an online spatial rich media authoring and publishing environment can support the everyday expression of mediated personal narratives. I have developed and evolved this approach over a number of years through personal experience as a storyteller and media-maker, and by constructing several experimental computational environments for personal media sharing. My own philosophy on media-making is strongly influenced by the tenets of Constructionist theory. Constructionism contains the constructivist suggestion of learning "as building knowledge structures", but adds to it the notion that this learning circumstance is greatly enhanced when it occurs in a context "where the learner is consciously engaged in constructing a public entity" [Papert 1991]. Following years of making short personal diary movies and sharing them with friends and family at home in a Jonas Mekas kind of way, the advent of web publishing, and in particular the growth in weblogs, afforded me the opportunity to discover a new audience for my media productions. As I began to experiment with this new form of public sharing, over time, I noticed how my media-making began to evolve and adapt to accommodate to the constraints and affordances of the weblog publishing medium. I also observed how my awareness of my audience and their opinionated feedback increased and I realized how creating and sharing personal media in this manner could be a deeply reflective process. I wanted to extend this burgeoning process of reflective story exchange further, by creating mediated story conversations with others in shared environments where commentary and creativity would be tightly integrated.

In concert with these explorations in personal media-making and analysis from the development of media sharing software, this thesis work is also grounded in the findings of a large-scale ethnographic survey of real-world personal story exchange. In the following chapter I describe the overall design approach for this thesis and detail my journey from foundational research through prototyping and final design concept. 


\subsection{Custom Software Applications}

Over the course of several years I designed and developed three custom technologies for creating personal mediated stories. The overall purpose of this research was to create user-friendly engaging solutions that both simplified and focused the process of authoring, exchanging and publishing personal media. Some of the tools developed were designed for expert users already familiar with technological tools for creating richmedia stories, while others were designed for novice storytellers with limited technical abilities. In the following sections, I will briefly describe each of the three applications, highlight some key features and summarize the main findings derived from evaluating and observing system use.

\subsubsection{PlusShorts}

I first began exploring mediated spatial story presentations in 2001, when I developed 'PlusShorts', a networked application for co-creating movie sequences online [Kelliher 2001]. PlusShorts allowed a distributed group of expert users to contribute to, and collaborate upon, the creation of shared movie sequences while also introducing an iconic language, consisting of punctuation symbols, for annotating, sharing and interpreting conceptual ideas about cinematic structure. To create a movie sequence, participants either created a new 'story thread' or responded to a previously created story thread. They then used a simple drag-and-drop interface to place uploaded short movie clips onto a five by five grid, which were played back to the viewer as a linear movie sequence. Viewers navigated through the collected movie stories using a threaded newsgroup style list, where movie threads contained original sequence posts, followed by a hierarchical ordering of additional movie sequences contributed by other system authors in response to the original posting. Viewers could also discover stories in the PlusShorts collection using keyword searching. In evaluation studies, users described the structural annotation process as helping them to reflect on their own approach to storymaking and to consider more deeply how an audience might interpret their work. Users also commented on the value of having the authoring and publishing interfaces displayed together. The process of viewing the construction grid populated with movie thumbnails and symbolic markup while the movie sequence played alongside, helped viewers quickly gain an overall sense of the sequence duration and served as a reference point for accessing information defining the author's intent. 


\section{Takeaways:}

- Displaying authoring and publishing interfaces together helps viewers understand the storymaker's intent

- Spatial storytelling environments support viewers in quickly grasping a general understanding of the displayed story

- Audience feedback in the form of story sequence replies helped the original story author understand their work in a variety of interpretive contexts

- Story threads provided viewers with direct navigation paths through thematically connected stories

\subsubsection{Media Fabrics Experiment}

Moblogs are weblogs that present media content (photos and movies) generated and uploaded from mobile devices. From their initial emergence in 2002, the creating and viewing of moblogs grew greatly in popularity due to increasing market penetration of camera-enabled cellphones and the overall technical ease with which moblogs could be created and maintained. In 2004, I developed the 'Media Fabrics Experiment' in order to analyze user behavior and activity on a rich-media moblog. The goal was to characterize and understand participant story authoring styles and story feedback approaches. From this analysis, I identified requirements for improving and augmenting the process for the storyteller and the audience in exchanging online personal mediated stories.

Using video cell-phones, the participants in the experiment constructed and shared multimedia artifacts, publishing their daily story exchanges as mediated conversations on a group moblog. In analyzing the data collected over a three-month period, it became apparent that there were distinct patterns detectable in participant posting and response behavior. Some participants functioned mainly as commentators, limiting most of their activity to generating comments and offering feedback to posts while other participants contributed numerous original postings but rarely responded to the contributions of the wider community [Kelliher 2004]. Regular posting was sustained for about two months, before slowly petering out. In particular, users stopped posting video messages early on in the study, which some attributed to having outgrown the novelty factor and being disappointed in the poor audiovisual resolution and quality. Another observation from the study was that the focus became on the continued gathering and uploading of media entities, with little evidence of additional reflection or interpretation of newly added content within the context of earlier postings. Participants in the study also expressed 
dissatisfaction at the repetitive list-style ordering of entries that were all displayed identically. The overt visual 'sameness' of the displayed entries, along with the reliance on only one navigation schema (chronological) gave participants limited opportunities for discovering entries of interest.

\section{Takeaways:}

- Supporting a singular storymaking strategy (chronological) is limiting

- Alternative authoring and display strategies are required for low resolution audiovisual media

- Developing more integrated consumer/producer activities could help create and sustain a diverse and vibrant community of participants

\subsubsection{Movits}

In response to the findings from the Media Fabrics Experiment, I began to explore ways for expanding the types of media messages and stories that could be constructed and shared using mobile devices. Essentially, I wanted to be able to use my cellphone, not only to capture and share media messages, but also to help me reflect on my media collections and to compose thoughtful mediated story presentations. I designed and developed 'Movits', a custom Java-based application for Series 60 cell phones that presented users with an integrated interface for capturing content, constructing, exchanging and publishing multimedia presentations. Selecting from a variety of default layout templates, participants could populate their Movits presentations with photo, video, text and audio segments captured using their cellphone. In so doing, participants could engage with their media collections in ways that moved beyond simply recording and cataloguing ever-expanding collections of individual media entities. Movits invited them to review their collections in an editorial process whereby recently captured content could be related and compared with older entities in playful rich-media compositions. These presentations could be temporarily stored for later completion, exchanged with a group of people or published directly online as a finished artifact.

\section{Takeaways:}

- Story templates can inspire users to begin creating quickly

- Flexible authoring strategies can stimulate and encourage creativity

- Spatial storytelling environments allow audiences to quickly intuit an overall understanding of the story begin presented 
Designing, implementing and evaluating PlusShorts, the Media Fabrics Experiment and Movits helped refine my approach to developing a model of the everyday reflective process of creating and sharing rich-media personal stories. In addition to this applied research, this model was also deeply informed by the findings from the ethnographic study detailed below.

\subsection{Ethnographic Study}

In 2004, I conducted a longitudinal ethnographic study to gain a greater insight into the overall process of personal storymaking, as a reflective, creative and interpreted endeavor. I wanted to establish some sense of the methods and practices being used in a variety of domain settings for observing, documenting and evaluating personal stories. Over the course of several months I interviewed a series of people who solicit, listen and/or respond to personal testimony as part of their daily job. From their described experiences and insights, I hoped to discover a variety of perspectives on best-practice working methodologies that would help me in constructing a thoughtful, effective and wide-ranging research approach. In the following sections I describe my interview approach and methodology, and summarize relevant observations and findings in the following areas: soliciting personal testimony, recording tools and practices, storybuilding strategies, and evaluation metrics.

\subsubsection{Interview Participants and Process}

I requested interviews from approximately 20 people working in diverse professional fields and 8 men and 5 women agreed to participate. I personally knew 5 of the participants while the remainder was approached after web searches or through the recommendation of colleagues. The interviewees ranged from age 27 to 69 and all were living in the Greater Boston area. Their job occupations were: registered nurse, investigative reporter/editor, corporate storyteller, medical internist, medical doctor, life-coach, therapist/facilitator, ombudsperson, police detective (2), detective sergeant, attorney and psychiatrist. Several of those interviewed had experience in a variety of related careers and answered questions from the perspective of each. In the case of the police detectives, I interviewed three as they each had very different levels and types of experiences; one had been in the force over 30 years, one was with the force only 3 years and specialized in computer and technology related crimes, and one female detective dealt mainly with sex related offenses. I asked each interviewee the same core set of 
questions with some minor variations according to career type and function. Over half of the interviews took place in the participant's workplace, with the remainder occurring in neutral venues. The interviews lasted between 40 minutes -2 hours and were audio recorded and then transcribed.

\subsubsection{Soliciting Personal Testimony}

The attorney, detectives and journalist described their strategies in extracting as complete a story as possible from their interviewee. In taking a deposition, the attorney aims to be as patient, attentive and meticulous as possible, following every branching path to its full extent, then doubling back and following another path. Prior to a deposition, the attorney prepares by constructing a detailed outline: background, employment history, where the subject is from, what they do. The attorney describes the key to the process as being to probe and flesh out the background story, as it is the little things that can be most revealing. The journalist equally described the importance of noting the little details, particularly in the surrounding environment of the interviewee. Placing the story into as full a context as possible will be important for the eventual audience of the story, whether it be a newspaper reader or a jury. The police detective's preparation for an interview or interrogation is similar to that of the attorney's. Prior to approaching the suspect, the detective establishes the known facts about the case, particularly details about chronology and place.

\section{Takeaways:}

- A structured story template is useful for ensuring all required details are included

- Creating context for the story is imperative

- Establish the facts (chronology, place) and proceed to flesh out the story with additional corroborating or conflicting testimony

\subsubsection{Recording Tools and Practices}

The police detectives and the attorney use sophisticated tools and standardized techniques for recording and organizing the stories told to them. For both of these professions, accuracy and truth are fundamental and confusion and gaps in knowledge must be minimized. The attorney uses timeline focused software tools such as JFS to help manage the chronology of events and real-time transcript software such as LiveNote to allow for real-time reading and marking of deposition transcripts. The police detectives follow standard procedures for writing narratives detailing what happened, 
covering the 'who, what, when, where and how' of the incident. In addition, the detectives use flowcharts and timeline visualizations to help establish the overall picture for a large and complicated case. Similar sounding stories are run through a customdesigned automated system to detect activity patterns that might point towards particular criminals or gangs. The corporate storyteller is working on developing a networked database of all the story content and structures generated by the company: soundbites, summaries, media, presentations, images. This networked system will help him and the organization to package their stories quickly, efficiently and in a workable fashion.

In direct contrast to this, the ombudsperson and the life-coach keep no records of their meetings with clients. Instead they encourage those who visit them to keep track of their own story in whatever form is most appealing. The ombudsperson describes how she might encourage a visitor to write their own story in the form of a letter and send it to themselves or to a lawyer in order to make a legal document of their complaint. The psychiatrist is interested in recording and documenting the family's story in a collaborative fashion. In one example, he described a project where he worked with teenagers with depression. Here, he interviewed the patients and constructed a condensed story with them over time that was then illustrated and animated to the accompaniment of the patient's voice. This was then shown to their peers in similar situations as a form of primer story. The psychiatrist regularly uses video recordings to document families working together around problem situations. He finds that particularly helpful for clients with poor language skills.

\section{Takeaways:}

- Organizational methods are helpful in transitioning from disconnected memories to connected narratives

- Creating connections between stories provides a sense of perspective on each narrative as part of a bigger picture

- Reusing content can be efficient and revealing

- Making stories just for yourself can be rewarding

- Telling stories in different media can create new understandings

- Some people are more comfortable with one medium than another 


\subsubsection{Storybuilding Strategies}

The reporter, lawyer and corporate storyteller take time to craft their stories using a variety of techniques and strategies. The investigative reporter and his team approach the job of putting a story together 'as the FBI would', with a group of reporters covering different aspects of a potential story. Information is collated and categorized in a computerized system with cross-indexes and multiple forms of filing. The team works together on the story over an extended period of time, using their diverse perspectives to keep the story fresh and targeted. The corporate storyteller generally works alone, therefore he aims to maximize his efficiency by paying close attention to the story structure as popular structures get reused again and again. He creates his stories with the target audience in mind. In retelling stories within the organization, he focuses on creating value for the audience by telling short powerful stories that can reach towards the audience and allow them to paint in other details themselves.

Psychiatrists, therapists and facilitators operate their storybuilding strategies very much in the 'now' of interacting with the client. The psychiatrist intervenes and helps sculpt the client's story. He is looking for transformational and positive stories. He shows primer stories to those who find it hard to articulate their problems, hoping to inspire clients to tell similar tales. The ombudsperson retells the story told to her from the perspective of other participants in the narrative in an attempt to find a possible 'gracious explanation'. This listening and retelling process back and forth helps the ombudsperson and the client agree on what precisely is going on with the story. The facilitator works to help people remember their enduring and overarching purposes instead of just the immediate goals. She supports conversation from personal perspectives that originate and focus on the self. She works to engage the clients as coresearchers. The therapist wants her clients to listen to each other and present themselves more fully. She described one exercise in which large groups imagine a story from their lives as told to someone who really understands them and then someone who doesn't understand them at all. This leads participants to think about the nature of social relations and their story. 


\section{Takeaways:}

- Collaborating in groups on a story allows for a variety of perspectives

- Saving and reusing successful story structures is efficient and useful

- Knowing and understanding your audience has an important effect on the types of stories told

- Primer stories can encourage people to begin to articulate their experiences

- Retelling your story and hearing it repeated by another person helps the storyteller focus on the important elements

\subsubsection{Evaluation Metrics}

For many of these professions, success is measured and evaluated in a variety of qualitative ways. The journalist described evaluating his work depending on 'the play' that a story gets, whether it made page one, was it at the front of your section etc. Looking at how significant your story was deemed in the eyes of your peers and the reaction of readers to it is important. The life-coach sees success in bringing in more conservative clients who would not normally be classified as early adopters of a new corporate service such as coaching. The facilitator sees success when a group of clients move from the phase of dialog to one of implementation and passing on the facilitation process to others.

Takeaways:

- Feedback from the audience (comments, letters to the editor, viewing statistics) is helpful in evaluating the effectiveness of a story

- Having a diversity of participants can be a measure of success

- Participants moving from peripheral participation to more involved levels of action (creating, mentoring) can be a measure of success

\subsection{Foundational Research Findings}

The key findings or 'takeaways' derived from evaluation of the applied research and the ethnographic study are summarized as research directives in Table 1. Some directives are supported by findings from multiple investigation sources. These directives form the basis for the design decisions and rationale used in the development of the Confectionary application. The design decisions and strategies used in developing the Confectionary application were strongly informed by the foundational research findings. 
The results and final directives helped formulate consensus on what the basic properties of the Confectionary application should be. These properties would determine, as defined by Ryan earlier, what types of mediated stories could be told, how they would be presented, why they were communicated and how the audience would experience and respond to them.

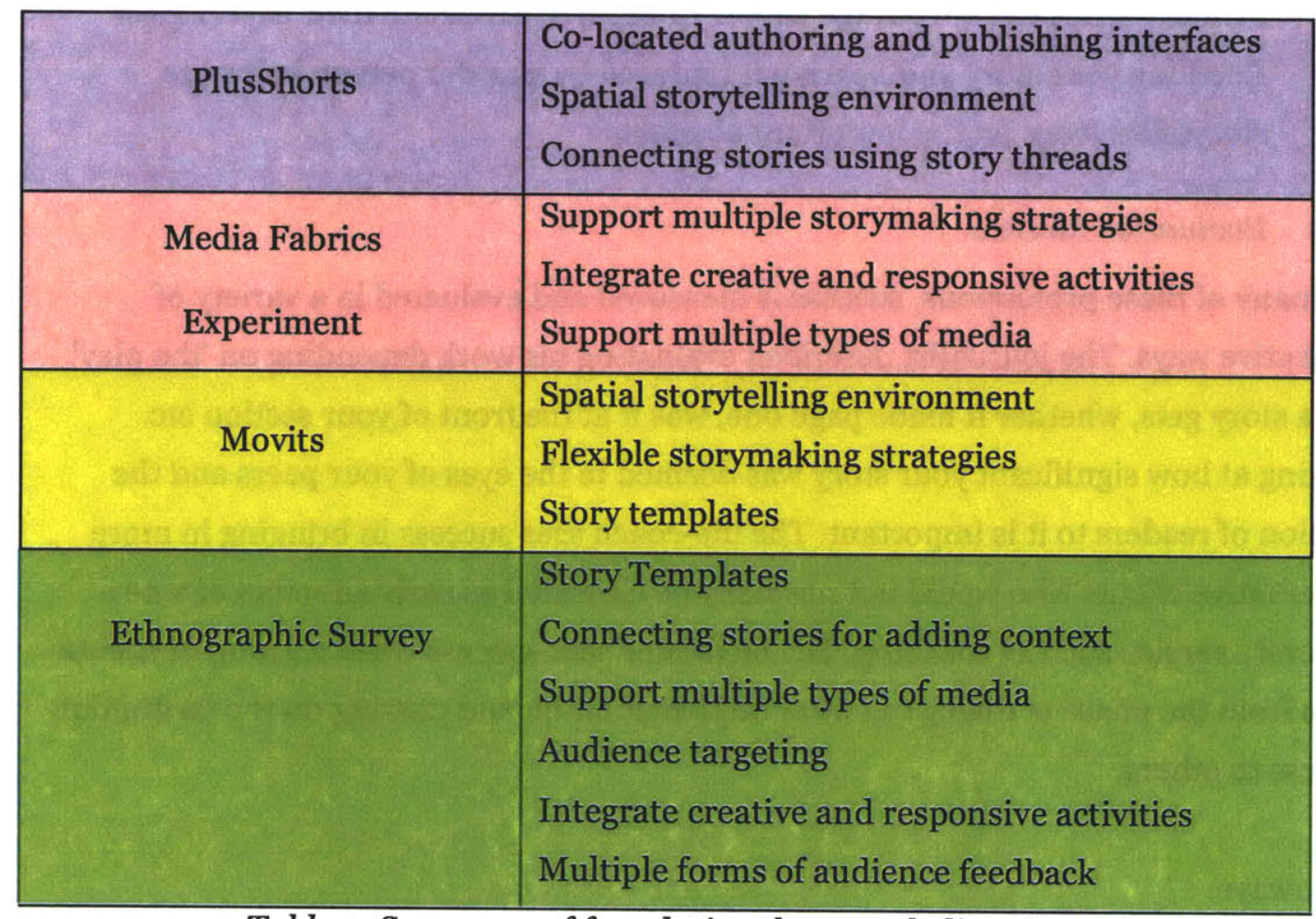

Table 1: Summary of foundational research directives

Based on the literature review, evaluations from previous software workshops and on observations of participants engaging with a variety of rich-media story authoring and publishing platforms, I felt that a spatial metaphor for creating and exchanging richmedia narratives would prove most successful in engaging the everyday storyteller. A spatial environment with its WYSIWYG and drag and drop attributes would require little prior computational or programming experience, and would encourage risk-free experimentation especially in novice users. I thought it was also imperative that the application support the integration of multiple forms of media to ensure that storytellers could create their narratives using what they deemed to be the most suitable media entities. Another key component would be the creation of a set of features for manipulating and altering media entities to ensure maximum flexibility in supporting 
the aesthetic and conceptual visions of the storytellers. Given the potential for personal stories to on occasion be of a deeply private nature, I wanted the system to also incorporate multiple levels of story disclosure, thus creating a welcome and safe environment for all forms of personal narratives. A final important goal for the software was to design a number of interactive functions to facilitate audience feedback that moved beyond simple response commentary and towards a more reflective creative process.

\subsection{Prototype}

The first prototype of the Confectionary application was designed and developed for use in a two-week workshop with children from the Armenian community in Watertown. This version of the application supported the creation of individual Confectionary stories, without any feedback, network or statistical components. Over the course of two weeks, the children, aged between 9 and 16 collected and recorded personal media, learned how to create short movies, manipulate photographs and record audio segments. This workshop was organized in collaboration with Lebanese artist Ara Azad, historian Chris Cleary, Ruth Thomasian and the staff of the Project SAVE Armenian Photograph Archives, Jacqueline Karaaslanian and colleagues at the MIT Media Lab. The workshop culminated with an evening of celebration and storytelling on July $14^{\text {th }}, 2005$ entitled 'Gathering History One Confection at a Time and the Hi:Nomadic Atelier'. The children selected one or in some cases two of their Confectionary stories to display to an invited audience at Bartos Theatre in the Media Lab. Figure 9 depicts some of the Confectionary stories made by the children at the workshop. The workshop introduced the children to many new recording technologies and software systems all at once. None of them had made movies before or recorded their voices, and their experience with taking photographs and manipulating them was limited. For that reason, much time was spent on the actual process of documenting, scanning and preparing the media for use in the Confectionary system. Extra challenges existed for one family of four siblings

participating in the workshop who had only recently moved to the United States from Armenia. The children, aged between 9 and 14 spoke very little English, but by virtue of observing other workshop participants and with high levels of enthusiastic determination, the children learned how to construct short movies, record their voices and make touching Confectionary stories. 


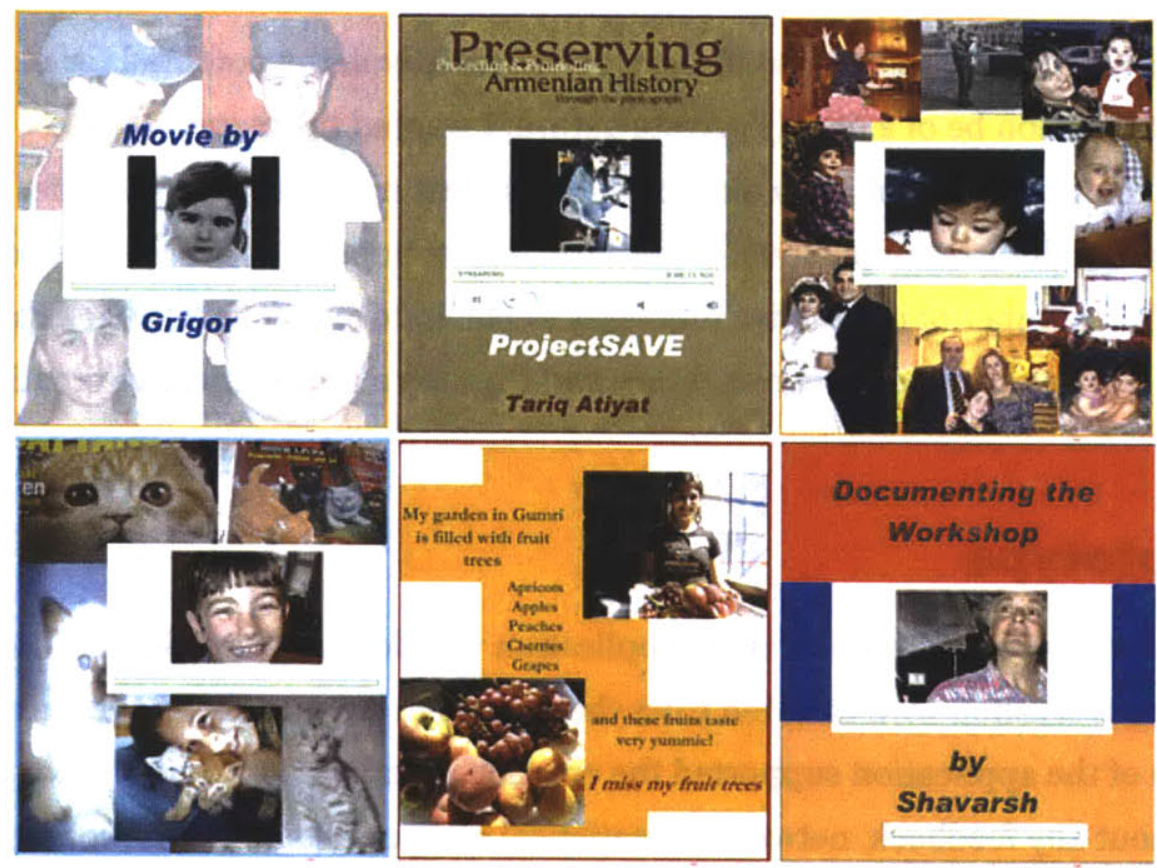

Figure 9: Confectionary Stories from the Hi:Nomadic workshop

Undoubtedly, the workshop was a helpful exercise in that all the children functioned as wonderful software debuggers. They were only too happy to point out quickly when the system wasn't working - usually at the top of their voice. They enjoyed playing with the application and persisted with it throughout the workshop, but were often frustrated when the software behaved inconsistently or slowly. They wanted to receive more immediate feedback as to what the system was doing and why. They also wanted to be able to see the stories created by others more easily. Ultimately, the final presentation required considerable brute-force hacking in order to make the stories appear as the children wished.

The second version of the Confectionary application addresses some of the problems highlighted in the workshop. Story viewers can navigate through the stories in the database using a number of organizational strategies. Functionality has been added to enable viewers to leave feedback in a number of different ways. The system provides feedback after each major function call letting the user know about the success or failure of the selected operation - "your comment has been saved", "your story has been updated" etc. The application has also been streamlined and optimized to minimize delays in loading media or swapping between different interfaces. 


\section{Implementation}

The Confectionary application was developed in an iterative process over a period of 18 months. A preliminary beta version was used in July 2005 over a two-week period in a storytelling workshop held in collaboration with the Project SAVE Photo Archive organization. From this initial experiment, the Confectionary application was refined and expanded until launched to the general public in July 2006.

\subsection{System Architecture}

The Confectionary architecture has a system layering that separates the presentation, application, and data layers into a scalable and flexible model. The system architecture is made up of three layers, as shown in Figure 10.

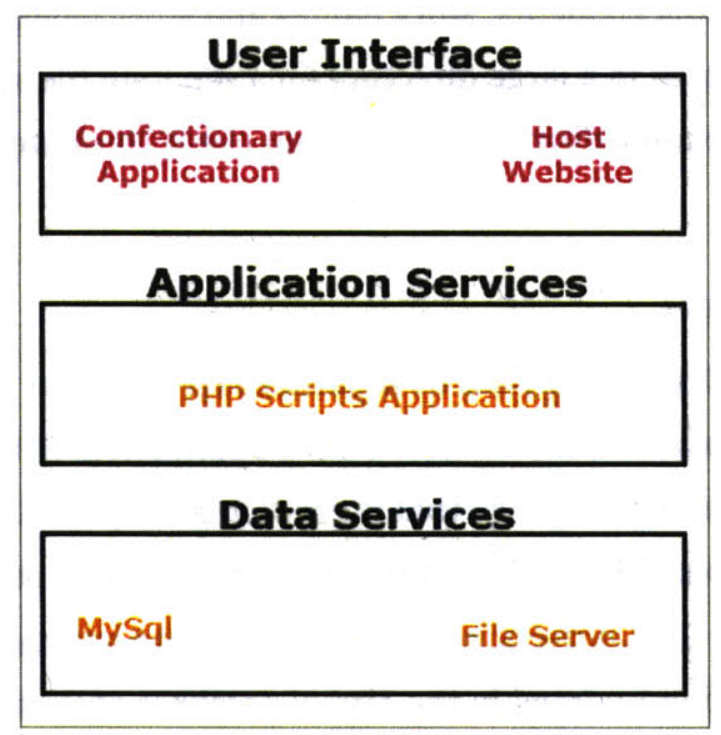

Figure 10: Confectionary three-layer system architecture

The Data Services Layer, composed of a MySql database and standard web server, is responsible for managing and storing all of the Confectionary media content. The Application Services Layer is implemented as a PHP scripts application that functions as the data conduit between the stored data and the user interface. It enforces rules on data access and manipulation. The User Interface Layer contains the main host website and the Confectionary software application. The Confectionary application was developed using the Adobe Flash software platform and communicates with the Application 
Services Layer using Actionscript, Flash's native scripting language. The purpose of this deliberate layer separation is to allow for the expansion of the research elements in a number of different, possibly simultaneous directions such as development into a truly large-scale mediated story repository or the design of an open-source Confectionary API. These and other potential future directions are discussed more fully in Chapter 6.

\subsubsection{Data Services}

A MySql database stores information about all the media content available in the Confectionary application and the relationships among these entities. MySql is an open source relational database management system where data is stored in a series of related tables defined as rows and columns. Relationships are thus defined through common values expressed across multiple tables. The Confectionary data model or schema in Figure 11 is a representation of important application entities and their relationships to one another. The Confectionary database contains 15 tables storing information about such entities as users, media elements, story names and story navigation paths. The media content itself is stored in a large directory on a separate file server from the MySql database that permits the uploading of content from client computers located outside the host domain.

\subsubsection{Application Services}

The Application services layer comprises 61 separate PHP files that handle queries between the MySql database and the Confectionary application. PHP is an open source general purpose programming language that is predominantly used for web development and server-side applications. The PHP scripts translate Actionscript calls sent from scripts and classes within the Confectionary application into appropriate SQL queries. Information is then added or updated in the MySql database and any information retrieved is sent back through the PHP files to the Confectionary application in a format that Actionscript can then manipulate. The PHP files can be categorized using the following groupings: user authorization, profile management, media upload, media collection, story lists, story media content, story comments, story paths, story favorites, story privacy and session management. 


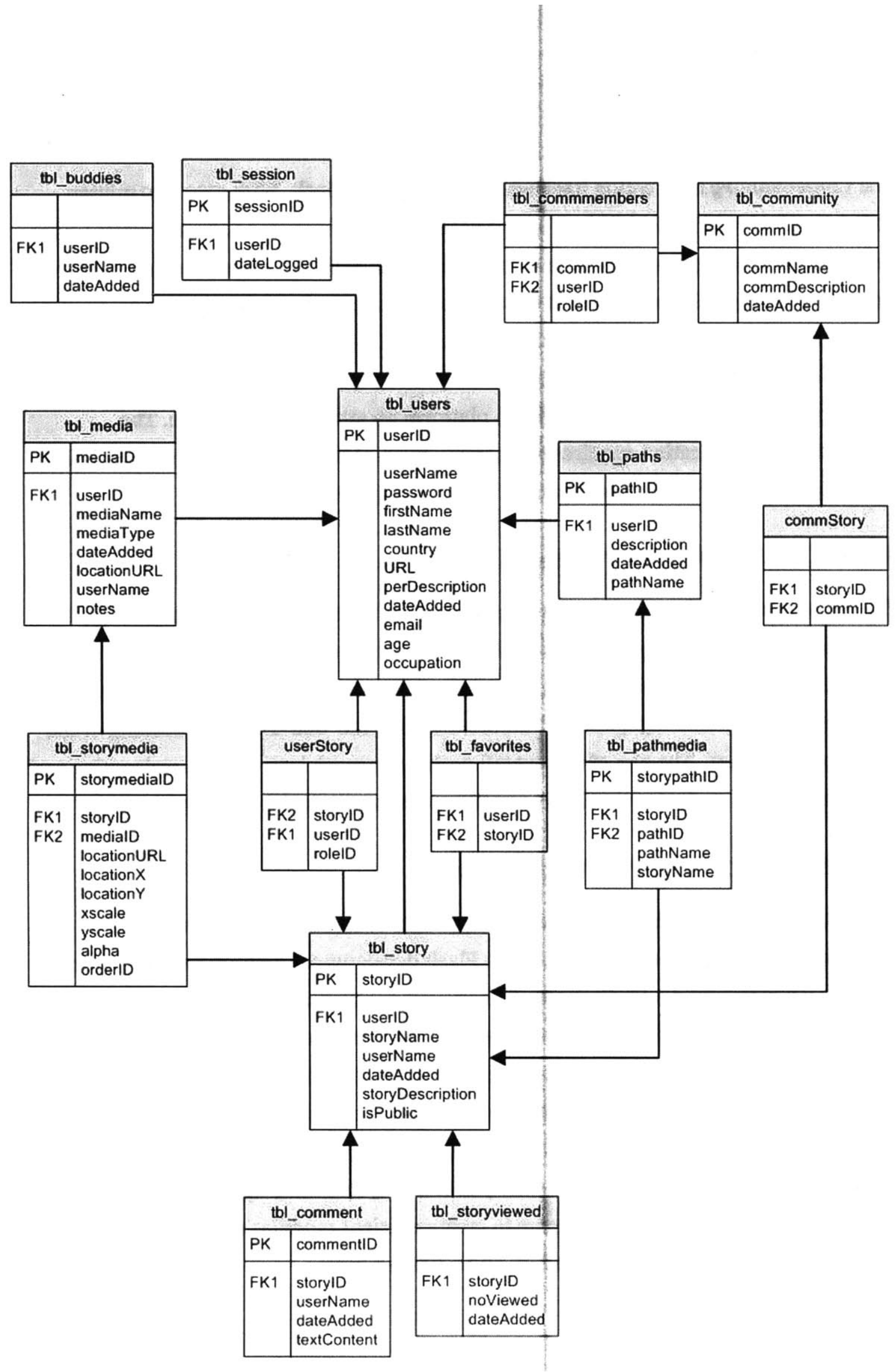

Figure 11: Confectionary database schema 


\subsubsection{User Interface}

The Confectionary application itself was built in Adobe Flash. With over two million active developers worldwide, Flash is a popular and well-regarded software platform for creating fast loading cross-platform web applications. Web browsers must have the free Adobe Flash player installed in order to access and run Flash applications and documents. According to a MillWard Brown worldwide survey of the ubiquity of the Flash Player version 8 , penetration is at $86 \%$ in mature markets [MillWardBrown 2006]. This level of penetration makes the Flash platform an attractive one to use. The Confectionary application requires the latest version of the Flash Plugin, version 8 and functions correctly in all major browsers (Firefox, IE, Netscape, Safari).

\subsection{Confectionary Visual Design}

The visual design of the Confectionary application is both playful and minimal. The restricted color palette of pink, white and grey contributes to an overall branding approach that is simple and memorable. Adding to this branded experience is the Confectionary cupcake logo, itself a humorous nod to the 'non-Tuftean' meaning of the term 'confectionary'. The aim of the overall design approach is to create a welcoming and non-intimidating environment that is equally appealing to novice and expert users.

\subsection{Confectionary Application}

The Confectionary application consists of 6 primary Adobe Shockwave movies. The Shockwave movies are rendered within the Flash development environment for online playback using the Adobe Flash player. The movies are then embedded in an HTML holder file that contains JavaScript for detecting the presence of the Flash 8 player and downloading/updating the player if necessary. Within the Flash development environment, hierarchical structure can be determined by: levels (virtual slots between multiple movies); layers (slots within a movie); and depths (slots within or between layers). Figure 12 details the level hierarchy in the Confectionary application. The hierarchical structure allows developers to create efficient modular applications where components are loaded and unloaded on an as-needed basis. 


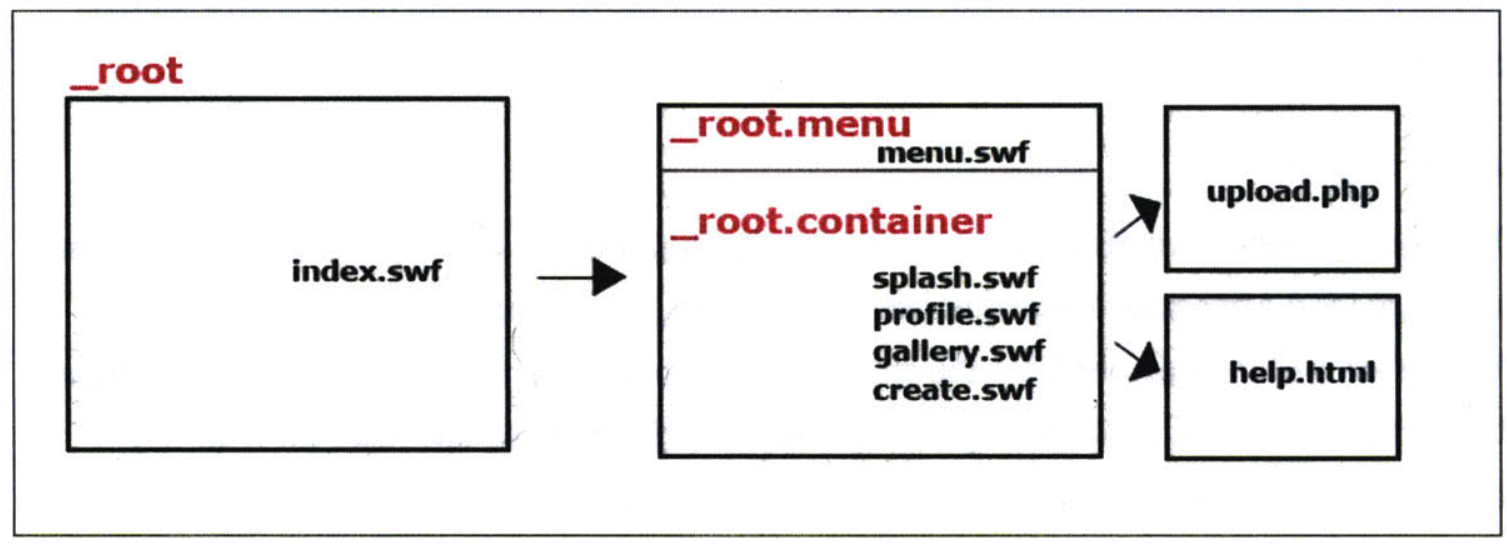

Figure 12: Confectionary level hierarchy

The index Shockwave movie is located at the application root level and contains the majority of the functions and classes used internally within the application and for communicating with the MySql database. The menu Shockwave movie is located in a sub-container on the next level and controls the loading and unloading of the profile (profile Shockwave movie), authoring (create Shockwave movie) and publishing interfaces (gallery Shockwave movie) into another sub-container located in the same level. The splash Shockwave movie is loaded into this same sub-container upon initial login. Two additional files complete the Confectionary application. The upload PHP file controls the upload of media content and metadata onto the file server and into the MySql database. The help HTML file is a webpage containing information and instructions describing how to use the application.

\subsection{Confectionary Interface}

The 6 primary Shockwave movies in the Confectionary application provide participants with a variety of interfaces for accessing, creating and viewing mediated personal stories. The following sections describe the functionality and visual design of each of these interfaces.

\subsubsection{Index}

The index Shockwave movie contains a login interface for user authorization and registration [See Appendix A for interface screenshots]. Users are required to register with the system to ensure that their uploaded media, authored stories and contributed comments can be correctly and solely attributed to them. Successful login to the Confectionary application will subsequently load the menu and splash Shockwave 
movies. Overall, the minimal interface of the index movie presents users with a simple and playful introduction to Confectionary.

\subsubsection{Menu}

The menu Shockwave movie contains six navigation buttons and a personalized welcome message [See Appendix A for interface screenshots]. Selection of the 'home', 'profile', 'create' or 'gallery' buttons load the appropriate Shockwave movies into the compartment below the menu movie. Selecting the 'upload' or 'help' buttons launches an external browser window for uploading media or accessing help information respectively. The menu movie appears consistently at the top of the browser screen throughout a Confectionary session. The buttons appear in a logical progression from left to right following the general activity ordering sequence required for creating and sharing a story.

\subsubsection{Splash}

The splash Shockwave movie contains two main interface components as shown in Figure 13. On the left, the system information interface displays system statistics about the current number of members, communities, media entities, stories, comments and paths. This information gives new and returning visitors alike a sense of the size of the Confectionary community and the extent of the activity on the site by both storytellers and the audience. This section also contains a link to the Confectionary feedback weblog, where users can enter their thoughts, comments and suggestions about their experiences with the system. On the right, the mediated story interface displays the Confectionary story canvas containing a random story selected from the database. Above the canvas, the story name, author and number of times viewed are also shown. The purpose of this interface is to instantly introduce the concept of a Confectionary story to new visitors who can then easily explore further by generating the random selection of additional stories through selecting the 'home' button. For returning users, it provides an opportunity for possibly showing them a story they haven't yet seen in the database collection. This is just one of the ways that the application provides participants with opportunities for the 'discovery' of Confectionary stories. 


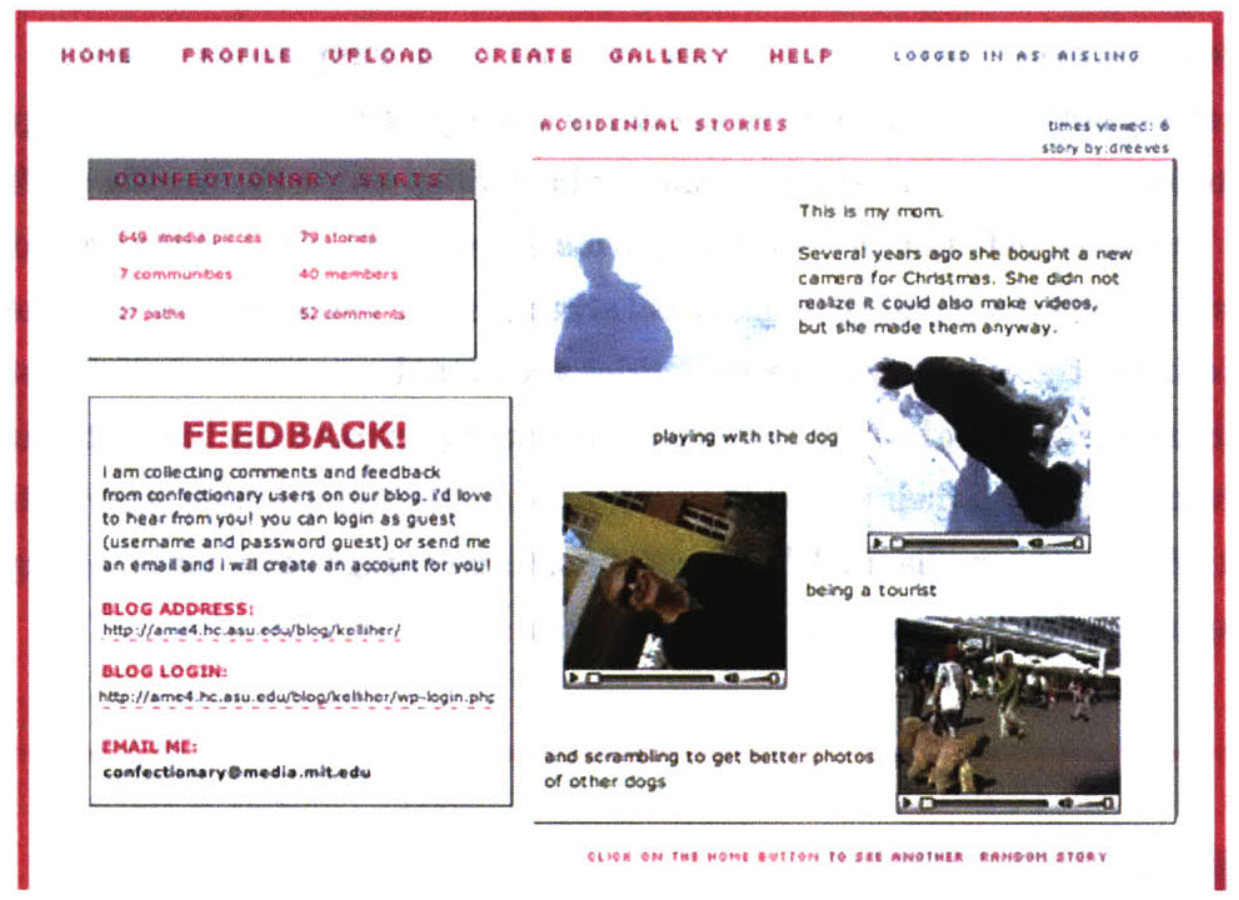

Figure 13: Confectionary splash interface

\subsubsection{Profile}

The profile Shockwave movie provides an editable interface for creating and updating personal user profiles [See Appendix A for interface screenshots]. Participants can choose to fill in general profile details such as age, occupation, personal website etc. There is no obligation to complete this information, and all data submitted is for research purposes only and is not shared publicly. This interface additionally provides an opportunity for participants to create and/or join community groups and add other Confectionary users to their list of contacts. The purpose of completing this information is to enable storytellers to select particular individuals or communities named in their personal profile as intended audience targets. Confectionary storytellers can assign varying audience access levels to their story creations. The default setting for all newly created stories is that they are completely public and accessible to the entire Confectionary community. However, within the 'create' interface (described in $\mathbf{4 . 4 . 5}$ below), the story author can choose to amend that setting to enable only specified individuals or communities to have access to a particular story. 


\subsubsection{Create}

The create Shockwave movie contains three main interface components: media archive, story settings and the Confectionary story canvas as shown in Figure 14. The storyteller can browse, select and create media entities within the media archive interface. The initial default media option is to display up to 25 of the user's uploaded images, as this creates a pleasing initial visual arrangement. The storyteller can alter the height, width and transparency of media entities added to the story canvas in the story settings interface. The author can also browse through example story templates and assign privacy settings to their stories in this interface. The initial default story settings option is to display the media modification sliders, to encourage participants to begin quickly experimenting and playing with their media.

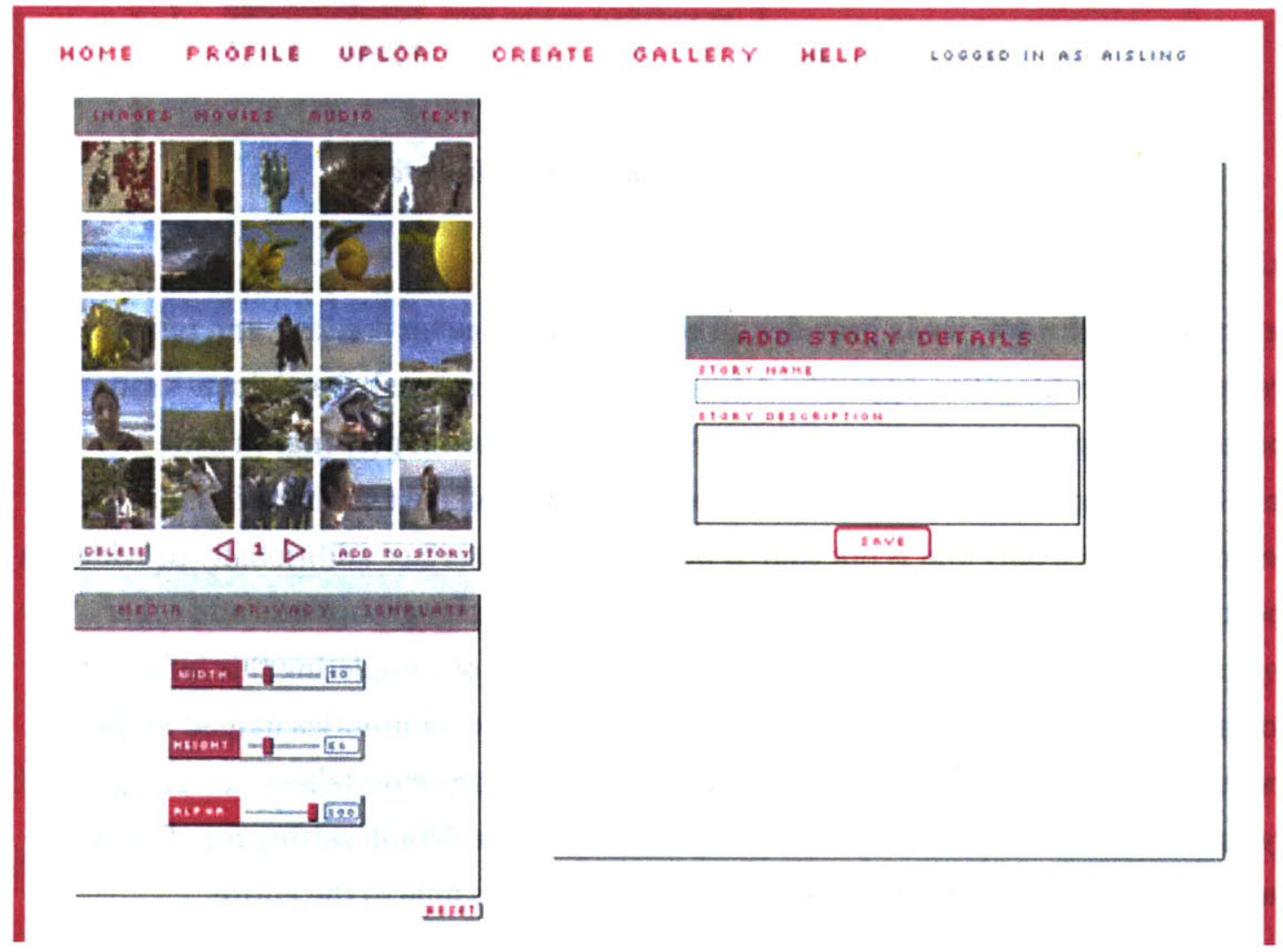

Figure 14: Confectionary create interface

The Confectionary story canvas measures $465 * 485$ pixels for both practical and aesthetic reasons. The canvas, and indeed the entire application, is designed to fit comfortably on a standard $800^{*} 600$ resolution monitor, which remains the gold 
standard for web designers and developers. According to web analyst companies such as onestat.com and w3schools.com, current global screen resolution statistics point towards a predominance of screens at $1024^{*} 768$ and higher. However, these numbers are derived from data gathered from visitors to large corporate websites and therefore do not necessarily include the everyday home users described in this thesis research. For this reason, the Confectionary canvas has been designed to display consistently on both newer and older monitors. For aesthetic purposes the canvas is limited in size in order to reduce cognitive overload on the storyteller and to encourage a playful approach to construction, along the lines of adding post-its to a notice board or putting postcards on a fridge. The nature of the smaller canvas also fosters an atmosphere of intimacy. Helen Harrison describes miniaturization in art as something that "invites close inspection, concentrates action, focuses attention and draws in the viewer; it also performs a similar magic on the artist" [Harrison 1981]. With limited space, the author must think carefully about the selection and sizing of media along with the thoughtful employment of compositional strategies such as layout, layering and repetition. In this way, the Confectionary application encourages and indeed focuses story-centered reflection. This purposeful reflection is further stimulated by the initial default setting of requiring the author to name and/or describe the story they are about to create before they can add any media to the canvas.

Figure 15 displays screenshots of the media archive interface when the image, movie and audio menu buttons have been respectively selected. The user can cycle through their images, 25 at a time, using the directional arrows located beneath the image gallery. Uploaded movie and audio files can be selected from scrollable lists and viewed/listened to in the preview pane located beneath the list. Media entities can be removed from the media archive using the delete button and added to the story canvas using the 'add to story' button. 

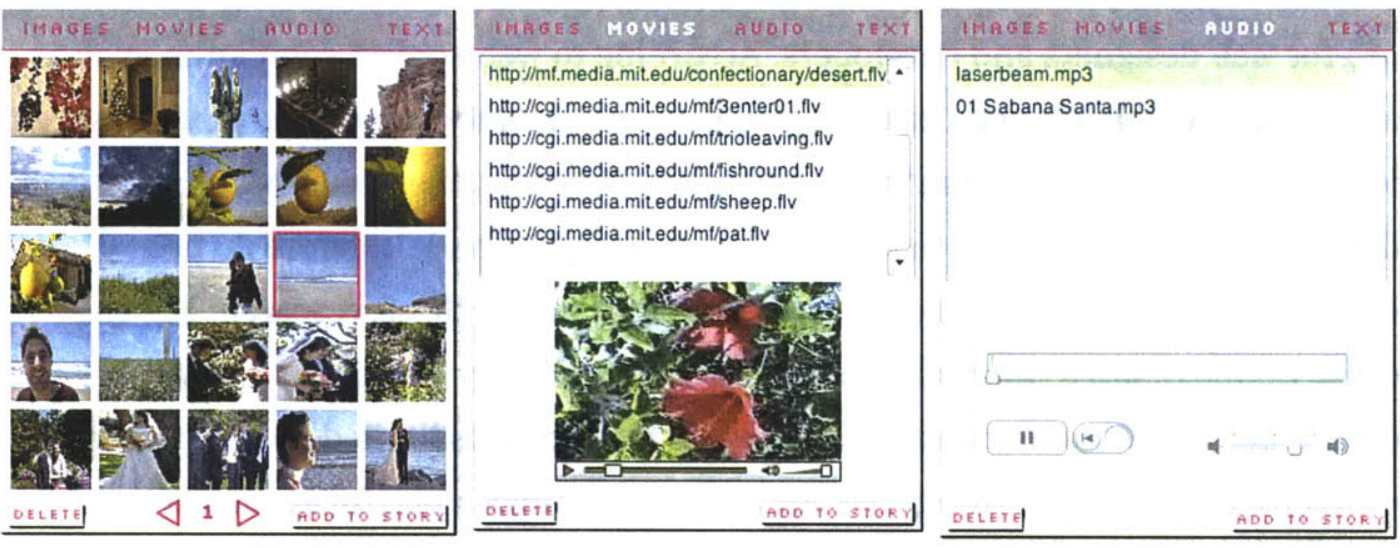

Figure 15: Image, movie and audio media archive display

Selecting the text button in the media archive loads a simple text editor where storytellers can create short text modules for their Confectionary stories as shown in Figure 16. The editor includes standard text formatting options such as size, color, bold, italics, underline and left, center or right alignment.

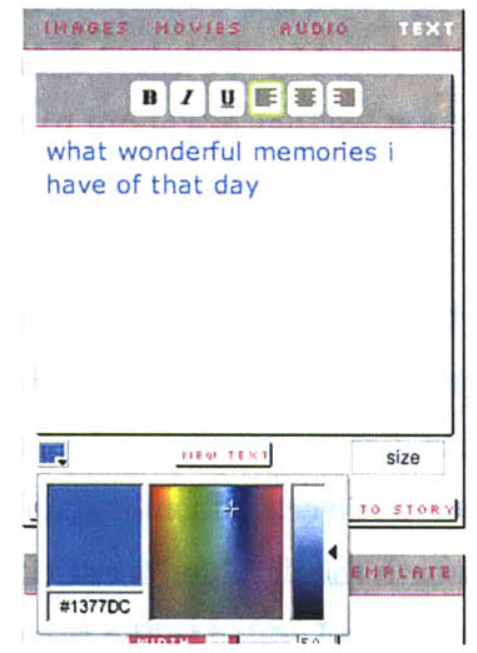

Figure 16: Confectionary text editor

All media entities added to the Confectionary story canvas can be subsequently dragged and dropped throughout the canvas area. Within the story settings interface, authors can manipulate width, height and alpha controllers to alter media entities on the story canvas as shown in Figure 17. Entities can also be removed from the canvas using the 'delete media' button. The 'update' button is used to save and update the story while in the process of being created/altered. 

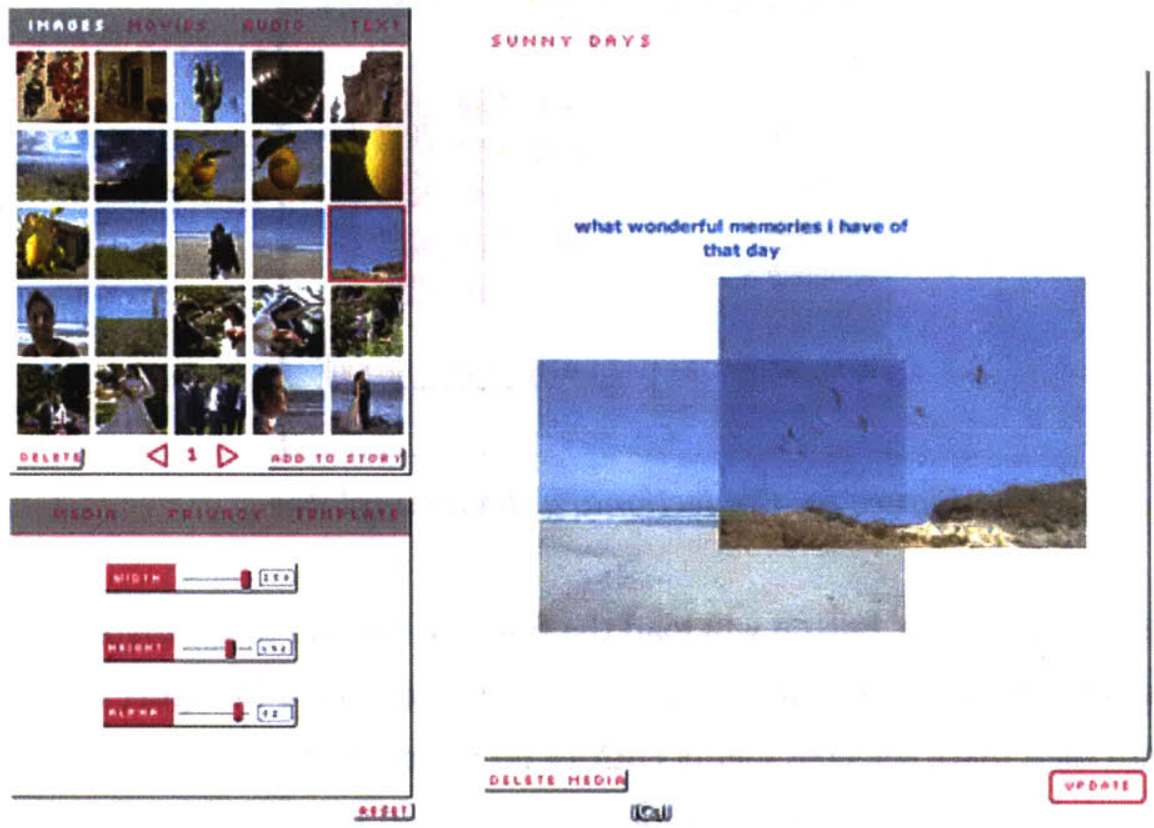

Figure 17: Confectionary story authoring

The story settings interface also contains controllers for assigning privacy settings to stories. The initial default setting is public, but the author can amend this instead to have the story be completely private or accessible only to selected contacts or communities as shown in Figure 18.

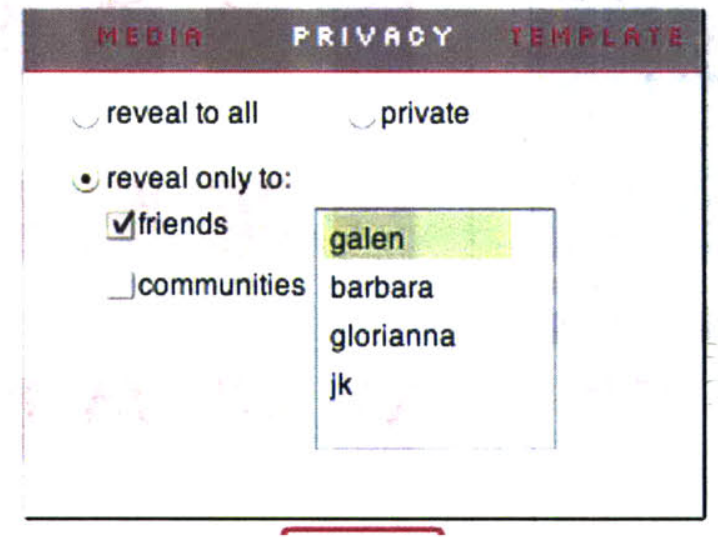

Figure 18: Confectionary story privacy settings

The final component in the story settings interface is story templates. Here, the novice author or an author seeking inspiration can garner ideas from a list of exemplar story layouts. Template layouts can be selected from a scrollable list and previewed in the thumbnail viewer as shown in Figure 19. 


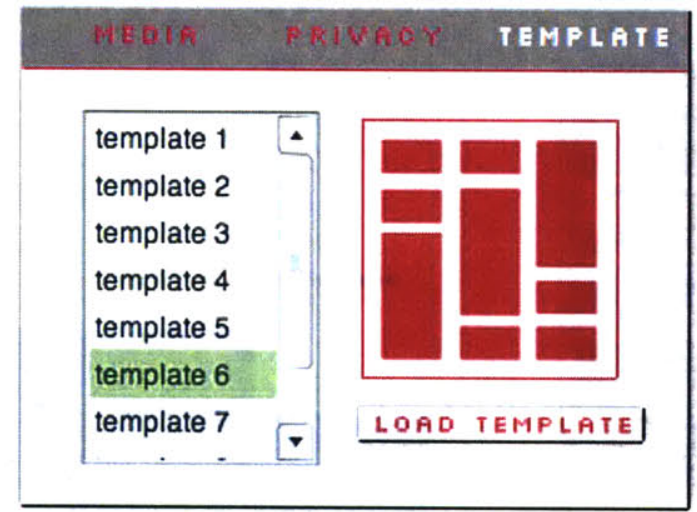

Figure 19: Confectionary story templates

Selecting the 'load template' button will load the full-size version of the displayed thumbnail layout into the Confectionary story canvas as depicted in Figure 20.

The author can then place selected media entities on top of the template mirroring the sizing and placement. The underlying template is not saved with the final story, but is merely a suggestive guide during the authoring process. The author can remove a template and load another at any time to sample a mixture of suggested styles.

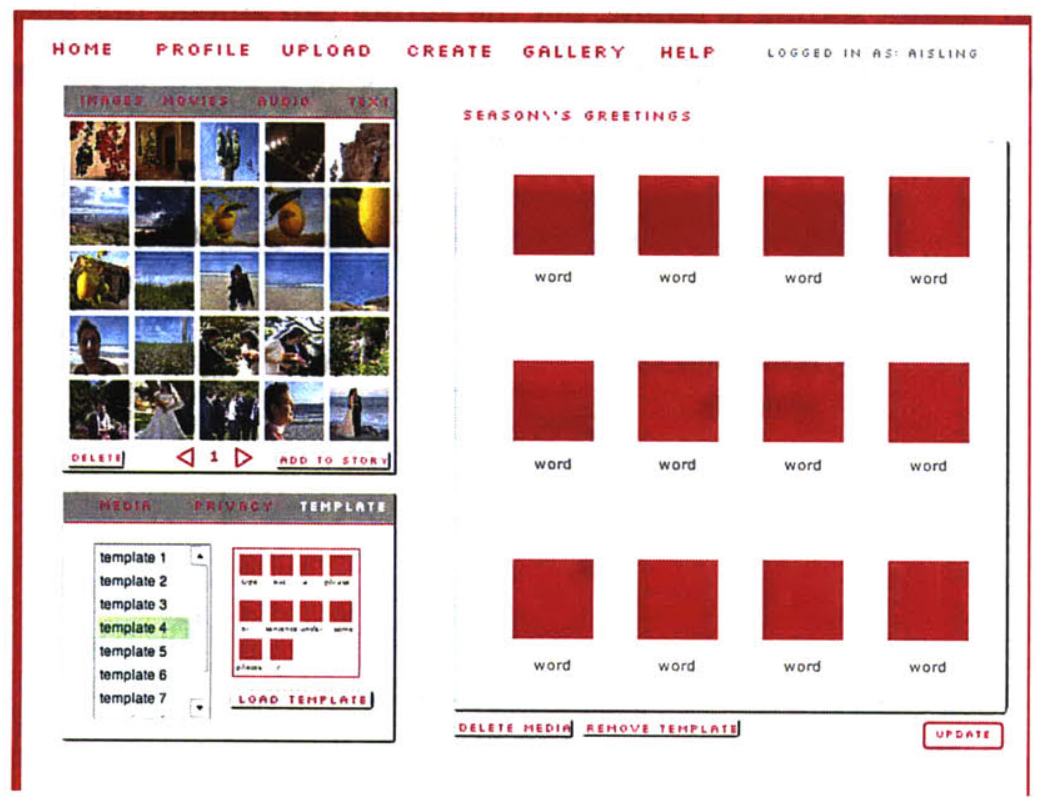

Figure 20: Confectionary loaded story template 


\subsubsection{Gallery}

The gallery Shockwave movie contains three primary interface components: story and path navigation menu, story and path metadata and the Confectionary story canvas as shown in Figure 21 in story navigation mode.

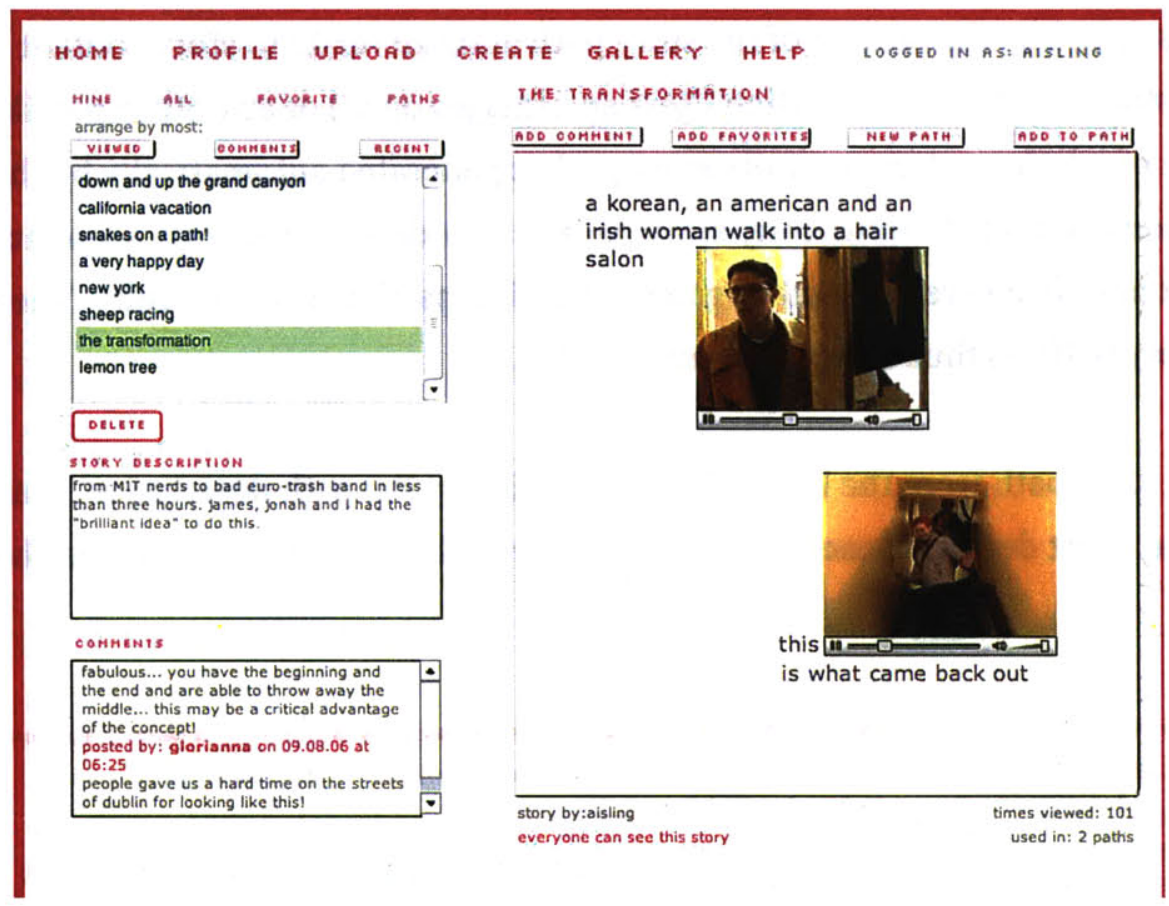

Figure 21: Confectionary story gallery

The story and path navigation menu allows the viewer to select and order particular story and path groupings from the database. In story navigation mode, the viewer can choose to explore lists of their own stories, all stories in the database or stories that they has previously added to their list of favorites [See Appendix A for interface screenshots]. The viewer can then choose to organize these selected lists according to the upload date, the number of times the story has been viewed or by the number of comments the story has received. Stories selected from the lists will be displayed in the Confectionary story canvas. In story navigation mode, the story and path metadata interface will display the description, if any, associated with the displayed story. Any comments that have been added to the displayed story will additionally be shown in a scrolling text box, along with the name of the comment author and data of entry. 
In path navigation mode, the viewer can choose to explore lists of their own story paths, all story paths or paths generated from community groups [See Appendix A for interface screenshots]. A story path is an ordered navigation sequence through the Confectionary story collection. A story path is made up of one or more stories that are thematically related and arranged in a preferred order. Preferred order means that stories in the path should be accessed in the numbered order determined by the path author. The path theme is assigned by the creator of the story path and can relate to story content ('summer stories)', story composition ('text and images only') or any other possible defined set of relations. A community story path is generated automatically by the Confectionary system. A community story path is an ordered navigation sequence of stories that have been created and targeted towards a particular community. The theme of these story paths is thus the community itself.

Selecting a story path from the lists of paths will display the path description, if any, and load a visual chart depicting each node in the story path in numbered order as shown in Figure 22.

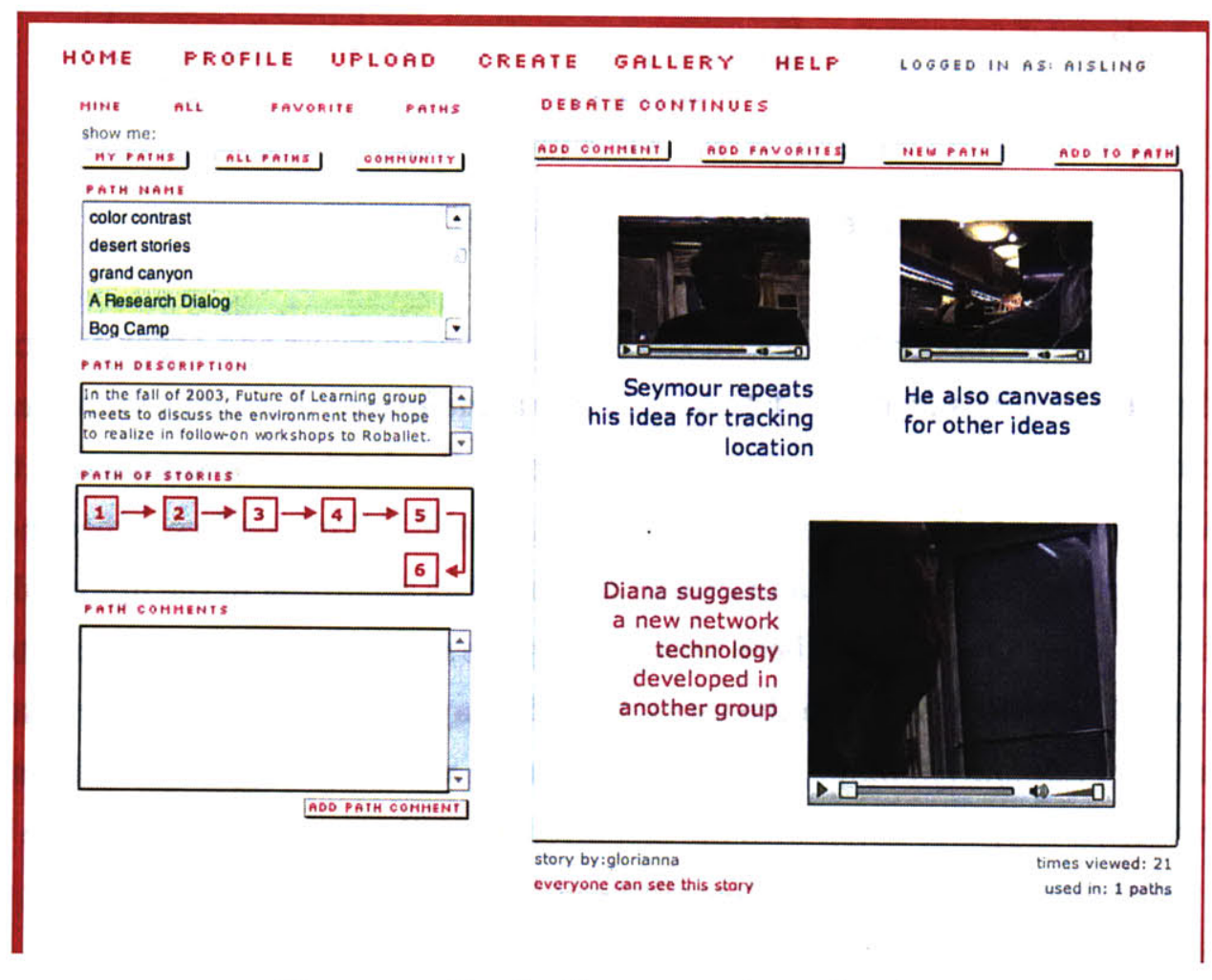

Figure 22: Confectionary path navigation 
Any comments that have been added to the selected story path will additionally be shown in the path comments text box, along with the name of the comment author and data of entry. To navigate through a story path, the viewer selects numbered story node buttons. Each numbered button will load the story associated with it in the Confectionary story canvas. Viewers can traverse through the path by selecting each story, one number after another.

The Confectionary story canvas displays selected stories. For each displayed story, additional information such as the name of the story, the story author, the number of times the story has been viewed, the number of paths the story is used in, and the story privacy settings are also displayed around the story canvas. Also surrounding the story canvas are a number of viewer feedback options as shown in Figure 23.

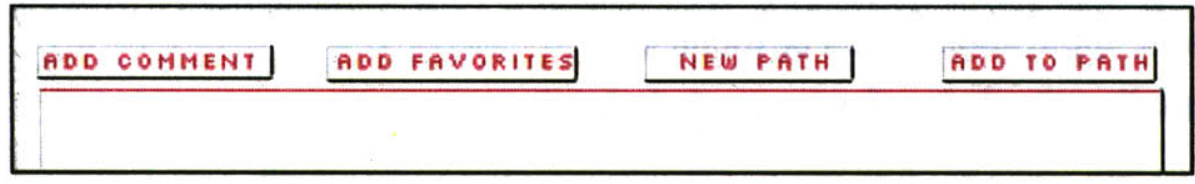

Figure 23: Confectionary viewer feedback options

The viewer can choose to add the displayed story to her list of favorite stories and/or can add a comment to the story. Selecting the 'add comment' button launches a text input window where the viewer can write some feedback for the story author [See Appendix A for interface screenshots]. The viewer can create a new story path by selecting the 'new path' button. This launches a pop-up window where the viewer can input the name and description of the new path. To add a story to a path, the viewer selects the 'add to path' button while the story is displayed in the Confectionary story canvas. This launches the path management interface component as shown in Figure 24.

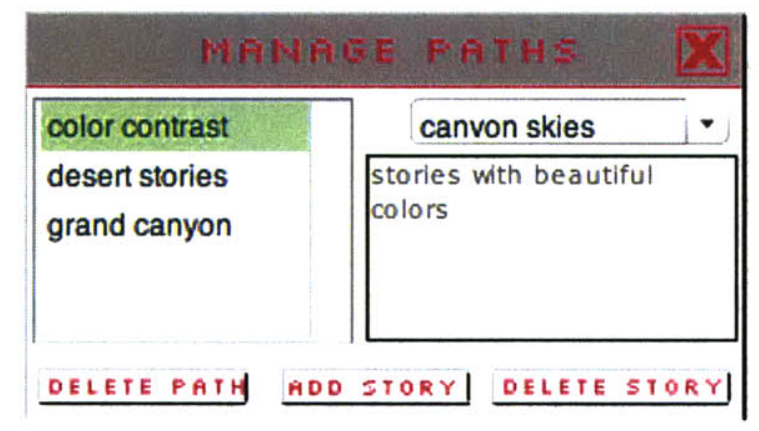

Figure 24: Confectionary story path manager 
All story paths created by the viewer are displayed in a scrollable list on the left. Selecting a story path name from this list will load the path description to the right, and create an ordered dropdown list of stories, if any, that already exist in the path. By selecting the 'add story' button, the story currently being displayed beneath the path management component will be added as the next story node in the selected path.

\subsubsection{Additional Elements}

To upload media entities for use in Confectionary, storytellers select the 'upload' button from the menu interface. This launches a browser pop-up window containing instructions and a file-browsing component [See Appendix A for interface screenshots]. Participants can upload a variety of media file types including image (jpg, gif), audio (mp3) and movies (flv). To access information and instructions for using Confectionary, participants select the 'help' button from the menu interface. This launches an external website that contains a comprehensive overview of all the functions and features of the Confectionary application. It can be found at:

http://mf.media.mit.edu/confectionary/help.html 


\section{Evaluation}

The purpose of this evaluation is to determine if a spatial metaphor for authoring and publishing, and a path metaphor for connecting and experiencing, mediated personal testimony, enable ordinary people to express, share and experience story-centered personal reflections.

The results and analysis described in this section seek to answer the following key questions:

- Can a spatial rich-media authoring and publishing environment support storycentered personal reflection by casual storytellers?

- Does a spatial rich-media authoring metaphor allow storytellers to easily create narrative relationships between media entities?

- Can these spatially defined narrative relationships make the process of constructing storied meaning direct and transparent?

- Can this system support a wide variety of storymaking strategies, motivations and styles?

- Does a path metaphor in a rich-media authoring and publishing environment increase the meaning making capability for all participants?

- Can a spatial rich-media authoring and publishing environment with multiple active feedback modes support story-centered reflective dialogs?

The Confectionary application developed to answer these questions was evaluated in two primary studies. In the first study, a one-day workshop with experienced rich-media storytellers was held to compare the Confectionary application with current best practice within the context of online media/story sharing applications. The purpose of this study was to determine how the storytelling affordances of the Confectionary application supported the Everyday Mediated Storytelling model in comparison with two other online story authoring and publishing applications. In the second study, the story authoring and sharing activities of participants using Confectionary was quantitatively and qualitatively analyzed over a 5-month period. The purpose of this study was to better understand and characterize the motivations, behavior and critical reflections of everyday rich-media storytellers. Through data analysis, surveys and in-depth interviews, this study examined the ease of use of the Confectionary application, the 
range of storymaking approaches and styles supported by the application and reflections on the use of the application in documenting personal experiences and exploring personal media collections.

\subsection{Comparative Workshop}

This workshop study compared the Confectionary system with current best practice within the context of online media/story sharing applications. This study sought to compare Confectionary with two other online story authoring and publishing applications along several task dimensions including: inspiring the author to begin creating, facilitating the authoring of a variety of types of stories and engaging the participant as author and viewer.

\subsubsection{Study Details}

The study involved 7 subjects each with considerable digital media experience. The study took place over a 3-hour period in a laboratory environment. Using their own digital media, subjects were asked to author, publish and review personal media stories using three different media authoring and publishing applications. After using each application, the subjects were asked to fill out a questionnaire describing their experience with the application on a range of different topics. At the end of the study, the subjects were asked to fill out one final questionnaire comparing and contrasting the three applications [See Appendix C for questionnaires]. The study then wrapped up with some general discussion and observations.

\subsubsection{Comparison Applications}

The Confectionary application supports users in authoring, publishing and responding to online rich-media stories. Currently there are several other popular applications and software tools that support a variety of forms of rich-media storytelling. Two platforms considered as exemplifying current best practice within the context of online media/story sharing were selected as appropriate for comparison with the Confectionary application - a rich-media weblog (WordPress) and a community photo-sharing site (Flickr). Both publishing platforms have a strong focus on usability, aesthetics and the sharing of personal media and commentary. WordPress was chosen as an appropriate representative of a rich-media weblog because it is popular (has been downloaded over one million times), has good market penetration and the team behind it has a strong 
commitment to developing and evolving the software 3 . As an open-source platform, WordPress has actively encouraged developers to add plugins, themes and additional features to the original source code. This has led to the emergence of numerous extensions to the traditional predominantly text based weblog that allow for the inclusion of other media forms such as images (Exhibit 1.1.d), videos (Video Blogger) and mp3s (Wimpy). Flickr was chosen for similar reasons - it is tremendously popular (over 2 million registered users), recognized for its ease of use and has a well-documented API that allows developers to create plugins and fun photo-related applications [Bausch \& Bumgardner, 2006].

For the purposes of this study, a media enabled WordPress powered weblog was created that supported the inclusion of the same media entities (jpg/gif/mp3/flv) as used in Confectionary. The default settings for WordPress do not include direct support for rich media files. In response, the most popular WordPress media plugins as demonstrated by their download rates were added to the weblog configuration. The Jeroen Wijerings FLV Video Player Plugin was implemented for playing FLV movies and Taragana's Del.icio.us mp3 Player Plugin was added for playing mp3 files. Flickr currently only provides support for image files. However, members of the Flickr community can also add text notes to segments of their uploaded photos, assemble their photos into grouped sets and tag, comment or mark as favorite any publicly available photographs. Overall, despite the implicit focus on one main media form, issues of community, viewer response and its function as an everyday application make Flickr an appropriate metric for comparison. For the purposes of this study, a Flickr group called 'EverydayStories' was created to collect the photos, descriptions, notes and tags submitted by the workshop subjects.

\subsubsection{Summary of workshop activity}

Table 2 displays data from the workshop activities. The large number of 'Media Posts' created during the Flickr exercise can be attributed to the fact that the Flickr upload and posting process are one and the same. With WordPress and Confectionary, media is uploaded but does not get posted unless integrated into a formally composed message.

3 [http://wordpress.org/download/counter]. 


\begin{tabular}{|l|l|l|l|l|}
\hline & Media Posts & Post Media Content & Comments & Metadata \\
\hline WordPress & 7 & text, photos, audio, video & 7 & 12 categories \\
\hline Flickr & 43 & text, photos & 29 & 23 notes \\
\hline Confectionary & $\mathbf{1 1}$ & text, photo, audio, video & 8 & 3 paths \\
\hline
\end{tabular}

Table 2: Comparative workshop activity data

Each of the three authoring and publishing environments provided subjects with particular storytelling constraints and affordances. The WordPress application allowed for the creation of rich-media stories arranged in a vertical, linear sequence and the addition of viewer feedback in the form of text-based comments. Figures $25-27$ are examples of some of the stories created during the WordPress exercise. In Figure 25, the author used several paragraphs of text to introduce his story, which is then broken up into pictorial episodes annotated with keywords. The author of Figure 26 used multiple media types to create a stream-of-conscious style story while in Figure 27, the author punctuated a long expository text with some final photo commentary.

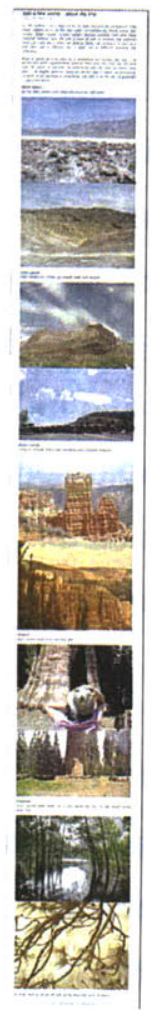

Figure 25: WordPress story

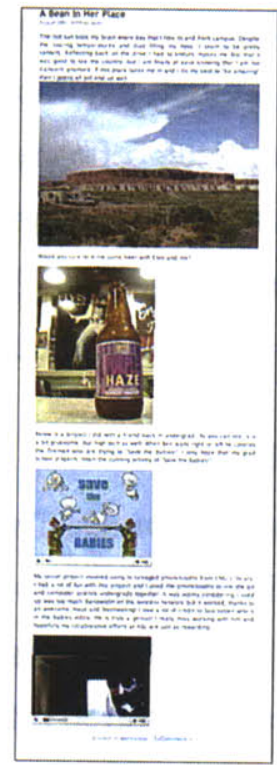

Figure 26: WordPress story

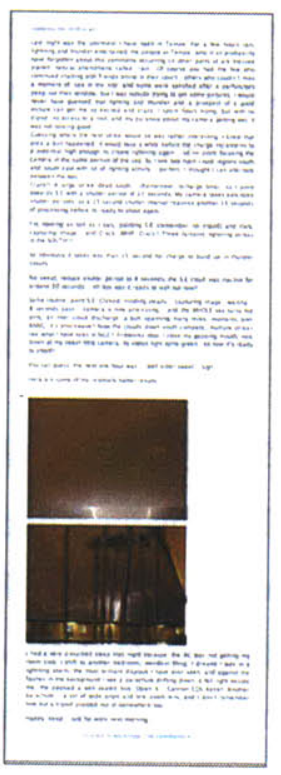

Figure 27: WordPress story 
During this exercise, viewer feedback consisted mainly of short pithy one-sentence comments, with the exception of the responses to one long text-intensive story, which drew paragraph-length viewer responses. Such responses possibly indicate that the storytelling strategies used by authors are suggestible for the viewing public.

The Flickr application allowed for the creation of annotated photo stories arranged as individual slideshow elements. Figures 28 - 30 are examples of some of the stories created during the Flickr exercise. In Figure 28, the author used the notes feature to add text commentary over four particular areas within the displayed photograph. Figure 29 depicts one of two thematically and structurally related stories created by the author where a photograph is accompanied by several paragraphs of descriptive text. Figure 30 depicts a posting that the author made in response to another similarly themed post. In this case, the author created connections between the two stories through the use of tags, comments and the addition of the story to several pool groups.

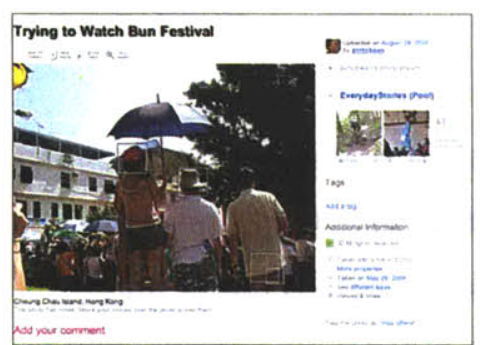

Figure 28: Flickr story

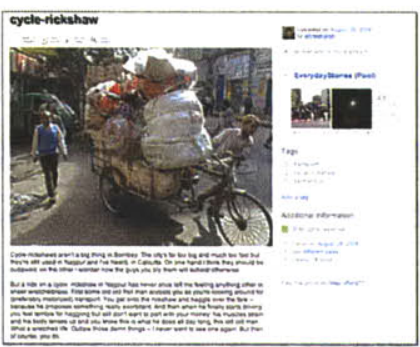

Figure 29: Flickr story

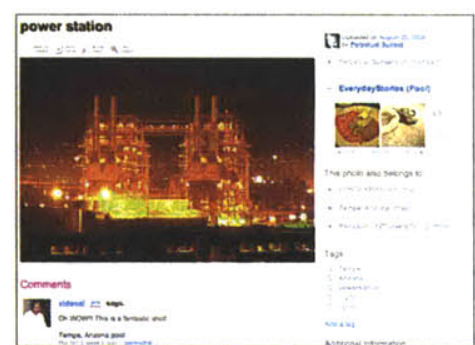

Figure 30: Flickr story

Viewer feedback during this exercise comprised the addition of text-based tags, comments and notes. A similar observation to the suggestibility of viewers to an author's storytelling strategy was made with the Flickr exercise. In this case, stories posted with author added notes garnered feedback through the addition of more notes and photos accompanied with long text descriptions drew correspondingly long comments.

The Confectionary application allowed for the creation of rich-media stories arranged in 2dimensional space and the addition of viewer feedback in the form of text-based comments and the creation of navigation story paths. Figures $31-33$ are examples of some of the stories created during the Confectionary exercise. In Figure 31, the author overlayed three identically sized and aligned movies with three identically sized and aligned audio files. The sounds heard when the audio files played complimented the visuals shown when the movies beneath played back. In Figure 32, the author placed four identically sized time-lapse movies in a formal grid-like 
arrangement. Three of the movies are pans of the same scene, while the movie at the bottom left is a stationary shot of a different landscape. In Figure 33, the author used paired photos and text to tell a story in three episodes.

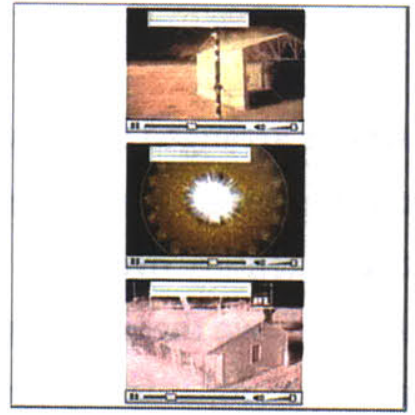

Figure 31: Confectionary story
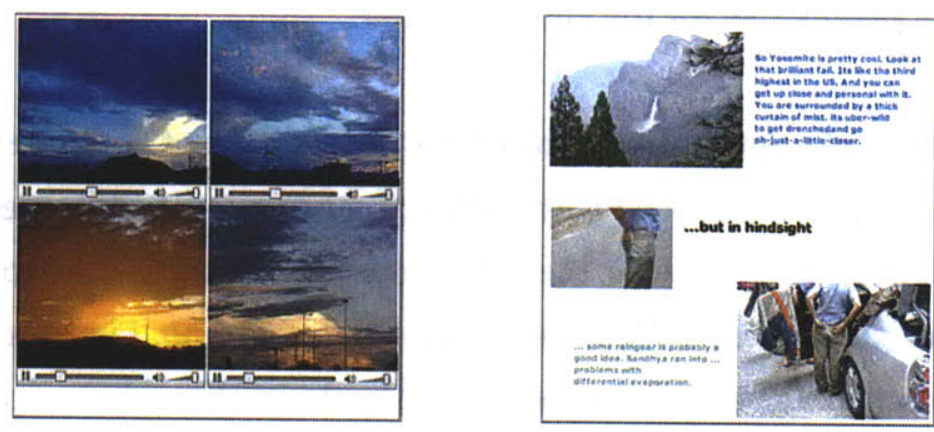

Figure 32: Confectionary story Figure 33: Confectionary story

Viewer feedback during this exercise consisted of the addition of text-based comments and the creation of several story paths.

\subsubsection{Results and Findings}

The subjects were introduced to Confectionary for the first time during the study but based on observation of their activities and on their own self-reporting, they found the application easy to use and became quickly familiar with its feature-set. In fact, they described finding the software comparably as easy to use as the other tested applications with which they had far more prior experience. In comparing his previous experience with rich-media tools, one subject commented: "For really rich media I'm used to working with applications that offer much more controls, but require much more learning to use. This [Confectionary] is limited but is a great way to sketch stories and images out". The subjects found the visual design of Confectionary appealing, with one commenting that it "had great potential...with an intuitive interface". The WYSIWYG nature of authoring and publishing personal stories using Confectionary found favor with the subjects who described being able to begin creating quickly in a clearly understandable environment. In comparison, the disparity between the authoring and publishing components in the WordPress application proved frustrating to some: "This [WordPress] was hard to navigate. I often couldn't find the right button I needed to 'edit' or 'view all' etc and often times I found myself using the browser's back button. I really didn't like this blog software. It gave me a headache." 
In terms of the complete storymaking experience, subjects ranked Confectionary over the other two applications. For some of the subjects, an important feature that contributed to their preference for Confectionary was its support for multiple types of media, with one subject commenting: "I liked the interface very much, but what is really great is the fact that I could use audio, video and text" and another "I enjoyed coupling music with images that had personal meaning." In comparison, subjects reported finding it hard to both think of, and make stories using Flickr. In particular, the subjects drew attention to the limited layout opportunities with Flickr, describing it as being more a 'showcase' rather than a storytelling environment. One subject commented: "Flickr's presentation scheme makes it really hard to actually tell stories. I wanted to juxtapose two pictures. I guess I could have photoshopped them together beforehand and then used the notes feature to say what I wanted to say but that makes the preparation part really time-consuming and not worth it really". The ability of Flickr to evoke, as Ryan might say, a 'narrative script' is therefore considerably less than that of Confectionary, which with its support for multiple media types and broad range of possible story configurations affords the storyteller a richer environment for exploring levels of narrativity.

Overall, the subjects defined their favorite stories from the entire workshop as being authored using the Confectionary application and reported strong levels of engagement with the observed work. During the workshop participants spent more time investigating the stories created by others in Confectionary than with the other two applications. With Flickr, the subjects tended to rapidly skip from one post to another, while WordPress posts were quickly skimmed. While viewing Confectionary stories, the workshop subjects played movies in individual stories repeatedly and returned several times to particular stories to view again and again. This prolonged period of story viewing may have impacted their use of the feedback features of the application during the study as only 8 comments were submitted and 3 paths made, as compared to the 29 comments and 23 notes added during the Flickr session. In addition, the comments and notes features of the Flickr application are extremely well designed and each of the subjects were very familiar with using them. With Confectionary, the subjects had first to familiarize themselves with the idea of a story path and then browse through all the stories before creating a thematic collection using the paths interface. Although several of the subjects created story paths, it is difficult to reach any strong conclusions from this 
short study about how this process might have increased their meaning making capabilities. Greater results possibly would be found after increased exposure to the tool and with a larger data-set of stories, as will be described in the findings in the longitudinal study in section $\mathbf{5 . 2}$.

\subsubsection{Summary}

Participants in the comparative study determined that Confectionary performed as well as, or indeed out-performed current best-practice story authoring and publishing applications. Participants found the application intuitive and easy-to-use, and were able to begin creating quickly. The stories created demonstrated a broad range of storymaking approaches and styles and the participants were particularly pleased with the ease-of-use with which the application supported the addition and manipulation of multiple forms of media. The workshop participants also demonstrated a high level of engagement with the Confectionary stories created by others, spending considerable time browsing the gallery and adding comments.

\subsection{Longitudinal Study}

In this study, the story authoring and sharing activities of participants using Confectionary was quantitatively and qualitatively analyzed over a 5-month period. This study aimed to provide a general understanding of the primary design features, constraints and affordances of the Confectionary application as evidenced by regular participant use. In addition to the general body of Confectionary users, three dedicated storytellers participated in numerous interviews, surveys and online exchanges regarding their interactions with the Confectionary application during this time. The purpose of this particular study element was to better understand and characterize the motivations, behavior and critical reflections of everyday rich-media storytellers. The results and analysis described below, therefore, encompass both general and specific Confectionary story exchange activities, including story authoring styles, levels of story disclosure, the use of wayfinding story paths and reflections on the use of the application in documenting personal experiences and exploring personal media collections. 


\subsubsection{General Activity}

Between July-December, 2006, 142 individuals created accounts in the Confectionary application. During this time, the Confectionary application registered 1004 unique login sessions by these 142 individuals, with 18 participants logging in more than 10 times. In addition, new visitors to the Confectionary host website could also log in as a 'guest' and explore the stories in the system before formally registering. The majority of the application subscribers can be defined as story explorers, as 26 participants created no stories at all, while $\mathbf{8 1}$ participants created stories that were then subsequently deleted or removed from the database. There are several reasons for this occurrence, including occasional instability in the system itself leading to stories not being properly saved and subscribers logging in once or twice out of curiosity but declining to invest more time into uploading media or creating stories. The remaining 35 participants created 155 stories from some of the 584 uploaded media entities. Overall, participants contributed a variety of media file types and formats. The majority of uploaded media files were photographs and/or graphics, with 450 images uploaded in total. 119 movie files were also contributed to the system and 15 audio files. Figure 34 indicates the timed relationship between the uploading of media entities and the creation of Confectionary stories.

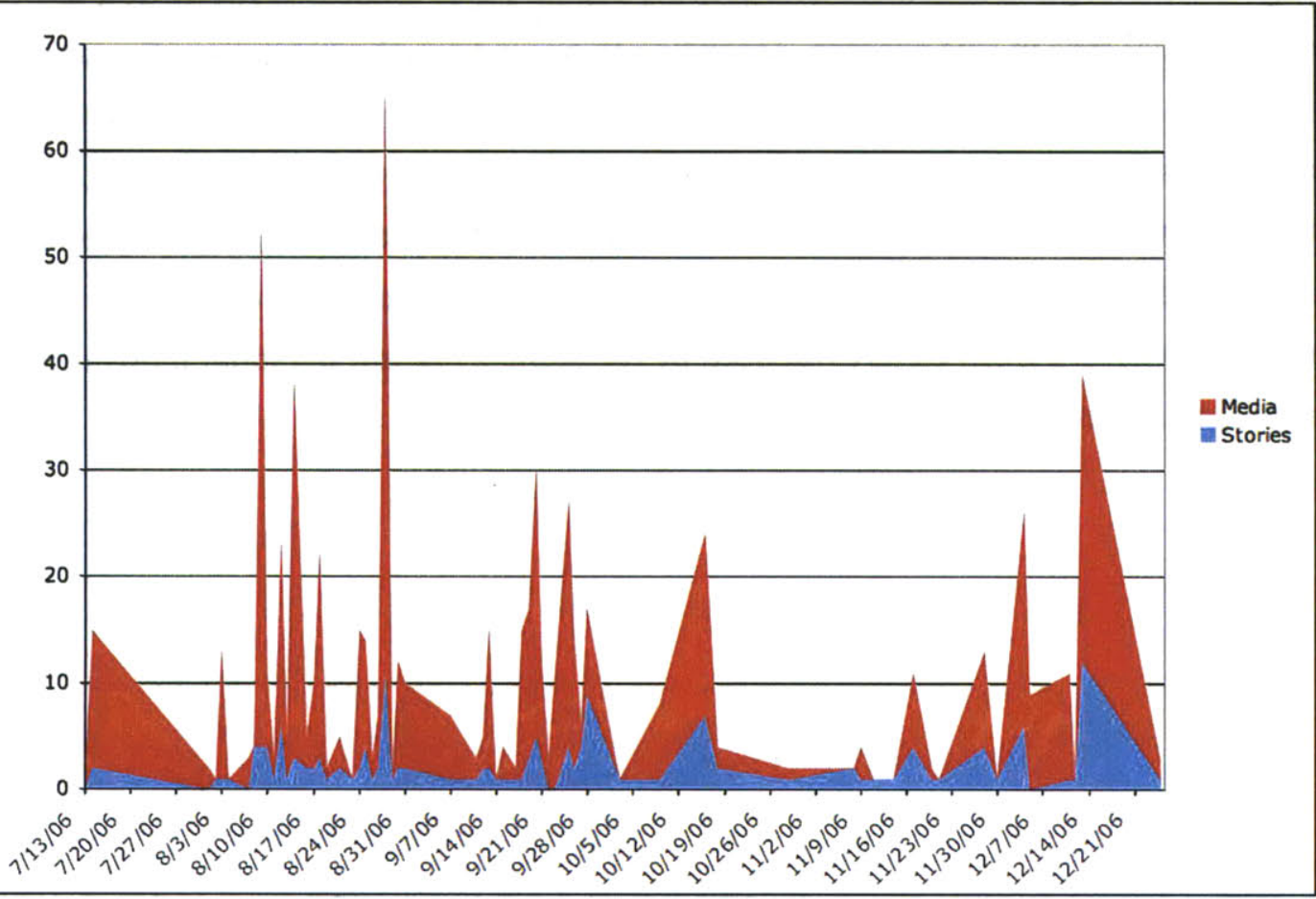

Figure 34: Timed relationship between media upload and story creation 
In general, spikes in media upload corresponded with overall spikes in story generation. The majority of story making participants uploaded media and created stories in the same login session, although a number of regular storymakers logged in on several occasions and made stories from previously uploaded media. Of the 155 stories created in the Confectionary application, 101 were openly accessible to all visitors to the website. 13 stories were revealed to members of particular community groups and 41 stories were revealed only to designated individuals, including the author themselves. In total, only 4 community groups were formed during the 5-month period and 7 Confectionary participants joined either 1 or more communities. The community group feature was not comprehensively used during the study. One reason could be that participants were using their own media to tell personal stories that did not necessarily fit with an as yet defined community experience. The wayfinding story paths feature was much more extensively used for creating 'personal communities of stories', as described more fully below.

\subsubsection{Story genres}

In Chapter 2, I described the six steps involved in the creation of a work in any medium as defined by Scott McCloud as being: idea/purpose, form, idiom/genre, structure, craft and surface [McCloud p182 1994]. For the creation of works according to the Everyday Mediated Storytelling model I also identified feedback as one further crucial step in this process. According to our model, the purpose of creating personal stories is to make our experiences memorable over time and to come to better

understand ourselves as individual and social beings. In this study, these personal stories were manifest over a 5-month period in the Confectionary application in the form of online rich-media stories. During this time, we can identify the existence of a variety of different Confectionary genres as evidenced by the subject matter, personal motivation and storytelling styles used by the participants 


\section{Personal Documentary}
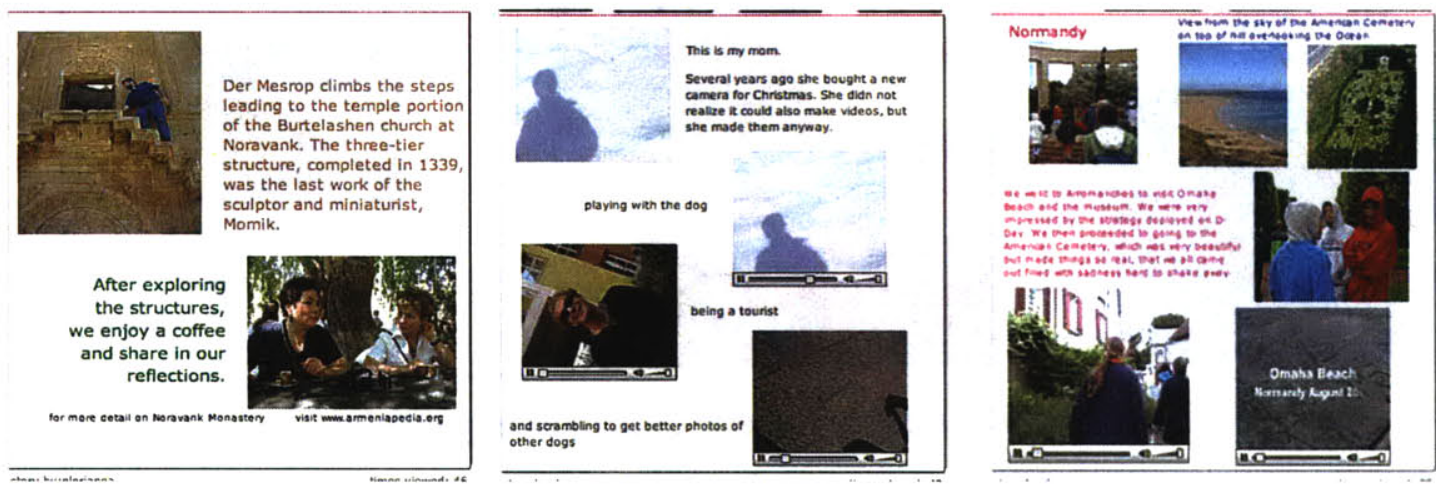

Figure 35: Examples of personal documentary Confectionary stories

In these stories, the participants used images, movies and supporting text to create stories that documented and reflected upon their own personal experiences.

\section{Informative}
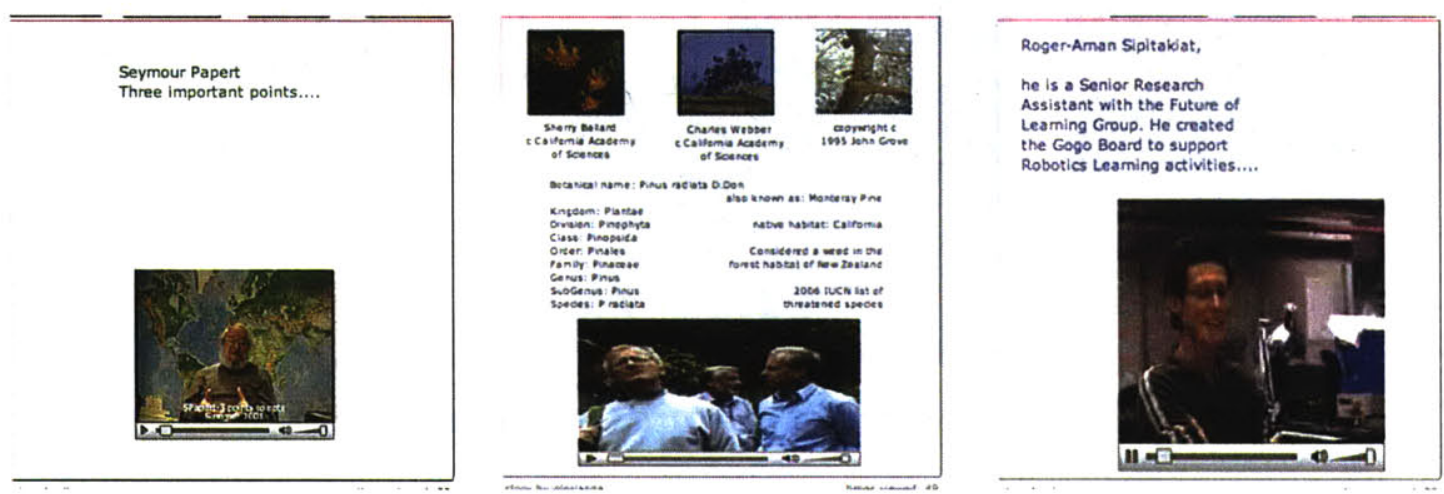

Figure 36: Examples of informative Confectionary stories

The participants constructed informative stories that contained educational content and created opportunities for audience learning. 


\section{Poetic}
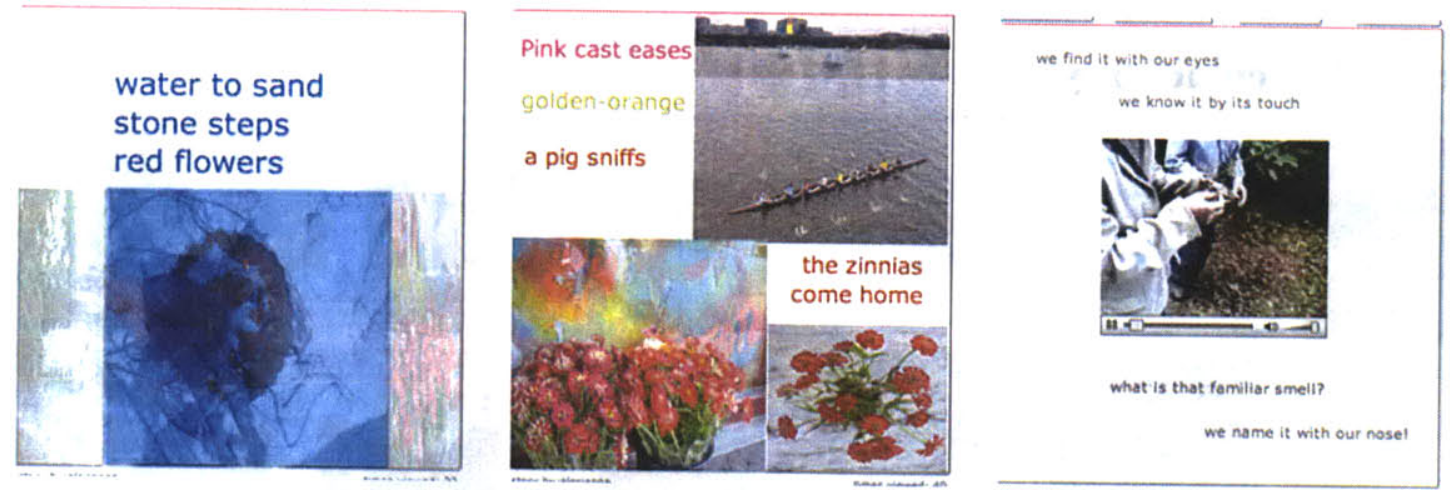

Figure 37: Examples of poetic Confectionary stories

With these stories, the participants created dreamy juxtapositions between the visual imagery and the text in layered and carefully composed arrangements.

\section{Media Postcard}
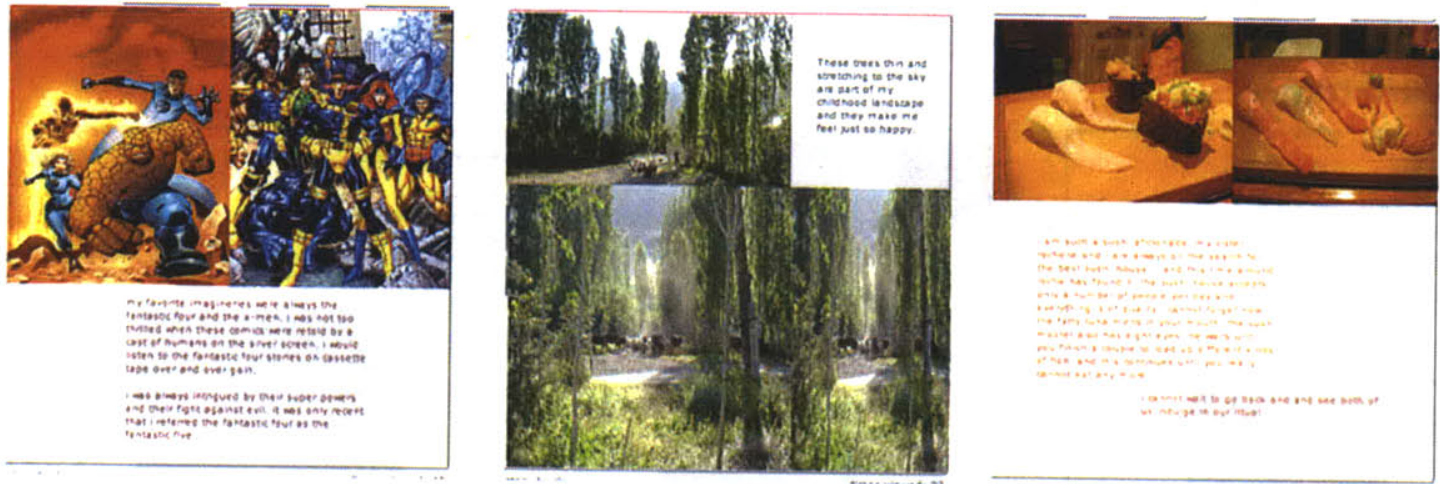

Figure 38: Examples of media postcard Confectionary stories

Media postcard stories contained carefully aligned imagery and supporting text that visually filled and connected the horizontal canvas. 


\section{Comedic}
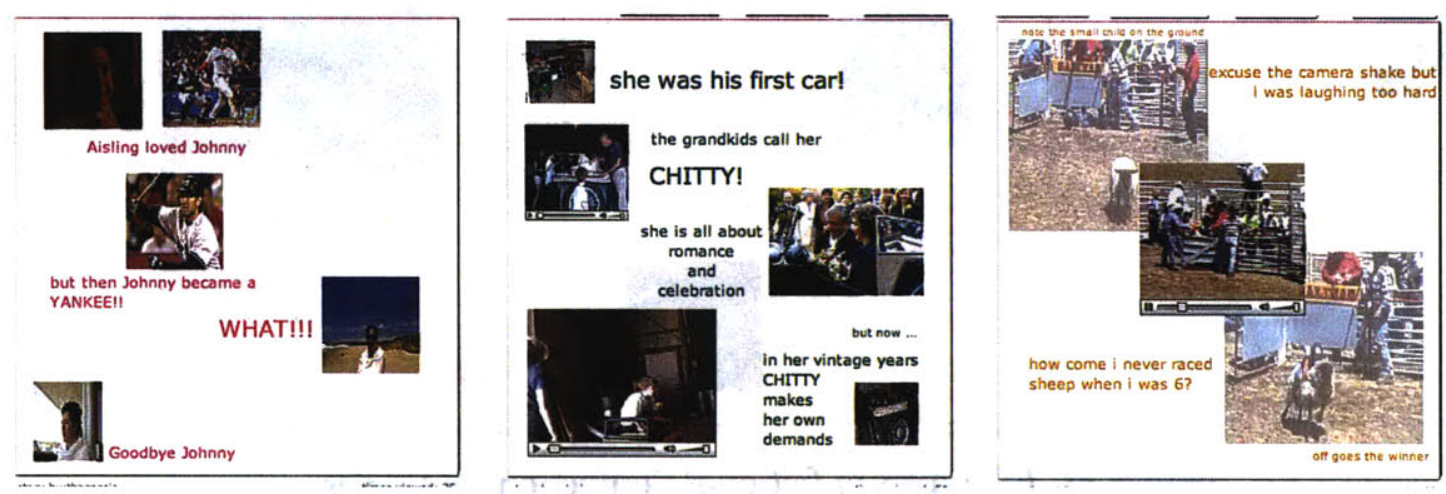

Figure 39: Examples of comedic Confectionary stories

These Confectionary creations related funny stories through the juxtaposition of richmedia and text elements for great comedic effect.
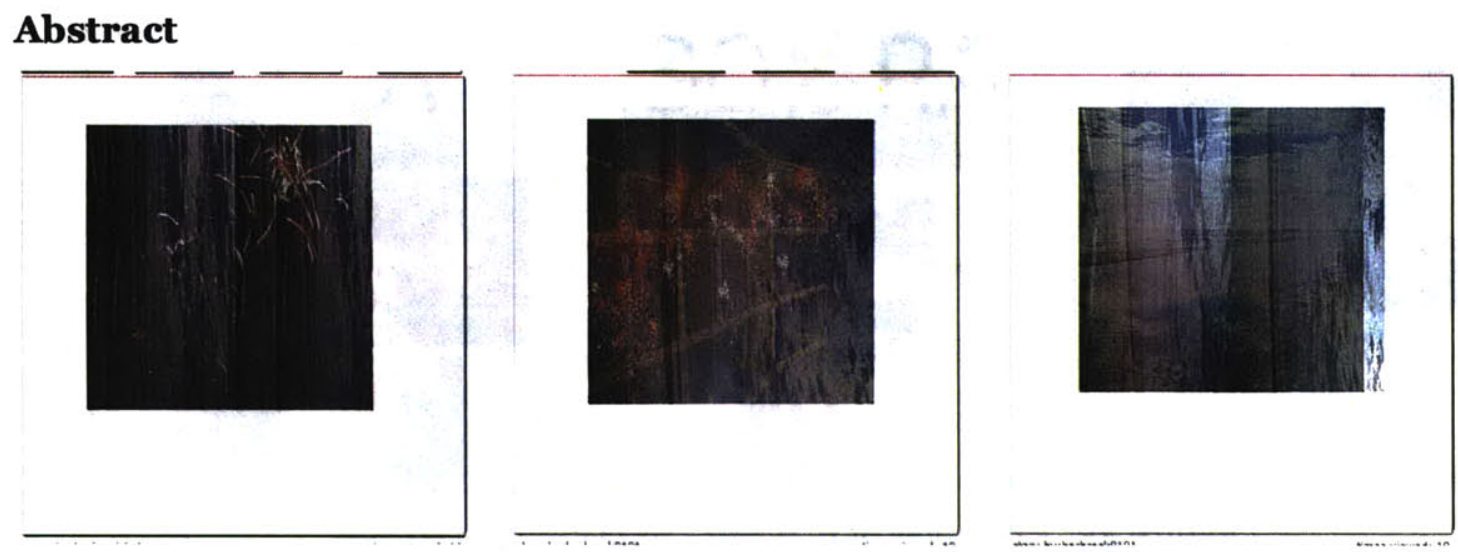

Figure 40: Examples of abstract Confectionary stories

Abstract Confectionary stories used complex layering of visual imagery with various levels of transparency to create narratives that slowly revealed themselves to the audience. 
Fictional

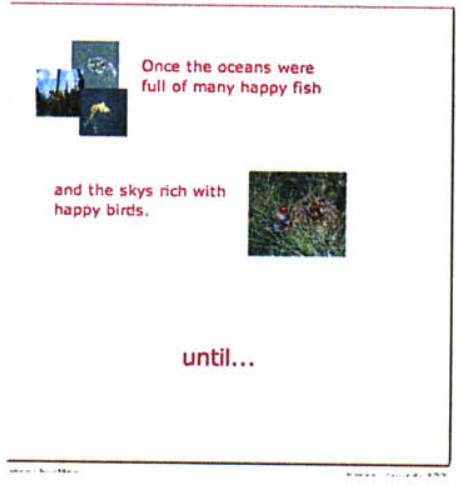

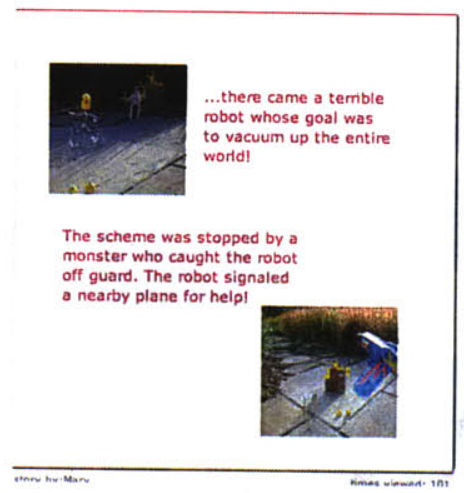

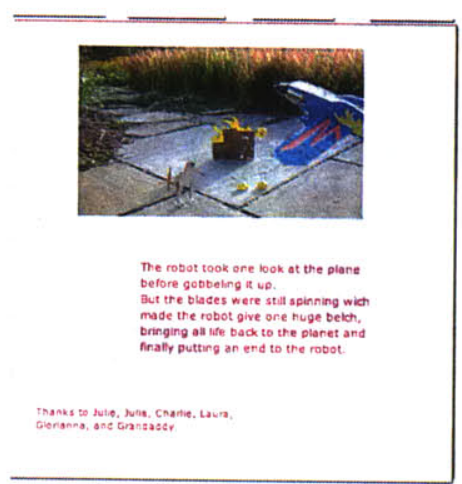

Figure 41: Examples of fictional Confectionary stories

Participants created fictional worlds using photographs and suggestive text that lead the audience on an imaginative journey.

\section{Portrait}
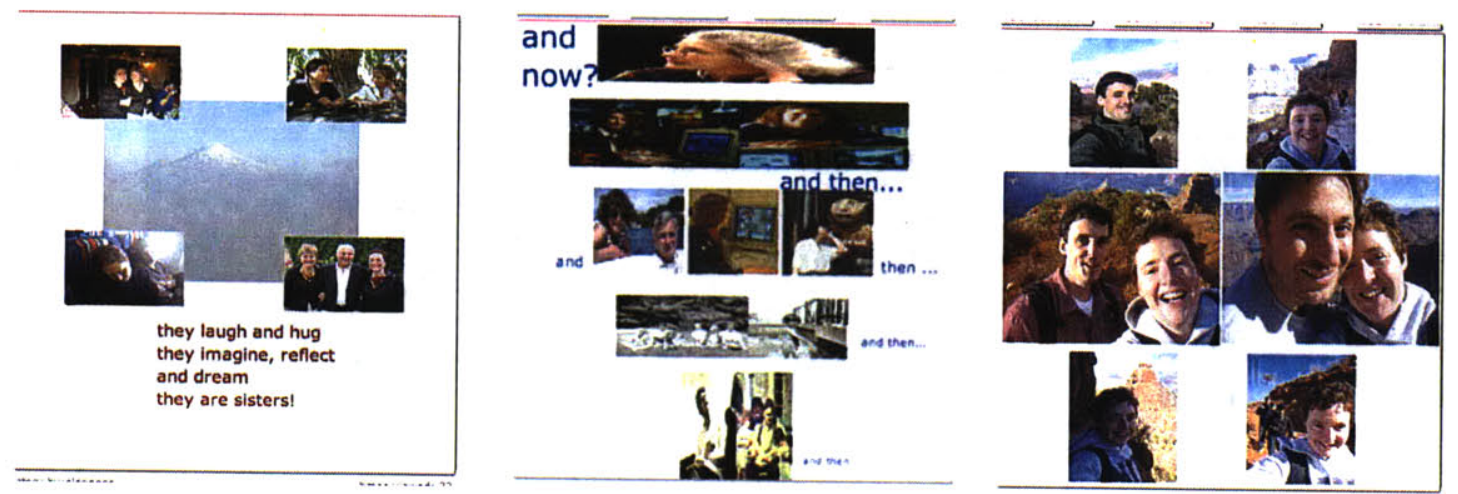

Figure 42: Examples of portrait Confectionary stories

Portrait stories contained event focused or time driven rich-media compositions portraying individuals or groups of individuals.

Each of these story genres help support the motivations of the story author, whether it be to encourage personal reflection, to inform, to entertain, to stimulate or to emotionally move a viewing audience. Within each story idiom, the storytellers communicate and express using a variety of Confectionary's structured authoring features and functions. Having selected the media entities that best represent the experienced moment, the author then uses the layout and compositional functions to not only reveal, as described in Chapter 1, what they have experienced but also how they remember experiencing that 
moment. On the spatial composition plane, storytellers used the rich-media vocabulary of the language of Confectionary to draw the eye across the canvas and highlight areas of significance. Through the manipulation of compositional techniques such as layering, balance, repetition, transparency, size and color, the participants create emphasis, provoke contrast and altogether demonstrate the broad range of storymaking approaches and styles supported by Confectionary.

\subsubsection{Story styles}

As described in Chapter 2, we are strongly conditioned to approach a visual piece in a left-to-right, top-down way. Participants in the 5-month study regularly used the spatial plane of Confectionary to construct stories that had such a preferred reading as indicated in Figure 43 below:
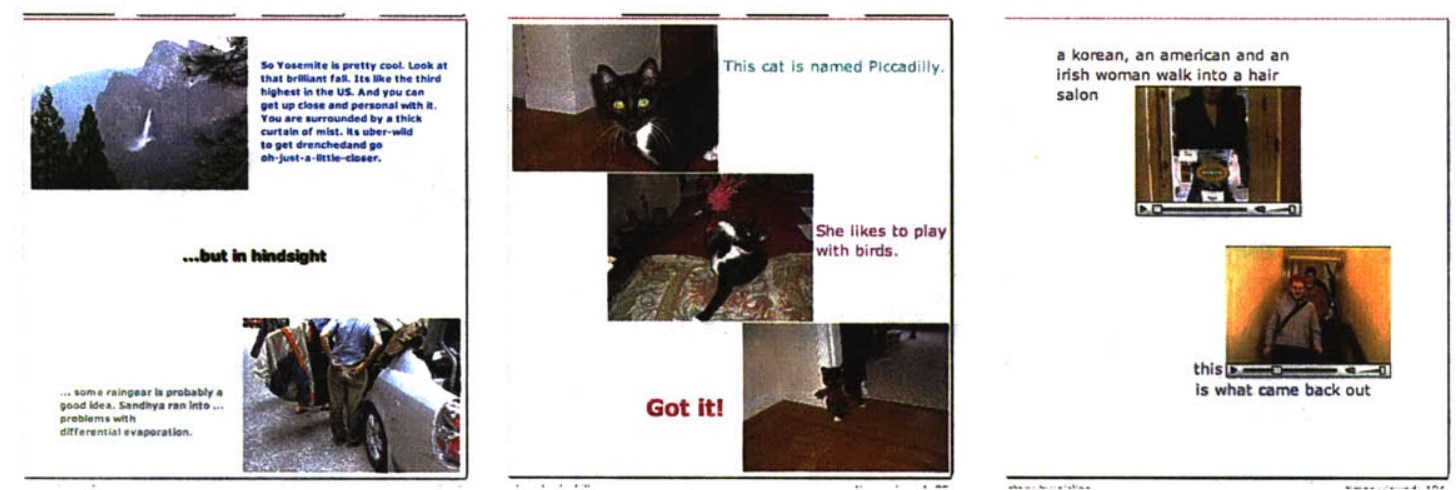

Figure 43: Examples of left-right, top-down spatial story layouts

Each of the stories depicted above also made use of size repetition and a balanced compositional layout to create a leveled and harmonious audience experience/reading as described by Dondis in Chapter 2. In Figure 44, symmetry and consistency are additional conditions evident as balancing techniques in the depicted stories created by the study participants: 

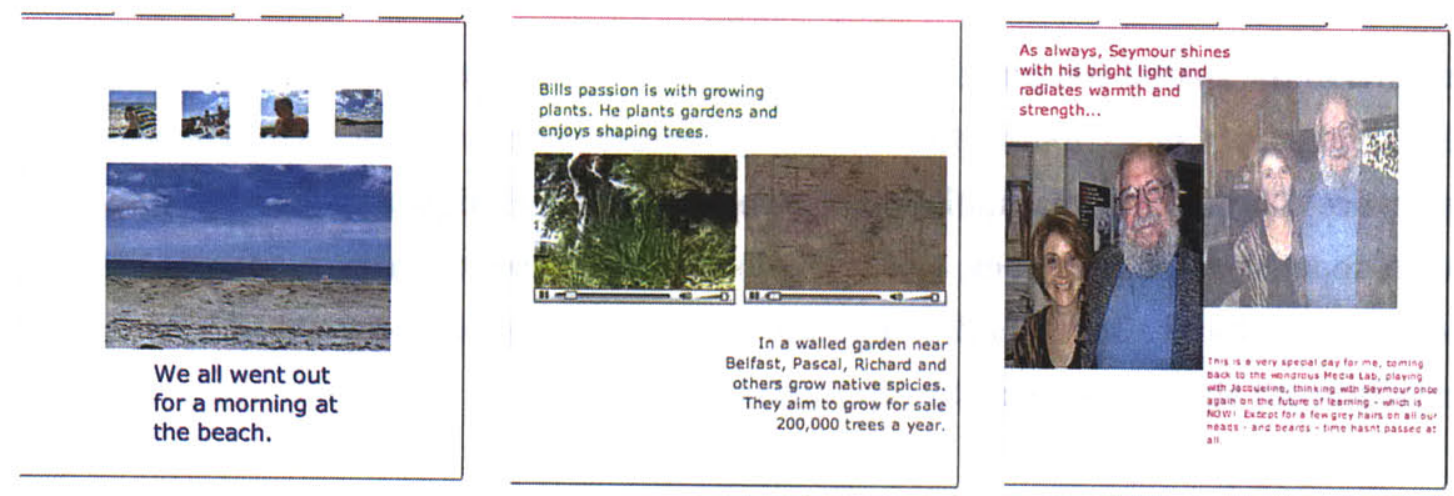

Figure 44: Examples of symmetrical spatial story layouts

The study story authors also used grouping techniques to create preferred associations and relations between story entities. Similarities and differences in media size, color and placement were used to form connections between composition subsections as demonstrated in Figure 45 below:
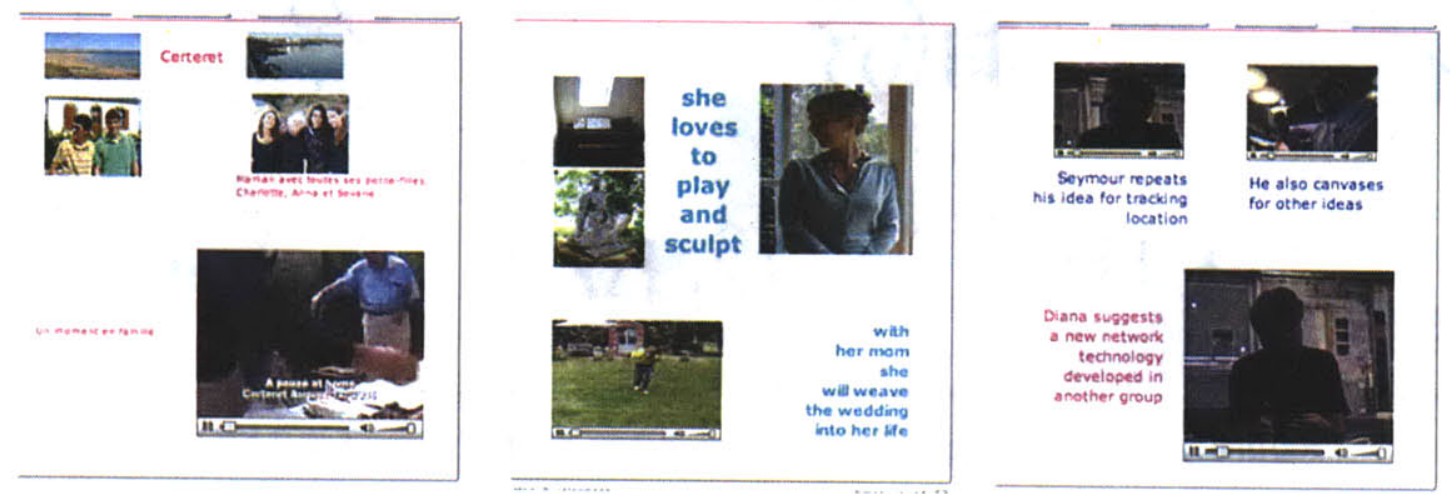

Figure 45: Examples of grouped spatial story layouts

Strategies using predictable evolution of visual features in entity size and position were also evidenced during the study in stories that drew the eye in obvious sequential steps as depicted in Figure 46: 

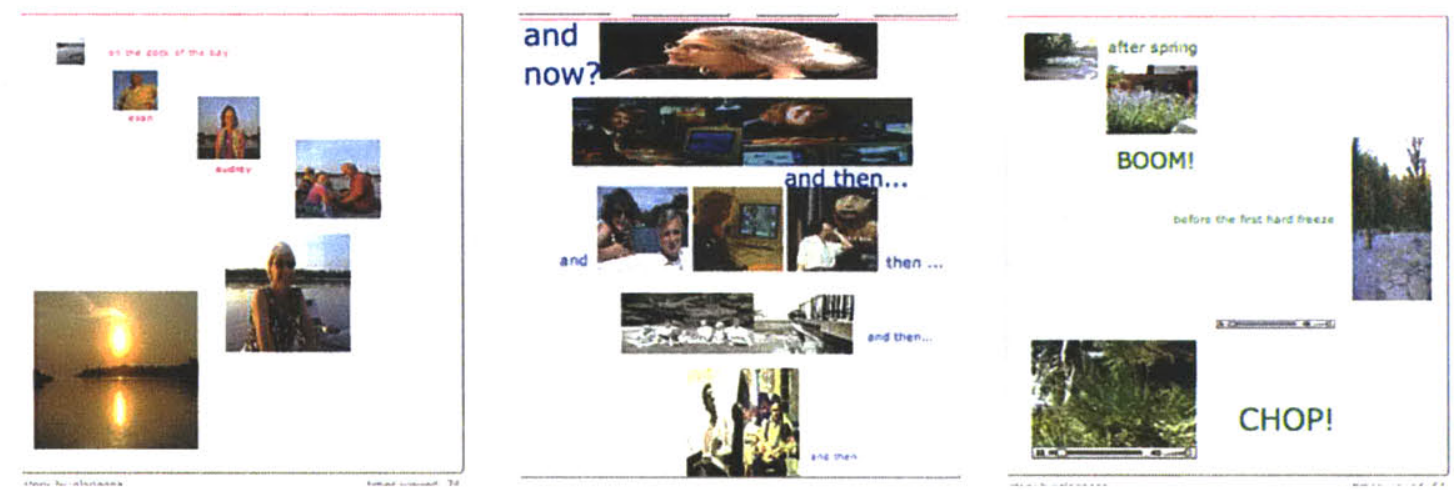

Figure 46: Examples of predictable spatial story layouts

Individual study participants experimented with a variety of styles depending on the type of story they wished to tell and how they wanted to convey it. Figure 47 displays two stories created by a study participant that use quite complex and fragmented compositional strategies. Each story represents one day from the participant's vacation and she described how she 'wanted to fit everything in' to fully represent all of the day's activities and adventures.
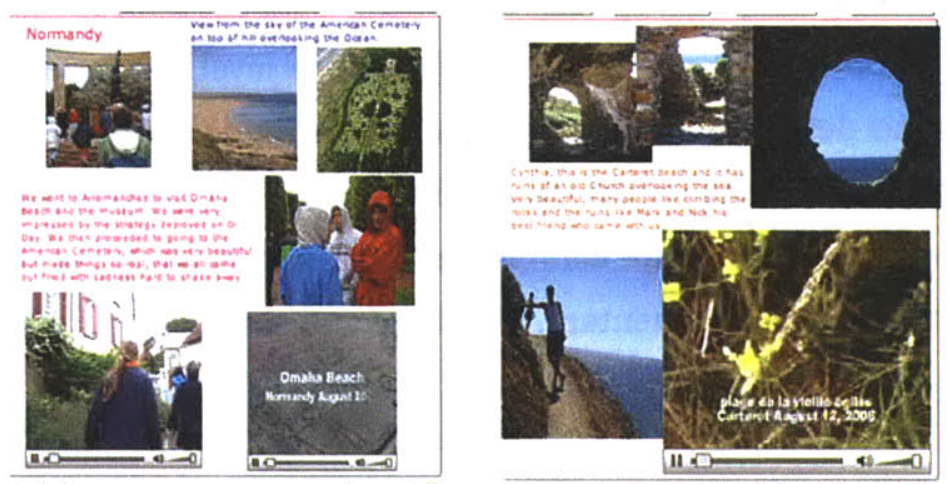

Figure 47: Examples of complex spatial story layouts by one participant

This same participant also created two much simpler and thematically related compositions as shown in Figure 48. With these visually 'quiet' stories, the participant invited the viewer to focus on one particular facet of a larger story that was revealed over several Confectionary canvases. 

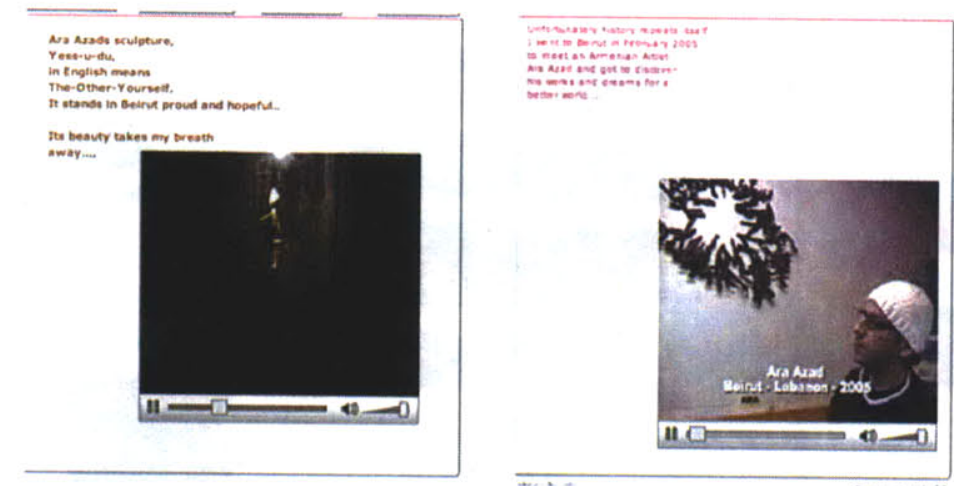

Figure 48: Examples of simple spatial story layouts by one participant

Overall, participants in the study demonstrated a broad range of stylistic and compositional approaches in creating narrative relationships between media entities in their Confectionary stories. The contributed stories used clearly identifiable visual strategies as defined by the literature that helped create preferred, direct and transparent story meaning.

The workshop participants developed their craft over the 5-month period, experimenting with story template layouts, borrowing from the approaches of others and generally honing their own personal style. At the surface level, the production value of the created stories was determined by the quality of the original media and the presentation interface of the Confectionary application itself. The final additional feedback stage formed an important component in the entire study, as audience interpretation, manifested as commentary, 'curating' and connecting, helped expand and grow the work.

\subsubsection{Story feedback}

On average, stories created during the study were viewed 11 times. This statistical information was relayed to the Confectionary community underneath the story canvas each time a story was selected for viewing. Additional displayed information informed the community about the story's possible presence in a story path or paths. Stories were designated as favorites 39 times during the study and overall, the story collection received 68 comments. The comments contributed during the study expanded the process of story exchange and strengthened the narrative meaning along each of the three dimensions described by Ricoeur in Chapter 2. Authors left comments relating to their own creative process and personal reflections (self-understanding), commentators 
asked authors direct questions and offered praise and advise (communicability) and contributors in general created connections between the story texts and their own life world and experiences (referentiality). The comments can be categorized into the following general types:

\section{Commentary on the story form}

- "fabulous... you have the beginning and the end and are able to throw away the middle... this may be a critical advantage of the concept!"

- “This confectionary surprises and delights.... I love its use of different visual media"

- "I love the idea of using two voices here. The first is sort of observational reportage although with a touch of personal emotion..eg. "thankfully the snake...."; the second is very first person. Nice!"

- "When I watched this story the dynamic way in which the elements were posted was very appealing."

\section{Commentary on the story content}

- "although $i$ cannot see the rattlesnake in the video, your story fascinates me! the sound of the desert makes me imagine the heat and all those reptiles you have out there!"

- "very complex and very absorbing...the top photo there. I looked at it for quite a while."

- "Such a lovely window into your vacation!"

\section{Poetic commentary}

- "slowly more beautiful. My mouth explodes with the memory of fireworks remembered, but more endearing are the ferns of the night."

- " $i$ look at this and $i$ keep thinking its fading in and out, in and out. in and out. so gentle."

\section{Questions for the audience/storymaker}

- “Who is Ernesto? a cliff-hanger of a story! "

- "Can you see the pig?"

- I love it. It is at once obscure and straight-forward. Which Asimov are you reading now? 


\section{Commentary from the story author}

- "I made this confectionary right after we came back from a weekend with friends at Georgian Bay. I had been playing with the templates, trying to understand what I thought of them. These pictures organized themselves once I realized that I could end with the Sunset which our friends treat as an awesome event every evening when one occurs. I like the way the orange light of the earlier pictures leads the story receiver around and into the sunset."

- "i did not get to video-take everyone in action! my batteries ran out! :(“

\section{Technical Problems}

- "I struggled a lot with the text and its position. It is unclear what the system constraints on the text layer are....."

- "The system is having a problem. Please return to view this story later. Tx. the author"

- "I am unable to successfully edit this story once its been created"

\section{Inspired memories}

- "This story reminds me of a recent visit to Georgean Bay, Canada where we witnessed a snake eat a bird. For the longest time the snake could not fit the whole wing in. When he did, you could hear the bones crunch and watch the shoulder bone move down as the snake squeezed the awkward form into a tighter and tighter mass of stuff."

- "I spent the night once in Stansted too and it was a day before the bombings. Very scary!

Overall the comments feature of Confectionary was reasonably well utilized and some of the comment categories point to the potential for developing the feature into a more attractive and unique application component. For example, some contributed comments suggested the potential for the comments field to support a mentoring or critique function, while some of the more poetic contributions might work well being integrated into the actual original story canvas itself. Figure 49 depicts the number of comments added to individual stories in the Confectionary application during the 5-month study. Of the 155 stories added to the system, 46 received 1 comment. An additional 22 stories had two or more comments added to them in which audience members and the story authors themselves engaged in referential dialogs about the nature of the story content, the story form or their subjective responses to the contributed story. 


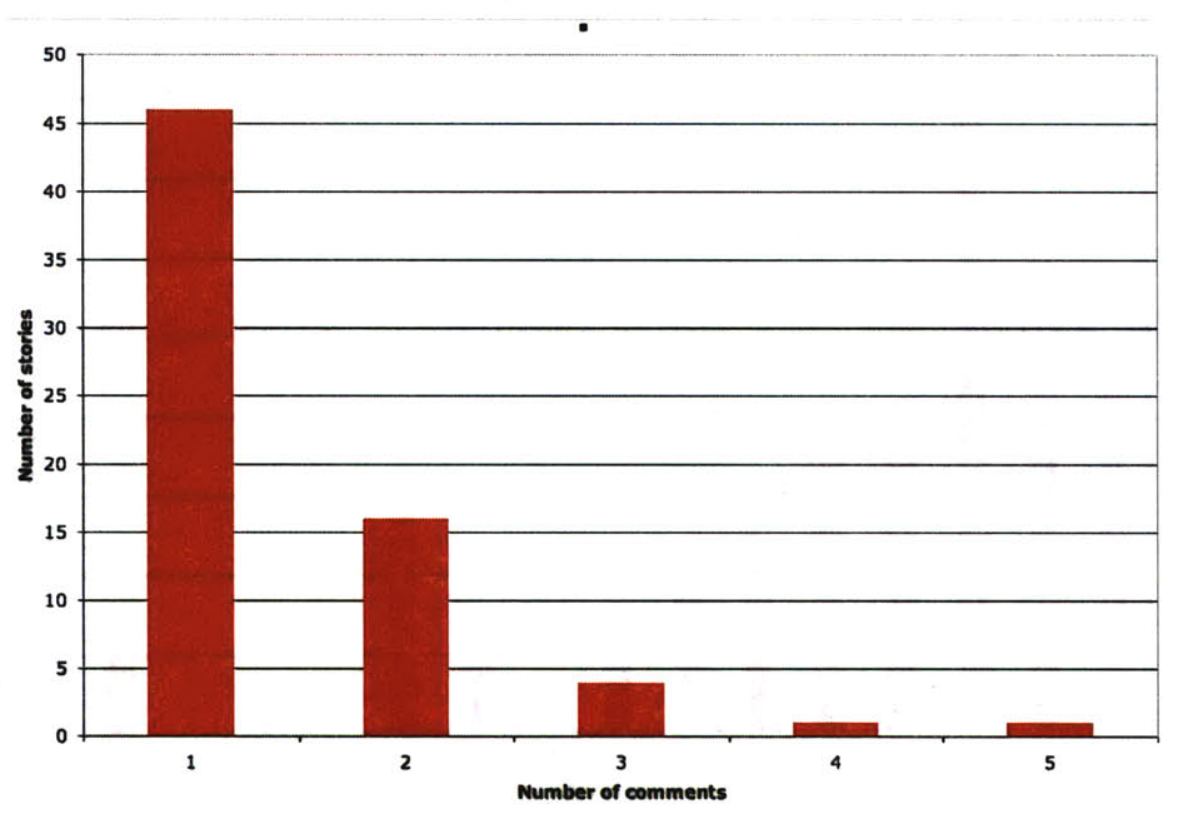

Figure 49: Number of comments assigned to Confectionary stories

During the study, 32 story paths were created containing 189 references to individual stories. These story paths connected stories according, for example, to aesthetic similarity ("stories with beautiful colors"), linear sequence ("This story begins with the discovery from the forest floor. A contrast then develops between the natural and the gardened. The panels focus on how ideas of age and youth, native and cultured shape our engagement with the environment") and content theme ("In the fall of 2003, Future of Learning group meets to discuss the environment they hope to realize in follow-on workshops to Roballet"). Figure 50 indicates the range of the number of stories contained in each of the contributed story paths. 


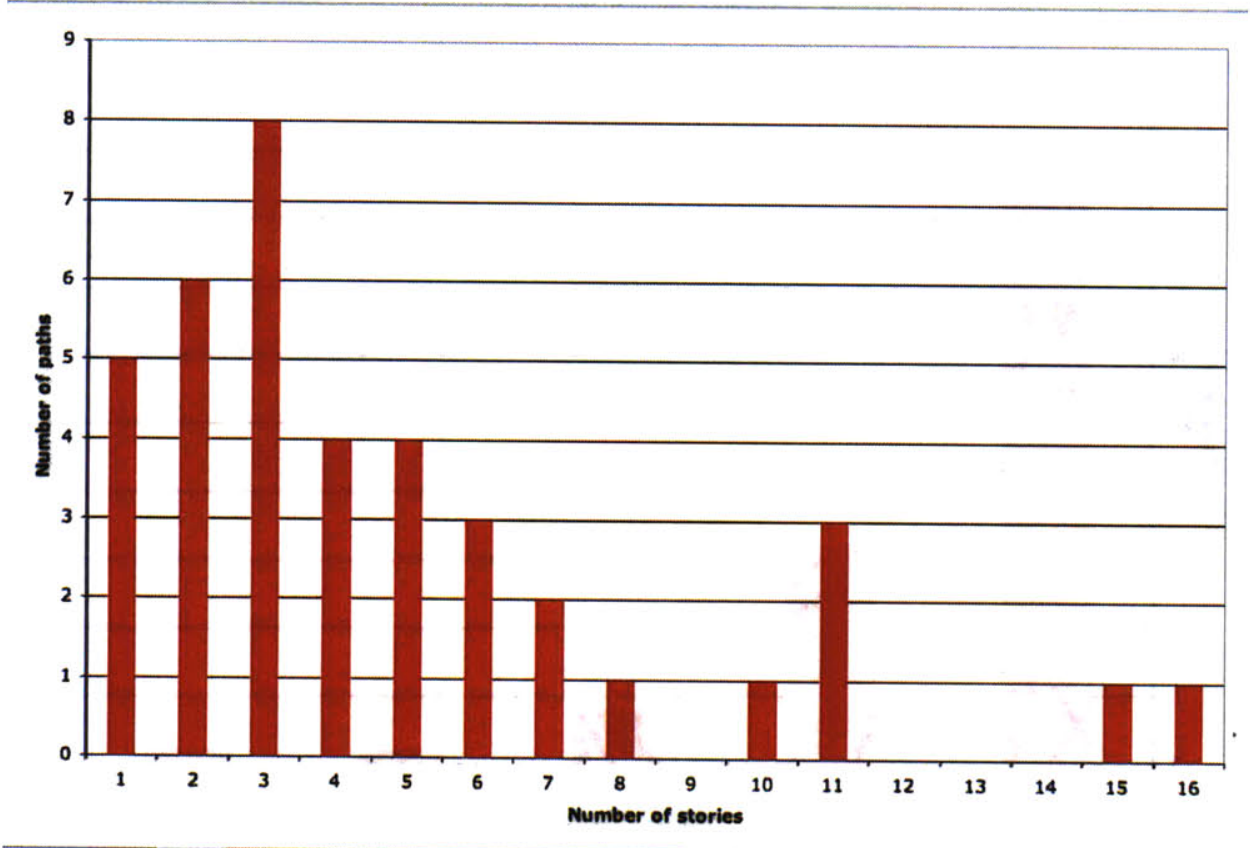

Figure 50: Range of number of stories used in wayfinding story paths

The majority of paths were made by authors creating connections between their own contributed stories, although 10 paths contained connections to stories by multiple authors [See Appendix B for examples of Confectionary story paths]. In discussions on the Confectionary feedback blog, participants in the study described their motivations for creating story paths. For example, one participant stated how she "preferred using the path function to overloading any one story with too much visual information". For this participant, the spatial canvas combined with the path feature allowed her to tell her complete story by creating aesthetically pleasing individual story panels that were then connected to one another thematically and serially. The participants in the study also used the path description feature to add additional context for the audience about the thematic connection between the stories ("Showing confectionaries that leverage image transformations and continuities" and "stories with beautiful colors") or instructions on how to navigate through the path ("This story is made up of 3 panes; follow the path!"). Again on the Confectionary feedback blog, the same participant as above described her preference for discovering stories in the application through the path function: "I prefer browsing the collection by path rather than by a total list or by a favorites classification. It is a way to search that is more serial, maybe not for everyone but my preferred method". This mention of a serial feature refers back to the anthology of poetry example described in Chapter 1. For this participant, pleasure was gained in discovering 
individual story moments within the larger context of a curated set of connected and related story moments. The contributed story paths also had 10 comments added to them. These path comments can be categorized into the following general types:

\section{Path author explanation}

- "I begin with a discovery from the forest floor and contrast this to the idea of constructing a garden. As the path develops, I explore how ideas of age and youth, of native and culture shape our engagement in and knowledge of the environment."

- "Made on the same day, each story in this path has a very different feel. After learning that we can harvest 40,000 pounds of berries in 90 minutes, we move on to the characters and actions of the day."

\section{Path audience commentary}

- "the story logic is impeccable!"

- "a magical story path, if only the world did not stop on 3 "

\subsubsection{Summary}

Rich-media stories created during the 5 -month study demonstrated a wide variety of author motivations, story content and storymaking styles. The activities of 35 regular participants showed that Confectionary functioned well as an engaging and easy to use everyday application for creating and sharing story-centered personal reflections. From initial simple creations using one or two media entities that relied on guidance from the supplied template layouts, participants demonstrated their growing sophistication and fluency with the tool as they developed more complex and evolved storytelling styles and approaches. Participants responded to works through the use of favorites, by repeated viewing, by adding comments and creating story paths. The comments provided by Confectionary participants showed a broad range of reflective reactions with exchanges relating to story content, story styles, poetic evocations and directed questions. The creation of story paths, along with their attached descriptions and comments, further extended and enriched the story exchange process. 


\subsection{Focused study with three storytellers}

Two of the storytellers in the focused study were proficient moviemakers and photographers, while one had only recently begun to experiment with digital photography and moviemaking and was less technically experienced overall. The two more experienced media makers had also worked before with weblogs and other forms of online publishing. The subjects were approached to participate in the study because of their storytelling experience, their previously expressed interest in the application and their willingness to commit to contribute regularly over an extended period of time. Periodically over the 5 months, the subjects created stories, added comments and constructed story paths. Two of the subjects documented their thoughts on the experience on the feedback weblog, and all three subjects also completed final questionnaire surveys. The three subjects were also individually interviewed about their experiences with the Confectionary application. The interviews lasted between 45 minutes-1 hour and were audio recorded and then transcribed.

\subsubsection{General overview of focused study}

Table 3 displays a summary of each of the subject's primary activities completed using the application during the study. It must be noted that subjects created and deleted stories continuously, but the numbers depicted below are of the stories that remained at the end of the study proper. In addition, while Subject $A$ designated 18 stories as favorites, some were subsequently deleted from the database. Subject $A$ was most consistent in logging into the system throughout the duration of the study, in contrast to Subject $C$, who focused her activities primarily within one particular 5-week period. Subject $B$ created the greatest amount of stories while Subject $A$ was considerably more active in providing commentary and feedback in contrast to the other two participants. 


\begin{tabular}{|c|c|c|c|}
\hline Subject & $\mathbf{A}$ & $\mathbf{B}$ & $\mathbf{C}$ \\
\hline Media Uploaded & $\begin{array}{l}\text { 123(5 audio, } 36 \\
\text { movies, } 82 \text { images) } \\
\text { and } 96 \text { text entities }\end{array}$ & $\begin{array}{l}\text { 108( } 1 \text { audio, } \\
44 \text { movies, } 63 \\
\text { images) and } \\
52 \text { text entities }\end{array}$ & $\begin{array}{l}40 \text { ( } 4 \text { movies, } 36 \\
\text { images) and } 19 \text { text } \\
\text { entities }\end{array}$ \\
\hline Stories created & 36 & 42 & 14 \\
\hline Comments added & 50 & 0 & 3 \\
\hline Favorites saved & 18 & 0 & 2 \\
\hline Paths created & 11 & 5 & 1 \\
\hline Contacts added & 9 & 3 & 3 \\
\hline Commumities joined & 3 & 0 & 2 \\
\hline $\begin{array}{l}\text { Number of unique } \\
\text { logins }\end{array}$ & 207 & 107 & 43 \\
\hline
\end{tabular}

Table 3: Summary offocused study Confectionary activity

\subsubsection{Story genres}

Each of the three storytellers experimented with a variety of story genres and authoring styles. Over the course of the study, the subjects created stories that can be categorized as personal documentary, informative, poetic, media postcards, comedic and portrait. Subject $B$ described the rich variety of stories as depicting "very different genres. You can nearly guess the person who made it. There were some that were very poetic where it's an invitation to contemplate the world in a different way." For this participant, the development of more poetic works came from her growing fluency with the tool, a sentiment echoed also by the other two subjects. For Subject $A$, the spatial authoring and publishing canvas offered a unique creative opportunity: "I made stories that I would not have made in any other tool that I know of because it allows you to juxtapose media and you reflect on the story, the characters, the sort of length of time or scenes that you might want to devote to that story. You reflect on those things as you try to take advantage of having this spatial canvas." The juxtaposition of elements separated by gaps on a spatial canvas can transport the reader, as McCloud states "across significant distances of time and space" [McCloud p71 1994]. Subject $A$ described how having viewed a story that depicted two scenes from a narrative that occurred at very different times she got "the idea that one thing that works very well in Confectionary is to have the start of a scene and then to have a big jump and then the main punch happen later...I love this arrangement". 
The WYSIWYG nature of the combined spatial authoring and publishing paradigm proved attractive to Subject $C$ who described the natural cognitive ease it afforded in working with the tool: "I think its great that everything is in front of you. It's a very different process from being in...I guess the closest thing I can think of is Go Live. It's very different because when you're in the application like Go Live you know that you want to create a certain type of message and the thing is you know the message but you have to cognitively find some space to allocate that to look for other stuff. Confectionary is in synch with my actions. You don't have to make a story but it becomes your think space. It isn't just a mechanical task of putting something together. Confectionary is more reflective as a storymaking process." For Subject $\mathrm{C}$, the spatial metaphor for story construction in the Confectionary application directly helped her to interact with her media entities in a natural and intuitive way, whereby she engaged with ease in a reflective process of story creation.

Subjects $A$ and $B$ made numerous stories that were viewable only by particular individuals or in a couple of cases, by selected community groups. Their reasons for choosing to utilize the privacy features of Confectionary included wanting to safeguard access to media depicting family members, particularly children, and wanting to create a more intimate audience for certain personal stories. Subject $B$ described the stories allocated with privacy settings as her "inside stories", noting that the ability to designate different disclosure levels to stories as being "a definite advantage with the tool. It's not like it's a big secret, it's just the way you like to be private. There are some things and topics that you just want to share with a smaller group". For Subject A, the privacy features were significant in that they afforded her control in knowing who her target audience would be: "That whole [privacy] part of Confectionary is very important to be able to say I'm just making these stories for people in my immediate family or I don't care who sees this or this story will interest a lot of people. It's not all about getting the largest audience possible". The power and success of the story exchange process as understood by this subject is therefore not limited to viewing figures or number of overall comments, but also allows for the impact and resonance of her narratives within a defined audience who truly matter to her. 
A key descriptor used by the subject to describe both the stories themselves and the authoring process in Confectionary was short. The swift nature of the storymaking process in Confectionary influenced their approach to the task, with Subject $B$ noting: " $I$ liked the fact that you can just document on the go. The fact that Confectionary is so short, I knew I didn't have to be perfect that I could simply make many. I was just cranking them out simply to get down the little bits of memories of that day". The spatial authoring canvas created a risk-free environment that invited rapid experimentation where stories can be created, discarded and improved upon quickly in a process that is described by all subjects as being engaging, and most importantly, fun. The short nature of the stories, where as a viewer, you can quickly grasp an overall impression of the story content was also remarked upon by the subjects. Subject $A$ described how: 'It doesn't take you long to look. The stories are short so you're much more willing to browse. I find myself browsing. You can spend all day browsing around the Internet but at the end of the day you might feel like you've wasted a day. Here, it's very fun and you're not spending a lot of time checking it out." The spatial canvas by offering all its story elements at once can therefore by sent to truly help make the process of constructing storied meaning direct and transparent. In this short and direct way, Confectionary functioned well as an everyday story authoring and publishing tool as, as an activity, it fit easily into busy schedules and actively encouraged quick experimentation and casual browsing all at once.

Although the actual process of creating or viewing a story in Confectionary could be accomplished quickly and efficiently, the subjects were keen to highlight the depth of their engagement with the application and the type of reflection their interactions with it engendered. Subject $B$ described how: "Sometimes I might take a long time [with Confectionary], like 2 or 3 hours a day, but it wasn't because it was difficult; it was because I got swallowed by it. I could have done it in 10 minutes too, but I just liked the process a lot. It's a process of spending more time with the people you like". For this subject, the process of arranging and rearranging her personal media collection afforded her an opportunity to reflect on her personal experiences and come to know herself, her family and her friends a little better. She explained her Confectionary creative process further: "I think its very zen. It's like talking out loud to yourself. It's fun because at the same time you are being alone with your own thoughts and at the same time being with others." For Subject $C$, the experience with using the application was more 
introspective, where her reflection was focused mainly on coming to know herself better: "Ultimately, I'm going to sound egocentric but the stories are about me. I guess I'm trying to understand me and what I'm like... I made them [stories] public as a challenge to me. The only public things I've made before are very designed and thought out and not personal. So I was trying to think about how I could make things that were personal and public. It's still a tricky thing. It's bitter sweet, but addictive in a way. You know that you shouldn't be doing this or you feel uncomfortable but you feel good that you're sharing and it's kind of therapeutic. I think it's been a good process for me to try and understand more about me and what matters." For these two subjects, the experience of using Confectionary enabled them to create and share story-centered personal reflections that helped them to come to better understand themselves both as individual and as social beings.

\subsubsection{Story styles}

The three subjects described how their growing fluency with the application over time influenced the development of their own particular storymaking style. For example, Subject $A$ after several weeks of exploration, began to make use of the story templates as depicted in Figure 51. In describing the story displayed below, the subject remarked:

"“The images from our annual trip to Georgean Bay suggested themselves as candidates for template 2. There were a total of 6 pictures. The sunset was amazing. The people portraits were reasonable as snapshots go. For the whole I wanted to give a sense of the diversity of life... Overall, I am gaining mental flexibility with the tool".
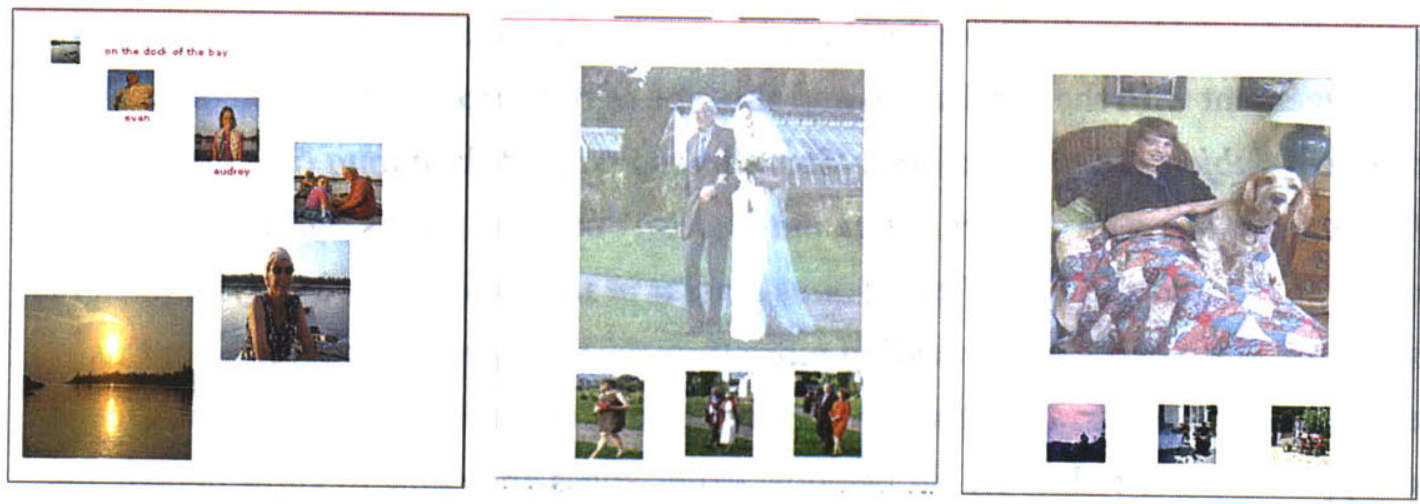

Figure 51: Subject A template based story layouts 
Ultimately, the subject refined her approach over time by creating preferred spatial layouts that became her own repeated exemplar structures as shown in Figures 52 and 53 .
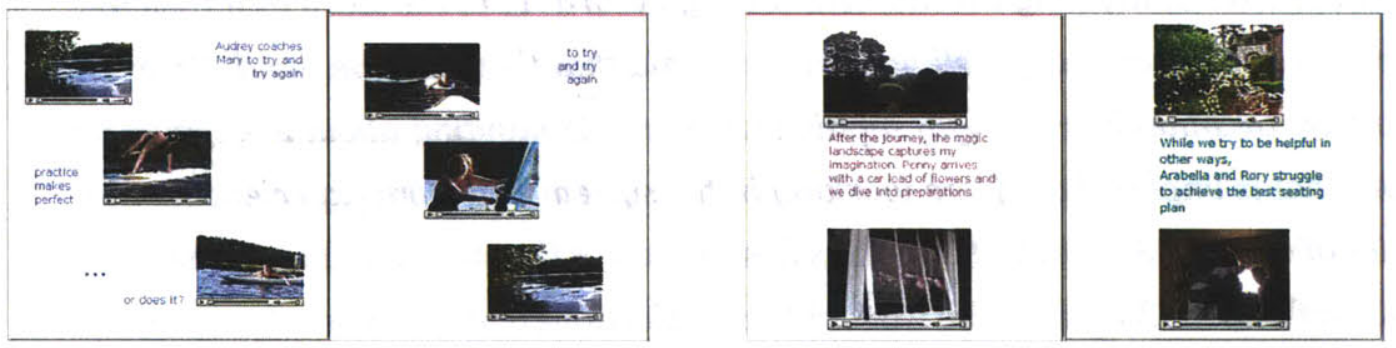

Figure 52: Subject A personal template Figure 53: Subject A personal template

In describing the emergence of her own preferred style, Subject A described her desire to create careful balance in her compositions that would allow for a particular preferred audience experience and interpretation of her created stories - "I really like that idea of squaring off the frame, let's say by making a cross on the frame, creating a symmetry in the space. I think that there is an emphasis that you will read left to right and top to bottom and that's how we read books. For instance, the one that is the semi-circle, you start at the left and you come around and then you come all the way to the left again. I really love that form. It reads exactly how it should read, that there is a temporal engagement with it." In the subject's stories in Figure 54 below, the spatial layout of all the media entities at once, along with the application of sizing, color and grouping demonstrate the ability of the Confectionary application to indeed support the creation of stories where 'reading and seeing and thinking [can be] identical'.
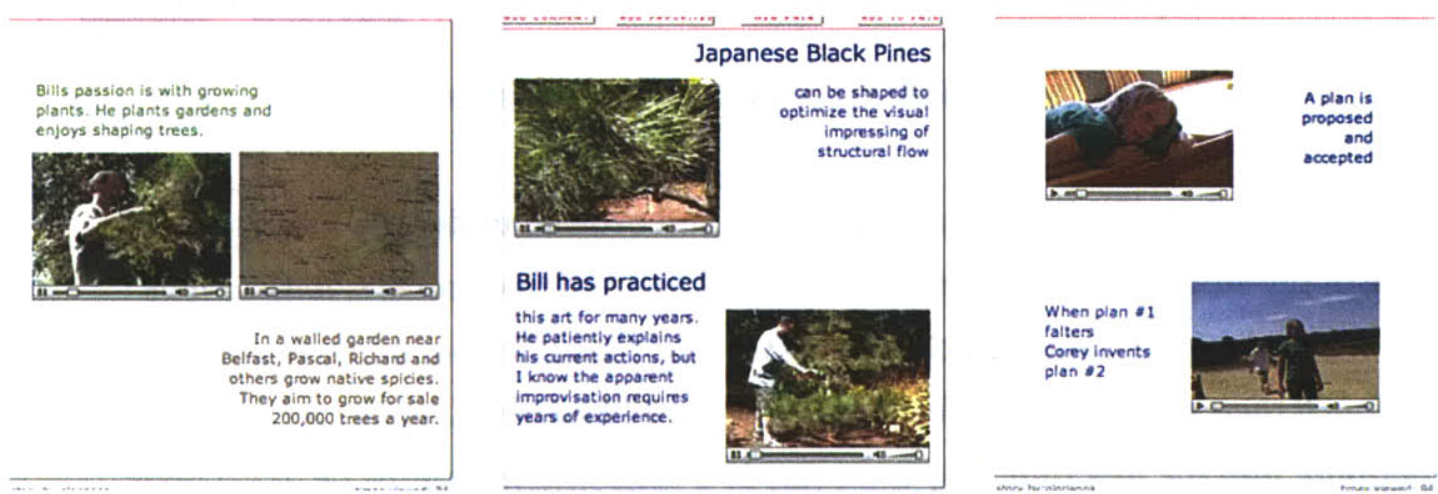

Figure 54: Subject A compositional style 
In further reflecting on the growth process an author experiences while using Confectionary, Subject A commented: "In Confectionary, the author picks the moment. For more experienced authors this also involves picking a genre: portrait, event, abstraction, metaphorical contrast or similarity. With each example, the author becomes better at defining the moment crisply according to the story that they feel warrants a "confectionary" telling and the media that they have on hand. Over time, the maker becomes increasingly sophisticated and demanding about $2 D$, temporal layout that is implied both from working in the system and from experiencing the stories of others." Similar to McCloud's description of the strategic choices made by comic authors in Chapter 2, the work of the Confectionary storytellers also involved choices regarding the selection of experienced moments and the media to represent them. Initially, the focus with novice Confectionary users may just have been on the moment itself, before growing fluency with the tool features allowed for the expression of additional stylistic and compositional strategies that added enhanced the chose moment and added value to the story. For example, Subject B's stories appeared as episodes in one large chronologically revealed collection. As the subject grew more experienced with Confectionary, with each successive story she began to use more and more media elements in a variety of experimental layouts. Figure 55 shows a progression of stories constructed by Subject B with every increasing levels of complexity and nuance.
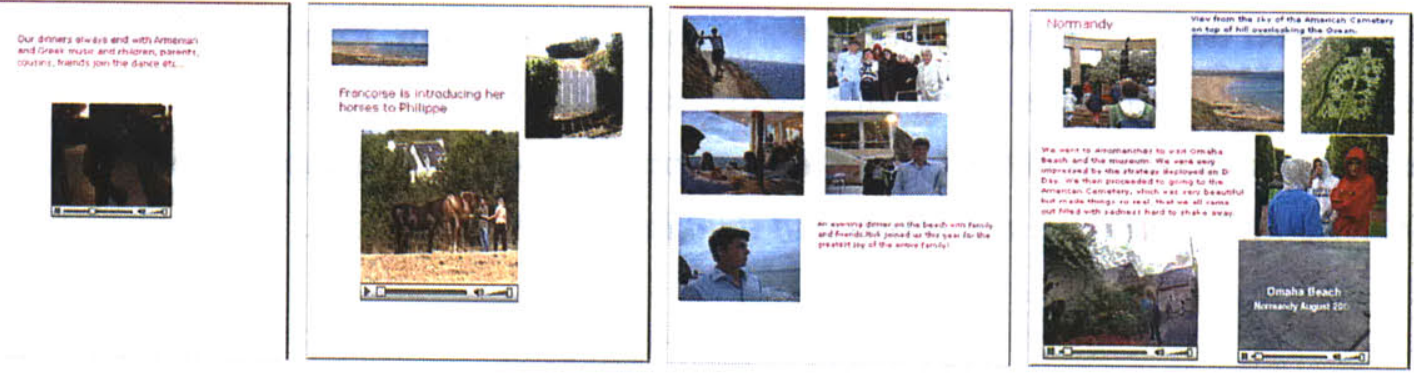

Figure 55: Subject B's evolving compositional style

Subject $B$ also spoke of how her style developed and evolved under the influence and guidance of the story constructions of others: “...I learned from others, when I was looking at the stories of others I got some ideas and I was like oh, this is a smart layout or how much they say with so little... For example, I liked that [Subject A] made images in a diagonal and the fact that they were not in a conventional shape or like a book. Your eye moved around the page differently. That inspired me”. Indeed, the entire 
collection of stories created in Confectionary during the study period provide strong evidence in the construction of stories over time that participants emulated, learned from, and appropriated the styles of others.

A similar stylistic evolution and development is noted by Subject $C$ who described this process as: "My technique and my openness have matured into how I want to express. First I was OK here's a photo of me and my mom and then as time goes on I'm adding more text on top of the images because I'm realizing that maybe the image isn't enough. I'm trying to find a balance". For this subject, the idea of a media postcard became important as she progressed from slightly off-balance and stressful compositions as in Figure 56 to creating carefully composed and exquisitely balanced compositions as depicted in Figure 57. The subject described her strategy as evolving as she wanted "to compose the stories so others would get the message straight away. The way I work is to put the images on there and make them all big and then I start placing them and then I start thinking about what would be visually compelling and would have an "oh" factor. That's when I would play around with the sizing and deciding what should have full color and then after that, once the images are put in place, then I know what the story is about. Then I put the text on and try to match that to the main image"

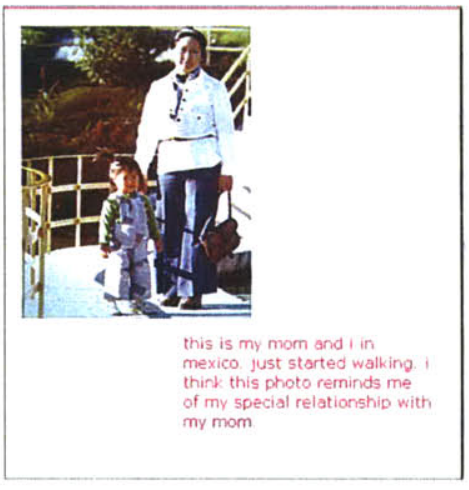

Figure 56: Subject C simple style

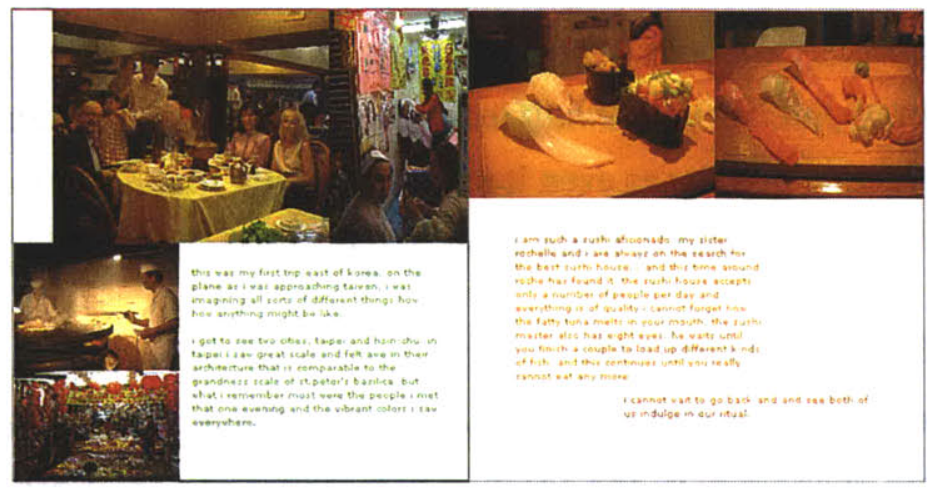

Figure 57: Subject C media postcard style

For Subject C, the spatially defined narrative relationships between her media entities served to make the process of constructing storied meaning direct and transparent as she felt that any audience viewing her carefully composed stories would immediately understand their meaning and intent. 
The subjects described the passing of different amounts of time between the capture of their media and the subsequent authoring of a story using that media in Confectionary. They spoke of using deliberate strategies at varying times to schedule and organize their time with the application. Subject $B$ made a series of daily stories over a 10 day vacation period where she was determined to create at least one story per day that documented her experiences: "I would shoot and then make a story the next day. The next day was when it was my pleasure to look at my media. It's funny because in a way I felt like I saw more of the vacation because I was reliving the day before. It put me in a good mood". Following this initial period of sequential activity, the subject returned to the topic of her vacation a month later, creating new stories both from her previously uploaded media and from other media captured at that time. These later stories stand alone as reflective summaries of different moments from the subject's vacation where she describes why the depicted moment was important to her - "It was very sad" or "Sometimes a few seconds of a film is a better insight in people's heart...". Subject A described her strategy in dealing with the desire to create stories everyday and the time constraints imposed by her daily schedule: "It's very easy to find an image and upload it and have it sit there until you feel like doing something with it. I think sometimes you're uploading and you're really into this idea that you're going to make a story each day and you're going to create a collection that represents a particular experience and sometimes you're doing this in a bit more random way and I'd like to do this in a more rigorous way but very often I don't have the time so just to get the images into the system felt like you're half way there". The act of uploading media helps to instigate the reflection process as even it might not result immediately in an authored story, the subject can begin to think about her future stories bearing that media in mind.

\subsubsection{Story feedback}

Subject $A$ provided a large amount of feedback to all Confectionary contributors in the form of comments, the addition of favorites and the creation of numerous story paths. As a regular contributor of original stories also, Subject $A$ can be understood as epitomizing an 'ideal' Confectionary participant - engaged in reflective storied dialog as one who, as Benhabib reminds us, knows how to listen, how to understand and how to represent. This subject created her paths "both for my own collection and when I saw things that fascinated me in the stories as a whole?. In considering the creative process of constructing paths, the subject commented: "In creating several stories for a path, voice becomes a critical part of the set...[the] term flow may be a useful one in discussing 
both movement within a frame; and movement through a storied path". For this subject, the experienced process of story exchange encompassed the integration of the construction of individual personal canvases and the creation and navigation of shared wayfinding paths. Subject $B$ described her experience of browsing the Confectionary story collection using the paths as being similar to flipping through the pages of an album....where you go from my story to yours because the topic is related". The stories created by this subject during the study were mainly concerned with two central themes so her stories lent themselves well for use as story path material. In fact, this subject created the longest paths, creating sequential connections between 10 or 11 stories at a time.

\subsubsection{Confectionary impact}

Each of the subjects described how using Confectionary had inspired them to reexamine their entire media collections, as their newly acquired media reminded them of previously captured footage and imagery. Subject B remarked: "If you think about it, there is a lot of good material that is just sleeping on shelves. I could see them taking life as a Confectionary". The subjects also described how over time, they began to observe their surroundings and capture media with Confectionary in mind: "I had Confectionary in mind when I went shooting. For example I was trying to see how I could be economical in the text. I would shoot actual signs so I wouldn't have to write the title or add some text or describe. You start learning little tricks like that. It gave me ideas about exploring media in a new way. I thought probably I will start always walking around with a camera now". During the course of the interviews and over email correspondence, two of the subjects referred on several occasions to the stories they made as "Confectionaries". For example, Subject $B$ described how when she was away from home once and had an idea for a story she "really couldn't wait to do a Confectionary later on that material" and also how she liked to "follow the paths through different Confectionaries". For this participant one could say that the Confectionary form had become an expressive and communicative medium in and of itself, with the term now used in casual conversation the same way one might say movie or collage. 


\subsubsection{Summary}

The three storytellers in the focused study found Confectionary intuitive and easy-to-use and it became the source of a regular creative exercise for each participant. The subjects described being engaged in the storymaking process in a reflective and thoughtful manner that supported them in coming to know themselves better both as individual and social beings. The application continued to prove attractive to the subjects as they grew more experienced with the tool, demonstrating that while simple, Confectionary is compelling to both novice and experienced participants. The WYSIWYG nature of the coupled authoring and publishing interfaces allowed the participants to quickly and intuitively begin authoring in a creative environment that was "in sync with their actions". The spatial canvas enabled the subjects to easily understand the authoring and meaning making process of others, which ultimately supported the participants in duplicating and quickly learning from the entire contributing community. The stories made by the three subjects demonstrated a broad variety of motivations, authoring strategies and styles that evolved over the course of the study and gained in complexity and impact. The subjects used the story paths feature to create clearly articulated or 'voiced' sequential story collections that expanded their meaning making from static individual canvas moments to a process of movement and flow between collections of story moments. Overall, the experience of the subjects with Confectionary had encouraged them to reimagine afresh the representation of their personal experiences as they developed new methods of observation and media capture techniques with the system in mind. 


\section{Conclusion}

This bedrock of this thesis research is the act of personal story exchange. It is through this process that we testify to our life experiences and come to better understand and communicate who we are as individuals and as members of a larger society. This document presents Everyday Mediated Storytelling, a model of how ordinary people can express, share and experience story centered personal reflections. In this model, everyday storytellers engage in a cyclical process of capturing, creating and sharing personal media testimony in order to reflect and learn from their lived experiences. Here, the choice of media capture device, story authoring software and publishing platform greatly impacts the types of stories told, how they are displayed and how they are understood. A key component of this model is the reflective process, as practised when an author chooses media epitomizing an experienced personal moment and then composes and frames that mediated moment in a meaningful storied form. The reflective process is also evident within the story receiver through mechanisms of direct responses or by positioning the individual story for further consideration within a broader narrative context.

Derived from this model, the hypothesis of the Everyday Mediated Storytelling work is that a spatial metaphor for authoring and publishing, and a path metaphor for connecting and experiencing, mediated personal testimony, enable ordinary people to express, share and experience story centered personal reflections. In order to validate this hypothesis, I developed Confectionary, an online authoring and publishing application for creating everyday mediated stories. Confectionary provided storytellers with a simple tool for uploading personal media and authoring story compositions by arranging and configuring multiple media elements on a spatial canvas. Stories could be targeted towards desired audiences or shielded from unfamiliar ones through the use of privacy disclosure features. Confectionary also provided audiences with several feedback mechanisms including a path-making feature that allowed participants to construct preferred navigational strategies through selected story groupings. The application was evaluated by expert users in a comparative evaluation study with other current best practice applications within the field of online media storytelling. A lengthy study with a group of committed expert and novice participants was also conducted to better 
understand and characterize the motivations, behavior and critical reflections of everyday rich-media storytellers.

Findings from the comparative study confirmed that a spatial authoring metaphor for creating personal mediated testimony was intuitive, easy-to-use and supported the expression and meaningful communication of a broad range of story genres and styles. Results from the longitudinal study corroborated the ability of a spatial media authoring and publishing environment to support casual storytellers in an everyday process of reflective story exchange. The study also highlighted the success of spatially composed media stories in making story meaning readily and intuitively apparent. Finally, the analysis showed that a path metaphor for creating preferred navigation strategies through a story collection helped participants to increase their meaning making from the consideration of singular stories to the comprehension of intertwining anthologies of personal testimony embedded within the entirety of a story collection.

\subsection{Contributions}

This thesis research presents a number of contributions to the fields of personal digital storytelling, rich-media story authoring and publishing, everyday interfaces and navigation methods. These contributions include:

- Creation of a model of the casual storyteller's process of creating and sharing personal everyday mediated narratives

- Introduction of a spatial metaphor for the construction of relational meanings and increased narrativity of everyday media.

- Introduction of a path framework to create sequential "narrative" or relational meaning between spatial frames of everyday media.

- Implementation of a spatial story authoring and publishing application for the everyday expression and publication of personal media narratives

- Demonstration that this environment enables story centered personal reflection and supports a wide variety of storymaking strategies, motivations and styles

- Demonstration that this environment supports story centered reflective dialogs through multiple active feedback modes. 


\subsection{Future Work}

The Confectionary application represents an initial movement towards the creation of storytelling tools for the everyday expression of mediated personal testimony. The application, while generally successful in supporting the authoring and publishing of rich-media stories, also presented intermittent technical problems and functional inconsistencies during its usage cycle. Further development and refinement is required in stabilizing the platform, particularly if it is to succeed, as planned, as a viable tool for the global exchange of mediated personal stories.

To date, the design and development of the application has been the mandate and sole obsession of one person - the author. This has been sufficient for developing and testing initial prototypes and for creating a working version of the system capable of supporting several hundreds of users. Based on the feedback from study participants and random visitors to the Confectionary website over the last 18 months, the next natural move is the development of an open Confectionary API or Application Programming Interface. The creation of a coherent interface to the fundamental classes, functions and methods thus far developed in the system opens up the possibility of expanding the future development of the application to account for the desires, whims and needs of any interested parties willing to invest some time and effort. For example, of interest to several candidates is the development of a 'zoomable' interface that would expand the current Confectionary spatial canvas to near infinite proportions, where Confectionary stories could exist within Confectionary stories in kaleidoscopic, interweaving and layered ways. Along with the development of additional features for the original application, an API could see the growth of the main Confectionary website into a community portal containing links to multiple variants of the software.

A key feature of the software that was semi-developed but not implemented during the study is the ability to re-edit or duplicate stories that have been saved to the system. Completion of this feature along with functionality for updating and amending story privacy settings will contribute positively to the overall user experience with the application. Additional improvements to some of the core functions of the system include amendments to the story paths feature, currently manifest in a relatively rudimentary state. As the Confectionary community grows and the number of stories and pathways increases, there will be a need to create alternative visualization schemas 
that highlight points of intersection and divergence, thematic similarity and overviews of the historical development of this 'legible story environment' over time. The potential of the privacy settings in the application have also not yet been fully realized. Opening up our media collections and storied personal experiences to others is indeed an invitation to intimacy that requires the establishment of a safe and trustworthy shared environment. Confectionary currently supports a gradient of disclosure possibilities ranging from fully private, to semi-private to public. To encourage participants to share their stories with potentially supportive viewers, auditability or conditional privacy mechanisms are required that will facilitate the actual or automatic introduction of new audiences members. Participants could register interest with a storyteller in seeing their full collection by sending them an alert describing why they would like to see their stories. Or the system could automatically promote audience members to a storyteller's circle of acquaintances or friends if they have added more than 3 of the storyteller's narratives to their favorites or if they have created paths containing 10 or more of the storyteller's narratives. Of course, this raises the possibility that the paths created could place a participant's story in a negative or undesirable context, but ultimately it serves to raise awareness about how the storyteller's personal testimony is considered and reacted to by the general community.

\subsection{Final Remarks}

The Confectionary storytellers contributed personal testimony that was thoughtful, revealing, and at times profound. The candor with which experiences were revealed and the respectful nature of audience feedback fostered an atmosphere of shared intimacy and an inclination to tell more. Storytellers were listeners and audiences were authors participating in a cyclical process of reflective story exchange that spoke of the individual and the collective heart and mind. The integrated process of mediated story exchange described and supported by this research advances the everyday digital storytelling process from one of media collection to one of storied reflection. Mother's static photo album has become an evolving, multi-voiced rich-media environment containing personal stories shared with audiences of one, some or many. Such an approach, based on the Everyday Mediated Storytelling model has implications beyond the domain of personal testimony towards broader interaction between the storyteller, the story and the audience within the fields of traditional online publishing, social networking, the semantic web and social software. Here authors are supported in crafting shareable 
narratives disclosed to desired audiences while the story exists both as an individual expression of entity relationships and as part of a connected trail of narrative intentionality. The audience is encouraged to actively participate as a creator of editorialized story meaning. We exchange stories to communicate that which is considered memorable and valuable. By understanding and creating models of how people express, share and experience stories we can better support the process of story exchange through the creation of appropriate technologies and representative forms. With this work we are taking an initial step towards creating an environment for personal story exchange that encourages reflection, stimulates active dialog and continues to help give us a shareable world. 


\section{Bibliography}

Antle, Alissa. (2003). “Case Study: The Design of CBC4Kids' StoryBuilder”. Proceeding of the 2003 conference on Interaction design and children. Preston, England. Pages: 59 $-68$

Antle, Alissa. (2004) "Supporting Children's Emotional Expression and Exploration in Online Environments". Proceeding of the 2004 conference on Interaction design and children: building a community. Maryland. Pages: 97-104

Bausch, P \& Bumgarnder, J. (2006). 'A multimedia system for authoring motion pictures'. In Proceedings of the ACM Multimedia '98, pp 257-266.

Benhabib, Seyla. (1992). "Judgment and the Moral Foundations of Politics in Hannah Arendt's Thought", Situating the Self. Cambridge : Polity

Crane, Susan. (1996). '(Not) Writing History: Rethinking the Intersections of Personal History and Collective Memory with Hans von Aufsess. History and Memory. Vol. 8, Iss. 1.Pg 5.

Davenport, Glorianna \& Brondmo, Hans Peter (1989). "Creating and Viewing the Elastic Charles -a Hypermedia Journal”. Proceedings of the Hypertext II Conference, York, England, July 1989.

Davenport, Glorianna. (1997). Dexter and the Evolving Documentary'. Proceedings of the fourth ACM international conference on Multimedia, Boston MA, 1997, pp 441-442.

Davenport, Glorianna \& Murtaugh, Michael. (1999). “Automatist storyteller systems and the shifting sands of story”. IBM Systems Journal, vol. 36, no. 3, pp. 446 - 456.

Davenport, Glorianna. (2004). 'Media Fabric: a process-oriented approach to media creation and exchange'. BT Technology Journal, 2004.

Dondis, Donis A. (1973). A primer of visual literacy. Cambridge, MA: MIT Press.

Ellis, Jason \& Bruckman, Amy. (2001). 'Designing Palaver Tree Online: Supporting Social Roles in a Community of Oral History'. Proceedings of the SIGCHI conference on Human Factors in Computing Systems.

Endter, Ingeborg. (2000). Community Memory: Building Multimedia Archives on the Internet. MS Thesis - Media Arts and Sciences, Massachusetts Institute of Technology (M.I.T).

Harrison, Helen. (1981) “Works in miniature challenge the power of perception". New York Times, November $8^{\text {th }}, 1981$.

http://www.adobe.com/products/player_census/flashplayer/version_penetration.html http://wordpress.org/download/counter 
Kearney, Richard (1996). Paul Ricoeur: The Hermeneutics of Action. London: Sage

Kearney, Richard. (2002). On Stories. New York: Routledge.

Kelliher Aisling. (2004) 'Everyday Cinema'. Proceedings of the $1^{\text {st }}$ ACM Workshop on story, representation, mechanism and content pp 59-62.

Kelliher Aisling. (2001) 'Plusshorts: using punctuation as an iconic system for describing and augmenting video structure'. MS Thesis - Media Arts and Sciences, Massachusetts Institute of Technology.

Kelliher A; Seo JJH; Pan PK; Lin C; Davenport G. (2000) 'Visual Interfaces for Shareable Media'. ISEA 2000 International Symposium on Electronic Art December 2000.

Li, Francis. (2003). 'Trailblazer: visualizing community activity with contextual metadata. Masters Thesis, Interaction Design Institute, Ivrea.

Likert, Rensis. (1932). “A technique for the measurement of attitudes.” Archives of Psychology 140: 1-55.

Lynch, Kevin. (1960). The Image of the City. Cambridge, MA: MIT Press.

Maeda, John. (2006). The Laws of Simplicity. Cambridge, MA: MIT Press

Mallon, Thomas. (1984). A Book of One's Own. New York: Tickner and Fields.

McCloud, Scott (1994). Understanding Comics. New York: HarperPerennial

McCloud, Scott. (2000). Reinventing Comics. New York: HarperPerennial

McCloud, Scott. (2006). Making comics: storytelling secrets of comics, manga and graphic novels. New York: HarperPerennial.

MillwardBrown (2006)

http://www.adobe.com/products/player census/flashplayer/version penetration.html

Morville, Peter. (2005). Ambient Findability. Sebastopol, CA: O’Reilly.

Murtaugh, Michael \& Davenport, Glorianna. (1996). 'Dexter and the evolving documentary'. Proceedings ACM Multimedia, pp 441- 442, November 1996

Pan, Pengkai. (2004). "Mobile Cinema". Ph.D. Thesis - Media Arts and Sciences, Massachusetts Institute of Technology (M.I.T)

Papert, Seymour. (1991) "Situating constructionism". Constructionism, ed Paper \& Harel. Cambridge, MA: MIT Press

Popkin, Jeremy. (2003). “Holocaust Memories, Historians' Memoirs”. History and Memory; Spring 2003; 15, 1; Research Library Core pg. 49 
Ricoeur, Paul. (1984). Time and Narrative, 3 vols. Chicago: University of Chicago Press.

Ricoeur, Paul. (1991). "Life in Quest of Narrative", On Paul Ricoeur: Narrative and Interpretation, ed. D. Wood. London: Routledge.

Ricoeur, Paul. (1992). "Narrative Identity”, Oneself as Another. Chicago: University of Chicago Press.

Ryan, Marie Laure (2004). 'Introduction'. Narrative Across Media, ed. Ryan, MarieLaure. Lincoln and London: University of Nebraska Press

Saroyan, Aram. (1982). Last Rites: The Death of William Saroyan. New

York: Morrow.

Seo, James. (2001). 'Intercreative Cinema: Collaborative Expression with Digital Video'. MS Thesis Media Arts and Sciences, MIT.

Smith, B., Bender, W., Endter, I., Driscoll, J., Turpeinen, M., and Quan, D. (2000). "Silver Stringers and Junior Journalists: Active information producers", IBM Systems Journal, Vol 39, Nos $3 \& 4,2000$

Snyder, Stephanie \& Levine, Barbara. (2006). Snapshot chronicles : inventing the American photo album. New York: Princeton Architectural Press.

Stahl, Sandra K.D. (1989). Literary Folkloristics and the Personal Narrative. Indiana University Press: Bloomington and Indianapolis

Steiner, Wendy. (2004). 'Pictorial Narrativity' in Narrative Across Media, ed. Ryan, Marie-Laure. Lincoln and London: University of Nebraska Press

Steiner, Karl \& Moher, Tom. (2002). 'Encouraging task-related dialog in 2D and 3D shared narrative workspaces'. Proceedings of the $4^{\text {th }}$ international conference on Collaborative virtual environments.

Torrey, Bradford \& Allen, Francis, ed. (1949). The Journals of Henry D. Thoreau. Boston: Houghton Mifflin Co.

Tufte, Edward. (1997). Visual Explanations: images and quantities, evidence and narrative. Chesire, Connecticut: Graphic Press.

Williams, R., Barry, B. and Singh, P. (2005) 'ComicKit: Acquiring Story Scripts using Commonsense Feedback'. Proceedings of the ACM International Conference on Intelligent User Interfaces (IUI 2005). San Diego, CA, USA. 


\section{Appendix A}

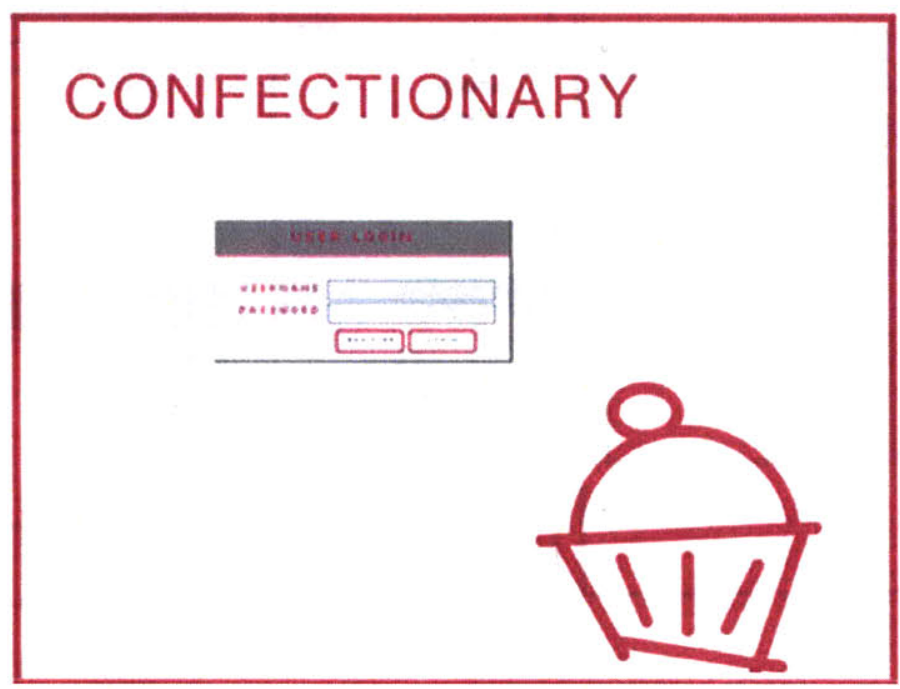

Confectionary login interface

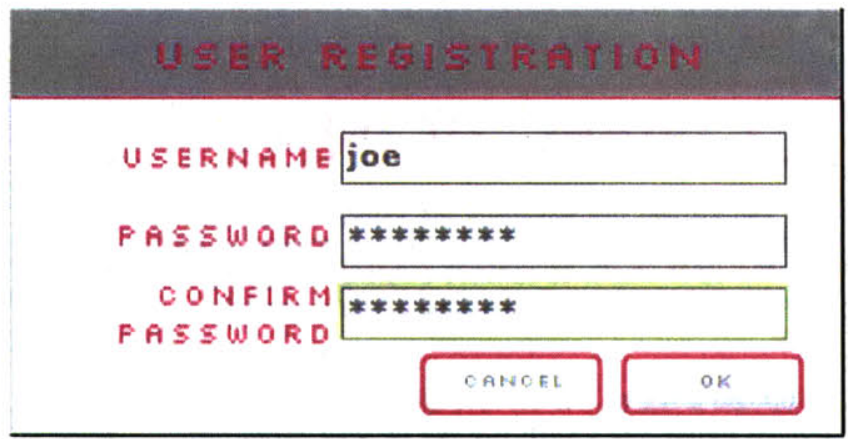

Confectionary registration component

HOME PROFILE UFLOAD CFEATE GALLEF' HELF Confectionary menu interface 


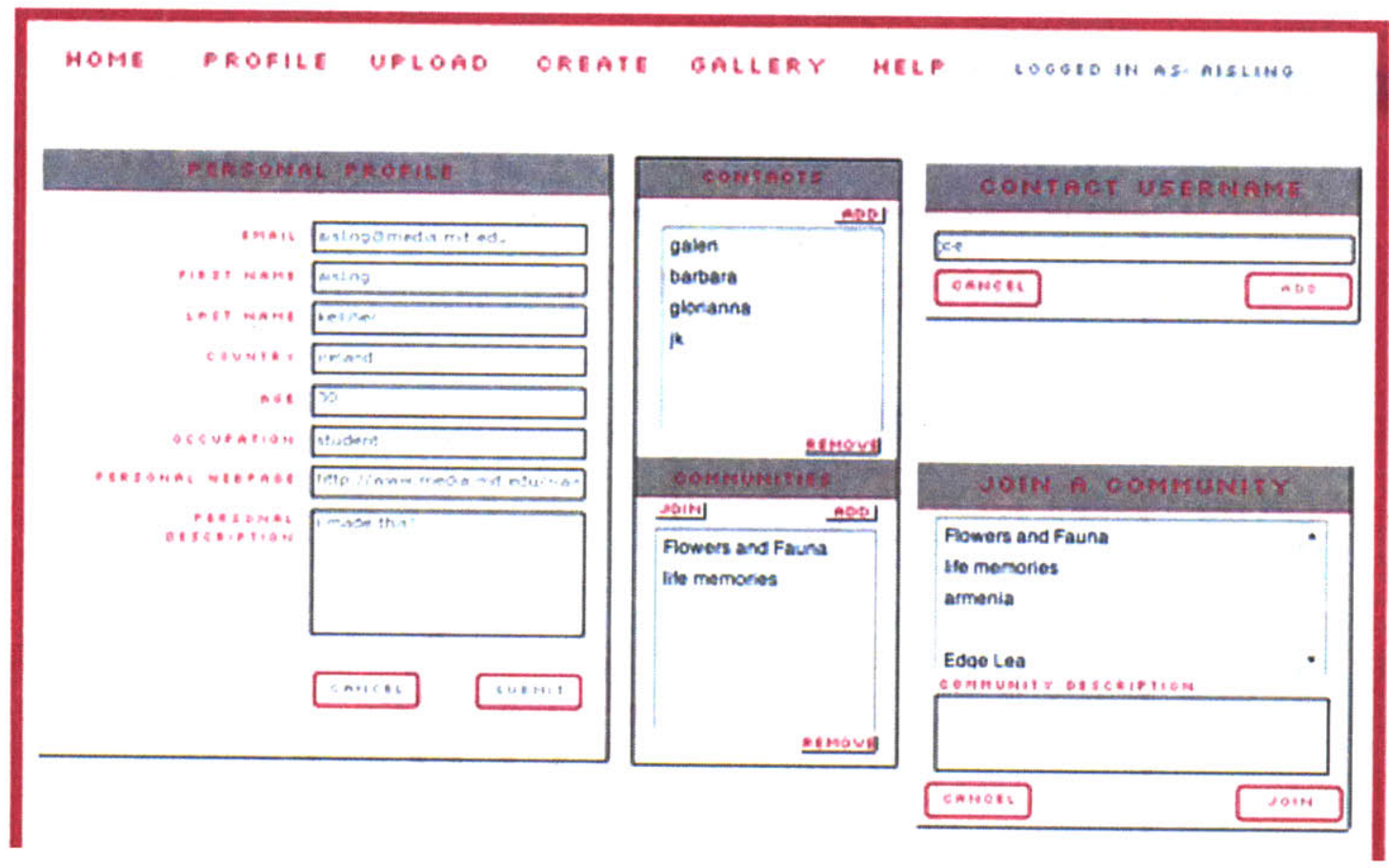

Confectionary profile interface

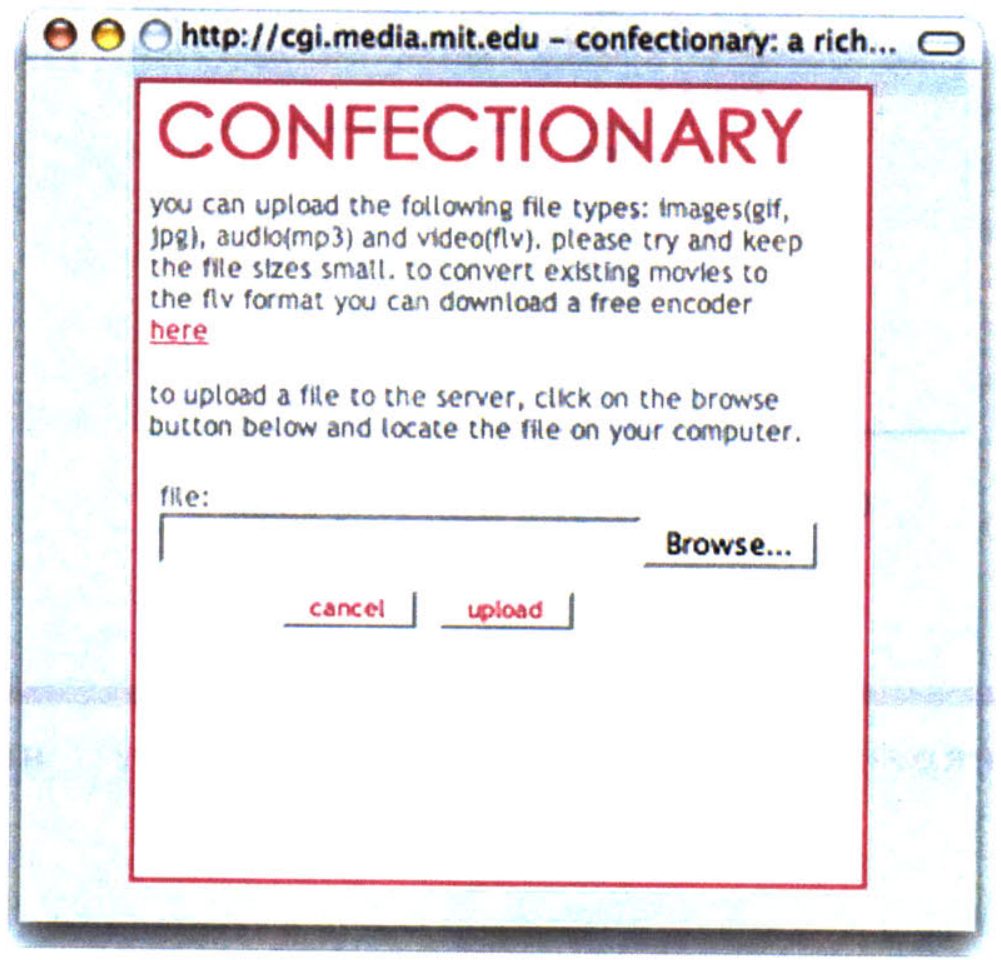

Confectionary upload interface 


\begin{tabular}{|c|c|}
\hline VIEWED J OOMMENTS & EIOENT \\
\hline rattlesnake (5) & $\Delta$ \\
\hline my first trip east (3) & $\equiv$ \\
\hline One Eye Up One Eye Down (3) & te \\
\hline Objects of Desire (2) & \\
\hline Cranberries (2) & \\
\hline Pour Ernesto (2) & \\
\hline tell me mo' (2) & 1 \\
\hline taishan (2) & \\
\hline Flowermania (2) & 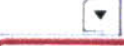 \\
\hline DELETE & EDIT \\
\hline
\end{tabular}

\section{Confectionary story navigation mode}

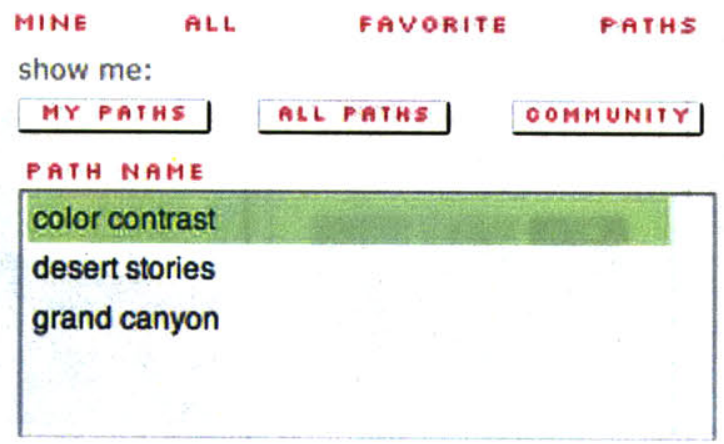

Confectionary path navigation mode 


\section{Appendix B}

Confectionary Path Example 1:

Path Name: Cranberry Harvest

Path Comment: Made on the same day, each story in this path has a very different feel. After learning that we can harvest 40,000 pounds of berries in 90 minutes, we move on to the characters and actions of the day.

\section{Path Stories:}

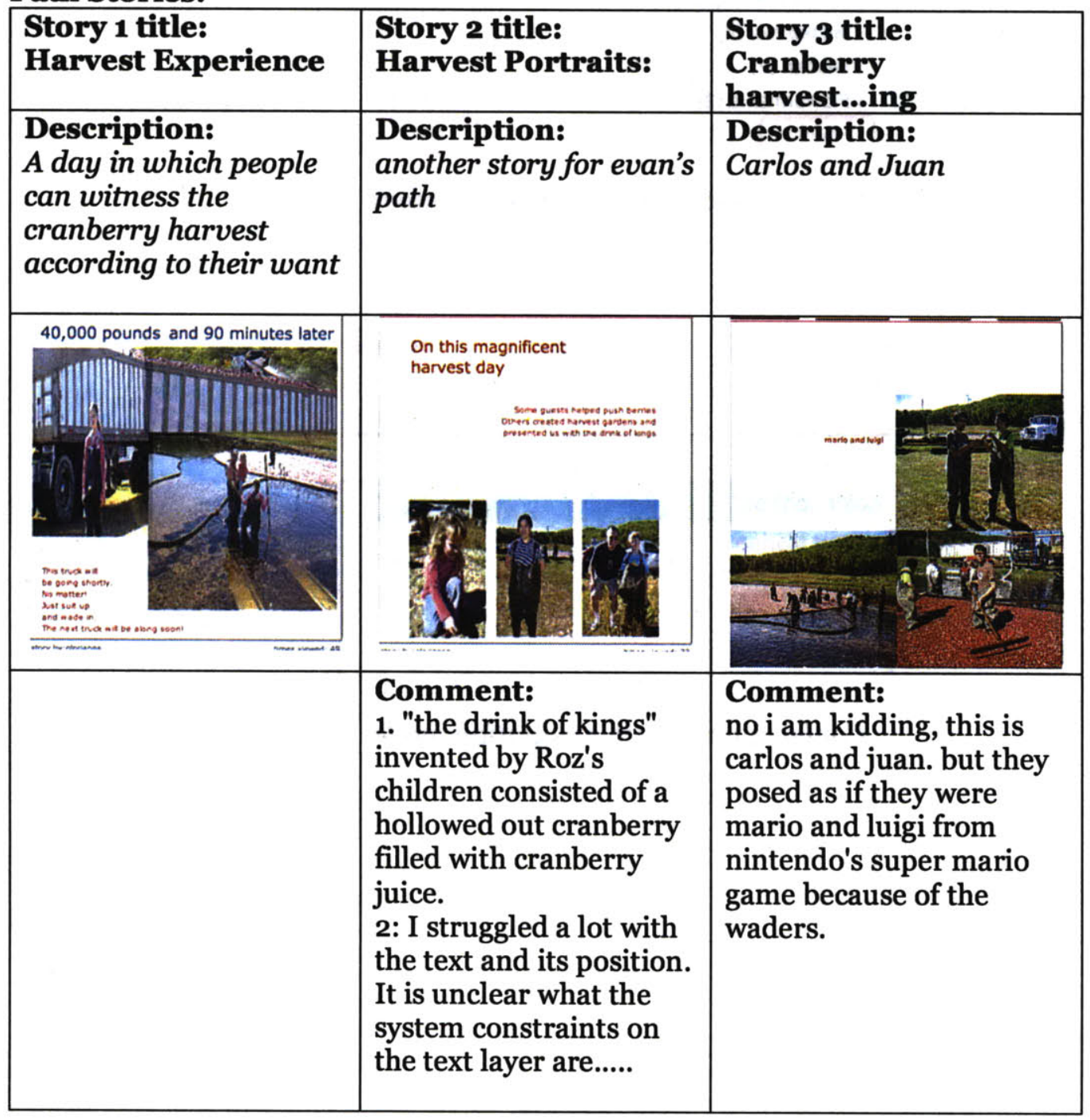




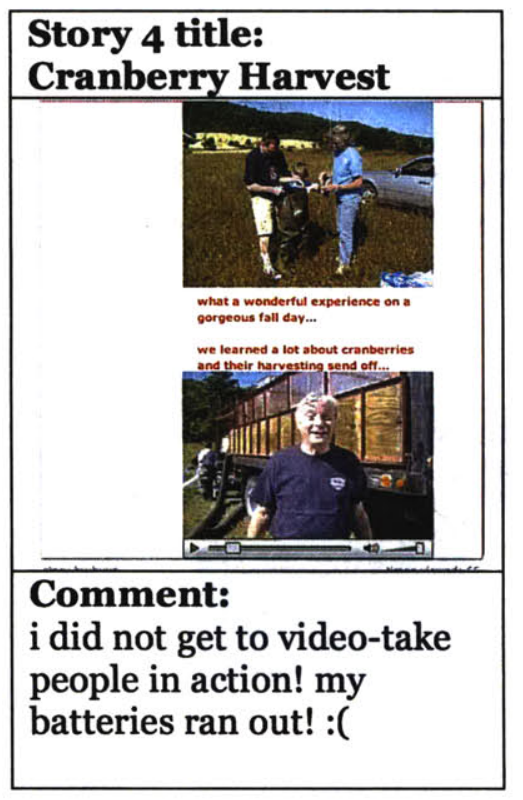

\section{Cranberry Harvest path screenshot:}

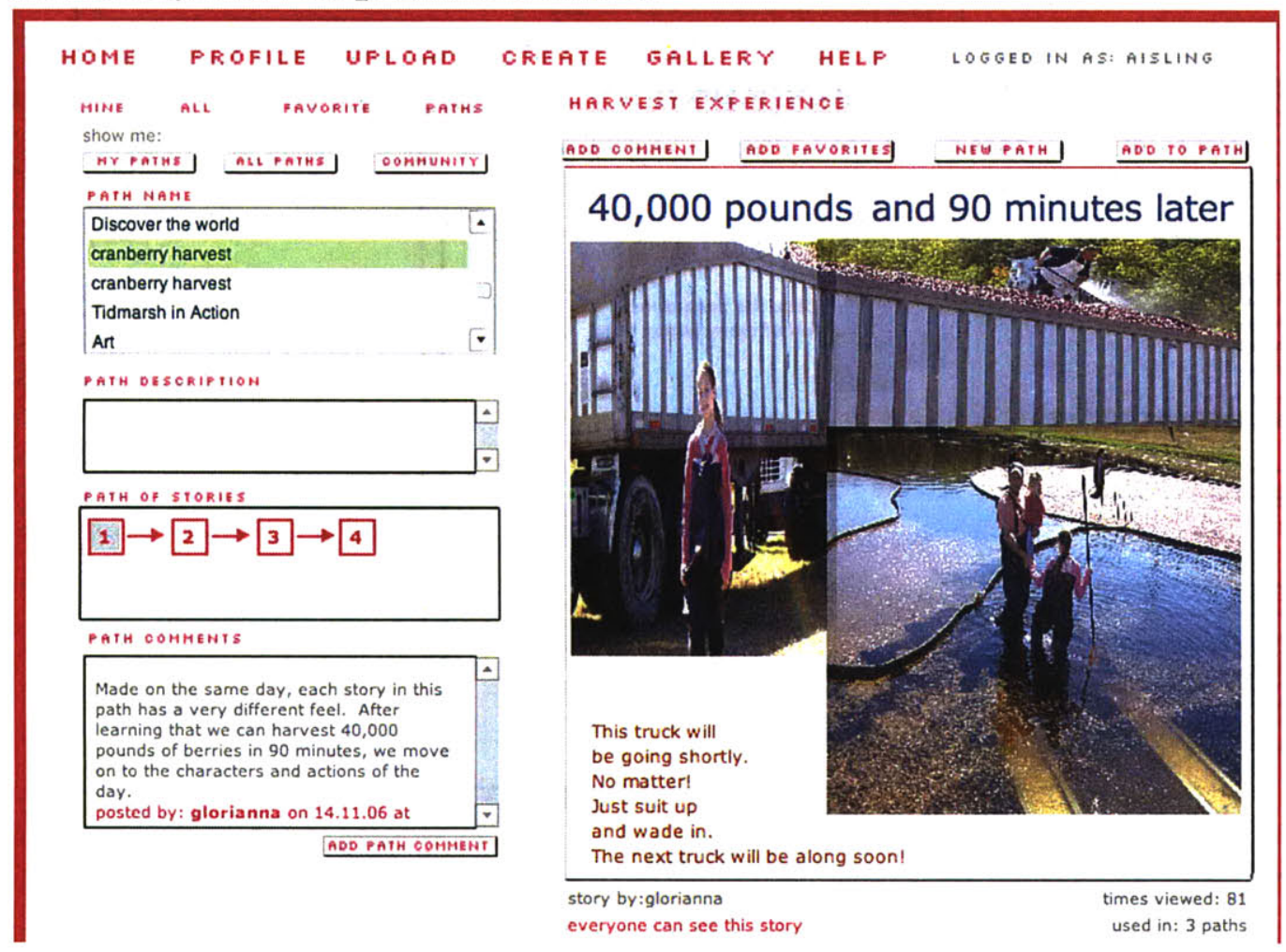




\section{Confectionary Path Example 2:}

Path Name: Wire Sculpture Complete

Path Description: This path is made up of three panes; follow the path!

Path Comment: This path is one of my favorites. The three canvases were made to tell a sequential story. A fitting ending to a brilliant workshop in wire sculpture by Laura Nichols.

\section{Path Stories:}

\begin{tabular}{|c|c|c|}
\hline $\begin{array}{l}\text { Story } 1 \text { title } \\
\text { Wire Sculpture Story }\end{array}$ & $\begin{array}{l}\text { Story } 2 \text { title: } \\
\text { Wire Sculpture } 2\end{array}$ & $\begin{array}{l}\text { Story } 3 \text { title: } \\
\text { Wire Sculpture } 3 \\
\end{array}$ \\
\hline $\begin{array}{l}\text { Once the eceans were } \\
\text { full of many happy fish }\end{array}$ & 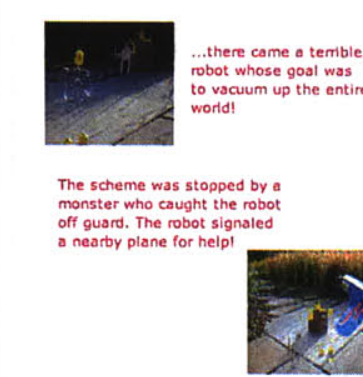 & 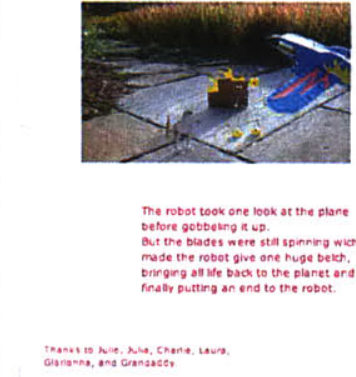 \\
\hline
\end{tabular}

Wire Sculpture Complete path screenshot:

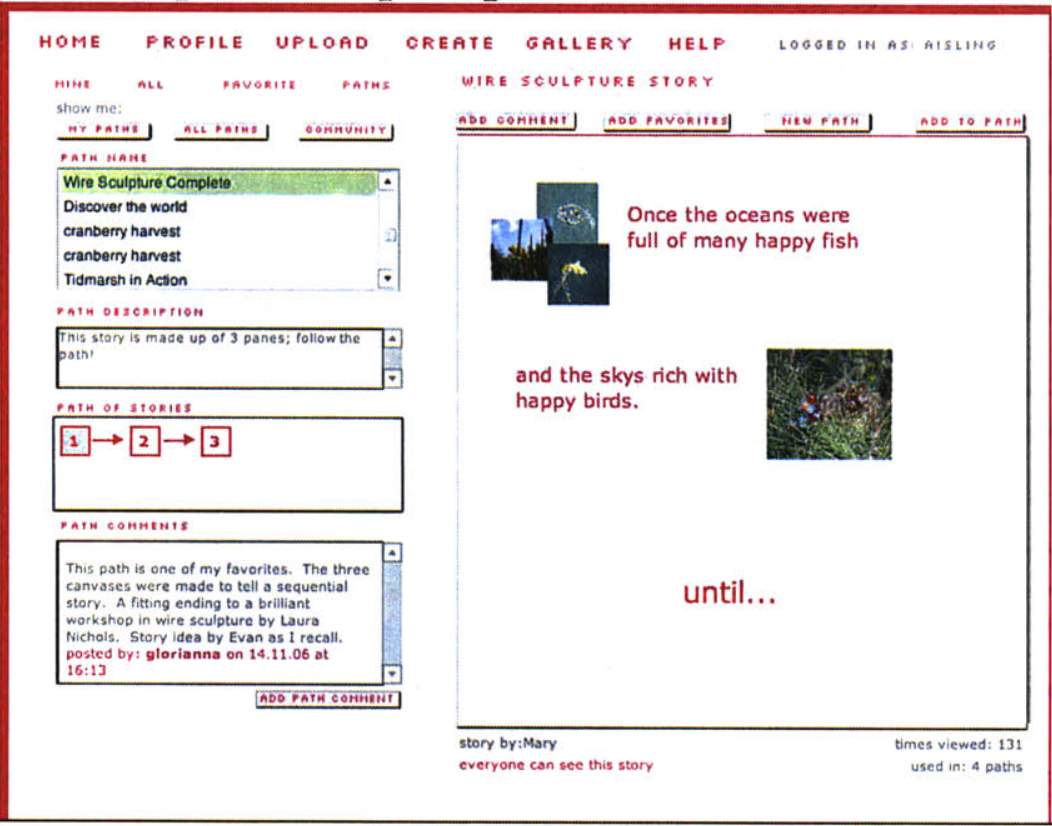




\section{Confectionary Path Example 3:}

Path Name: Trees and Forests 2

Path Description: This story begins with the discovery from the forest floor. A contrast then develops between the natural and the gardened. The panels focus on how ideas of age and youth, native and cultured shape our engagement with the environment.

Path Stories:

\begin{tabular}{|c|c|c|}
\hline $\begin{array}{l}\text { Story } 1 \text { title: } \\
\text { Something Familiar }\end{array}$ & $\begin{array}{l}\text { Story } 2 \text { title: } \\
\text { Measures of Age }\end{array}$ & $\begin{array}{l}\text { Story } 3 \text { title: } \\
\text { BOOM-CHOP }\end{array}$ \\
\hline $\begin{array}{l}\text { Description: } \\
\text { in which a curious } \\
\text { conversation confirms a } \\
\text { botanical investigation }\end{array}$ & $\begin{array}{l}\text { Description: } \\
\text { The Kew Garden team } \\
\text { enjoy their work at } \\
\text { Clandeboye }\end{array}$ & \\
\hline we find it with our eves & $\begin{array}{l}\text { and insoles many } \\
\text { on the soot lessons }\end{array}$ & 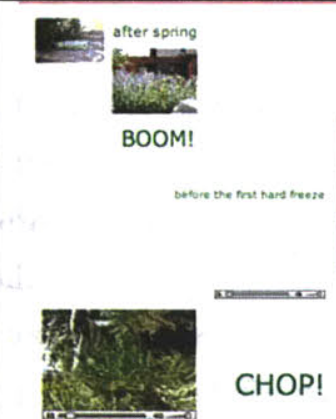 \\
\hline
\end{tabular}

\begin{tabular}{|c|c|c|}
\hline $\begin{array}{l}\text { Story } 4 \text { title: } \\
\text { Tree Knowledge }\end{array}$ & $\begin{array}{l}\text { Story } 5 \text { title: } \\
\text { Contrasting Roles }\end{array}$ & $\begin{array}{l}\text { Story } 6 \text { title: } \\
\text { Pruning a Japanese } \\
\text { Pine }\end{array}$ \\
\hline $\begin{array}{l}\text { Description: } \\
\text { In which we get a closer } \\
\text { look at Pinus Radiata D. } \\
\text { Don or the Monteray Pine }\end{array}$ & $\begin{array}{l}\text { Description: } \\
\text { in which the objectives in } \\
\text { two gardens are } \\
\text { compared }\end{array}$ & $\begin{array}{l}\text { Description: } \\
\text { Bill loves shaping these } \\
\text { trees. In this story he } \\
\text { offers come pointers as } \\
\text { he works }\end{array}$ \\
\hline 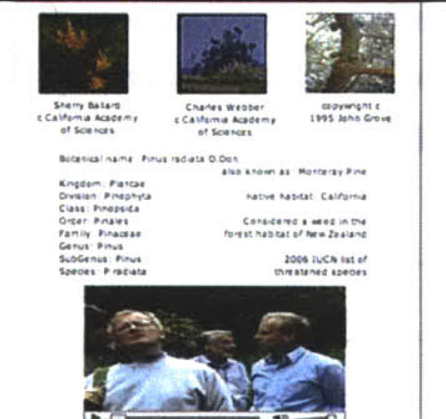 & 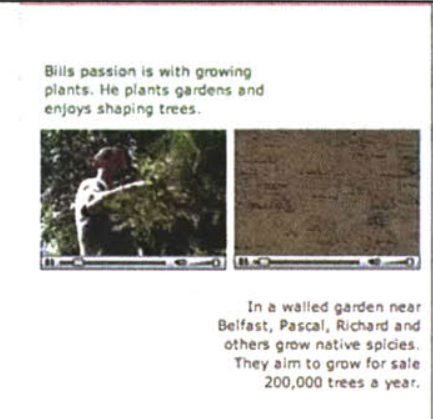 & 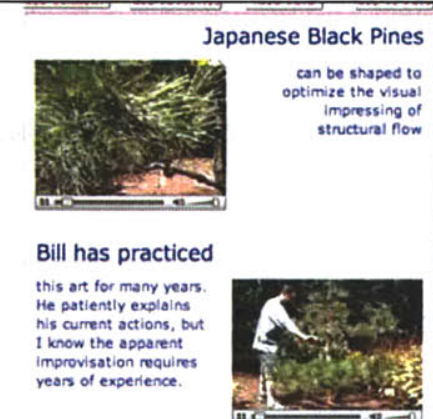 \\
\hline
\end{tabular}




\section{Appendix C}

\section{CONSENT FORM}

User ID:

This form is designed to provide you with information about this user study. Your participation in the following exercises is completely voluntary. You are free to withdraw this consent at any time, for any reason, and to request that any data collected be destroyed. If at any time you feel uncomfortable, or unsure that you wish your results to be part of the experiment, you may discontinue your participation and all information collected during your participation will be destroyed.

There are three parts to this experiment, each of which will last approximately 30 minutes. You will participate in three media storytelling exercises using one of three different software packages for each exercise. After each exercise, you will be asked to fill out an identical short questionnaire. At the end of the experiment, there will be one additional questionnaire, comparing the three exercise experiences. The entire experiment will last approximately 1.5 hours. You will be given a $\$ 10$ gift certificate to E-Joy coffee store as compensation for your participation.

Any responses that are collected during the experiment will be completely anonymous. From this point forward, only the ID number that appears on the upper left corner of this page will be used to refer to you. If you have any questions at any point during the experiment, the experimenter will gladly answer them. Please read the following and sign on the lines below:

"I, the undersigned, have read and understood the explanations of the following research project and voluntarily consent to my participation in it. I understand that my responses will remain confidential and that I may terminate my participation at any time. I also understand that by my participation in this study I am not waiving any of my legal rights."

Signature:

Name (Printed):

Date:

Location: Brickyard Building, Room 395 


\section{Demographics}

\section{User ID \#}

1 What is your gender? Male/ Female

2 In what year were you born?

3 How often do you record personal media (images, video, audio)?

- A few times per day

- Once a day

- A few times per week

- Once a week

- A few times per month

- Once a month

- Less than once a month

4 How often do you edit personal media (images, video, audio)?

- A few times per day

- Once a day

- A few times per week

- Once a week

- A few times per month

- Once a month

- Less than once a month

$5 \quad$ How often do you share personal media (images, video, audio)?

- A few times per day

- Once a day

- A few times per week

- Once a week

- A few times per month

- Once a month

- Less than once a month

6 How do you share your personal media (circle all that apply)

- regular mail

- email

- personal website

- $\quad$ personal weblog

- cellphone

- $\quad$ community website (please specify)

- $\quad$ performance(please specify)

- $\quad$ gallery (please specify)

- $\quad$ other (please specify) 
$7 \quad$ How familiar are you with weblogs?

$\begin{array}{lllllllll}\text { Not at all } & 1 & 2 & 3 & 4 & 5 & 6 & 7 & \text { Very much }\end{array}$

$8 \quad$ How familiar are you with the Flickr website?

$\begin{array}{llllllllll}\text { Not at all } & 1 & 2 & 3 & 4 & 5 & 6 & 7 & \text { Very much }\end{array}$ 


\section{Questionnaire \#}

\section{User ID \#}

1 What is your gender? Male/ Female

2 In what year were you born?

Please circle the number that corresponds to your answer. Except where specified, all questions pertain to the specific application you have just used.

Story Authoring:

3 Did you find the application easy to use?
Not at all 1
2
34
5
$6 \quad 7 \quad$ Very much

4 Did you find the application pleasant and satisfying to use?

$\begin{array}{lllllllll}\text { Not at all } & 1 & 2 & 3 & 4 & 5 & 6 & 7 & \text { Very much }\end{array}$

5 Did you like the visual interface of this application?

$\begin{array}{llllllllll}\text { Not at all } & 1 & 2 & 3 & 4 & 5 & 6 & 7 & \text { Very much }\end{array}$

6 Did you understand how to navigate through this application?

$\begin{array}{lllllllll}\text { Not at all } & 1 & 2 & 3 & 4 & 5 & 6 & 7 & \text { Very much }\end{array}$

$7 \quad$ Did you find it easy to come up with ideas for stories?

$\begin{array}{llllllllll}\text { Not at all } & 1 & 2 & 3 & 4 & 5 & 6 & 7 & \text { Very much }\end{array}$

8 Were you able to tell the stories you wanted to?

$\begin{array}{llllllllll}\text { Not at all } & 1 & 2 & 3 & 4 & 5 & 6 & 7 & \text { Very much }\end{array}$

9 Did you find the storymaking process reflective?

$\begin{array}{llllllllll}\text { Not at all } & 1 & 2 & 3 & 4 & 5 & 6 & 7 & \text { Very much }\end{array}$

10 Do you think people will understand your stories easily?

$\begin{array}{llllllllll}\text { Not at all } & 1 & 2 & 3 & 4 & 5 & 6 & 7 & \text { Very much }\end{array}$

11 Did you make your stories with a particular audience in mind?

$\begin{array}{lllllllll}\text { Not at all } & 1 & 2 & 3 & 4 & 5 & 6 & 7 & \text { Very much }\end{array}$

12 Did you enjoy making stories with this application?

$\begin{array}{llllllllll}\text { Not at all } & 1 & 2 & 3 & 4 & 5 & 6 & 7 & \text { Very much }\end{array}$

$\begin{array}{llllllllll}13 & \text { Did you feel inspired using this application? } \\ \text { Not at all } & 1 & 2 & 3 & 4 & 5 & 6 & 7 & \text { Very much }\end{array}$

Story Viewing

14 Did you feel you understood the stories made by others?

$\begin{array}{llllllllll}\text { Not at all } & 1 & 2 & 3 & 4 & 5 & 6 & 7 & \text { Very much }\end{array}$

15 Did you find is easy to navigate through the collection of stories? 
$\begin{array}{lllllllll}\text { Not at all } & 1 & 2 & 3 & 4 & 5 & 6 & 7 & \text { Very much }\end{array}$ 16 Did you feel compelled to respond to the stories made by others?

$\begin{array}{lllllllll}\text { Not at all } & 1 & 2 & 3 & 4 & 5 & 6 & 7 & \text { Very much }\end{array}$ 17 Did you enjoy the stories made by others?

$\begin{array}{llllllllll}\text { Not at all } & 1 & 2 & 3 & 4 & 5 & 6 & 7 & \text { Very much }\end{array}$ 18 Were you surprised by how people responded to your stories? $\begin{array}{lllllllll}\text { Not at all } & 1 & 2 & 3 & 4 & 5 & 6 & 7 & \text { Very much }\end{array}$ 19 Did you enjoy getting feedback for your stories?

$\begin{array}{lrrrrrrrr}\text { Not at all } & 1 & 2 & 3 & 4 & 5 & 6 & 7 & \text { Very much }\end{array}$

20 Do you have any other thoughts or comments about this application? 
Final Questionnaire - Confectionary/Flickr/WordPress

User ID:

Please circle the number that corresponds to your answer. In all of the questions, the story exercise using the Confectionary application will be called "Confectionary", the story exercise using the Flickr application will be called "Flickr" and the story exercise using the WordPress weblog will be called "WordPress".

1 Which of the applications did you enjoy using more?

$\begin{array}{lllllllllll}\text { Confectionary } & 1 & 2 & 3 & 4 & 5 & 6 & 7 & \text { Flickr }\end{array}$

$\begin{array}{lllllllllll}2 & \text { Which of the applications did you enjoy using more? } & & \\ \text { Wordpress } & 1 & 2 & 3 & 4 & 5 & 6 & 7 & \text { Flickr }\end{array}$

$\begin{array}{llllllllll}3 & \text { Which of the applications did you enjoy using more? } \\ \text { Wordpress } & 1 & 2 & 3 & 4 & 5 & 6 & 7 & \text { Confectionary }\end{array}$

$4 \quad$ Which of the applications allowed you to tell the best stories?

$\begin{array}{llllllllll}\text { Confectionary } & 1 & 2 & 3 & 4 & 5 & 6 & 7 & \text { Flickr }\end{array}$

$5 \quad$ Which of the applications allowed you to tell the best stories?

$\begin{array}{llllllllll}\text { Wordpress } & 1 & 2 & 3 & 4 & 5 & 6 & 7 & \text { Flickr }\end{array}$

6 Which of the applications allowed you to tell the best stories?

$\begin{array}{llllllllll}\text { Wordpress } & 1 & 2 & 3 & 4 & 5 & 6 & 7 & \text { Confectionary }\end{array}$

7 Which of the applications provided you with the best audience feedback?

$\begin{array}{llllllllll}\text { Confectionary } & 1 & 2 & 3 & 4 & 5 & 6 & 7 & \text { Flickr }\end{array}$

8 Which of the applications provided you with the best audience feedback?

$\begin{array}{llllllllll}\text { Wordpress } & 1 & 2 & 3 & 4 & 5 & 6 & 7 & \text { Flickr }\end{array}$

9 Which of the applications provided you with the best audience feedback?

$\begin{array}{lllllllll}\text { Wordpress } & 1 & 2 & 3 & 4 & 5 & 6 & 7 & \text { Confectionary }\end{array}$

10 Which of the applications supported the creation of your favorite stories?

$\begin{array}{lllllllll}\text { Confectionary } & 1 & 2 & 3 & 4 & 5 & 6 & 7 & \text { Flickr }\end{array}$

11 Which of the applications supported the creation of your favorite stories?

$\begin{array}{lllllllll}\text { Wordpress } & 1 & 2 & 3 & 4 & 5 & 6 & 7 & \text { Flickr }\end{array}$

12 Which of the applications supported the creation of your favorite stories?

$\begin{array}{llllllllll}\text { Wordpress } & 1 & 2 & 3 & 4 & 5 & 6 & 7 & \text { Confectionary }\end{array}$

13 Which of the applications were you more comfortable using?

$\begin{array}{llllllllll}\text { Confectionary } & 1 & 2 & 3 & 4 & 5 & 6 & 7 & \text { Flickr }\end{array}$

14 Which of the applications were you more comfortable using? 
$\begin{array}{lllllllll}\text { Wordpress } & 1 & 2 & 3 & 4 & 5 & 6 & 7 & \text { Flickr }\end{array}$

15 Which of the applications were you more comfortable using?

$\begin{array}{lllllllll}\text { Wordpress } & 1 & 2 & 3 & 4 & 5 & 6 & 7 & \text { Confectionary }\end{array}$

16 Do you have any other thoughts or comments about any aspect of this study? 